

\section{DISCLAIMER}

This report was prepared as an account of work sponsored by an agency of the United States Government. Neither the United States Government nor any agency Thereof, nor any of their employees, makes any warranty, express or implied, or assumes any legal liability or responsibility for the accuracy, completeness, or usefulness of any information, apparatus, product, or process disclosed, or represents that its use would not infringe privately owned rights. Reference herein to any specific commercial product, process, or service by trade name, trademark, manufacturer, or otherwise does not necessarily constitute or imply its endorsement, recommendation, or favoring by the United States Government or any agency thereof. The views and opinions of authors expressed herein do not necessarily state or reflect those of the United States Government or any agency thereof. 


\section{DISCLAIMER}

Portions of this document may be illegible in electronic image products. Images are produced from the best available original document. 
Printed in the United States of America. Available from National Technical Information Service

U.S. Department of Commerce

5285 Port Royal Road, Springfield, Virginia 22161

Price: Printed Copy $\$ 4.50$; Microfiche $\$ 3.00$

This report was prepared as an account of work sponsored by the United States Government. Neither the United States nor the Energy Research and Development Administration, nor any of their employees, nor any of their contractors, subcontractors, or their employees, makes any warranty, express or implied, or assumes any legal liability or responsibility for the accuracy, completeness or usefulness of any information, apparatus, product or process disclosed, or represents that its use would not infringe privately owned rights. 


\title{
SURFACE-FINISH MEASUREMENT WITH INTERFERENCE MICROSCOPES
}

\author{
R. E. Sladky
}

Fabrication Systems Development Department

Y-12 Development Division

This work was supported, in part, by the Air Force Weapons Laboratory. Kirtland Air Force Base, New Mexico

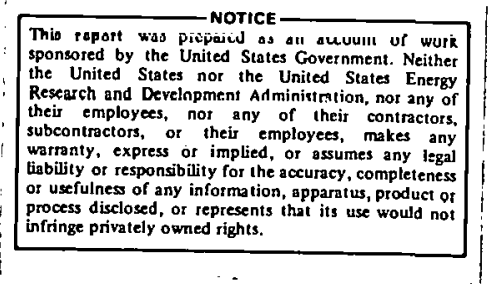

Oak Ridge Y-12 Plant

P. O. Box Y, Oak Ridge, Tennessee 37830

Prepared for the US Energy Research and Development Administration

Under US Government Contract W-7405-eng-28 


\begin{abstract}
Diamond turning copper and other metals, to produce mirror surfaces with reflectivities generally higher than can be obtained by lapping and polishing, has become an important new technology. Evaluation of the finish of these surfaces requires careful examination, using optical instruments. This document provides background information about the theory and equipment involved in this program. Data from several specimens have been acquired that show the type of surface finish that is obtained. Mirrors have been fabricated that show the state of the art that has been achieved in diamond turning copper and nickel.
\end{abstract}




\section{CONTENTS}

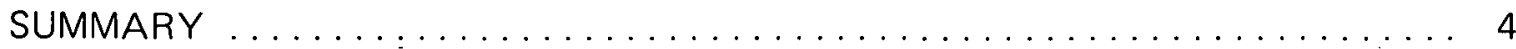

INTRODUCTION ........................................ 5

SURFACE-FINISH MEASUREMENTS WITH INTERFERENCE MICROSCOPES . . . . 6

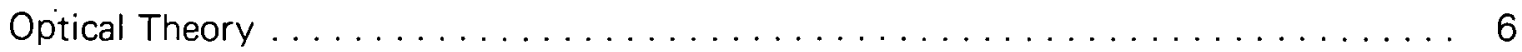

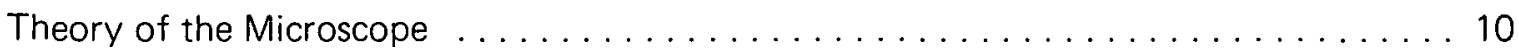

General Comments ................................. 10

Double-Beam Interference Microscope . . . . . . . . . . . . . . . . . . . 17

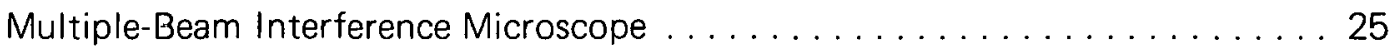

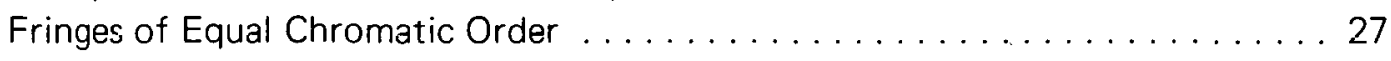

Nomarski Polarization-Contrast Technique ................... 33

Information and Numerical Data Obtained from the Fringes $\ldots \ldots \ldots \ldots \ldots \ldots . \ldots 6$

Film-Thickness Measurement . . . . . . . . . . . . . . . . . . . . 36

General Discussion of Diamond-Turned Surfaces . . . . . . . . . . . . 38

Types of Data that can be Obtained . . . . . . . . . . . . . . . . . 46

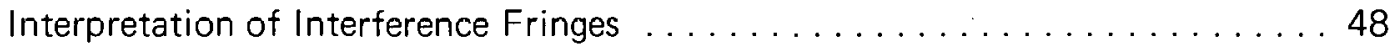

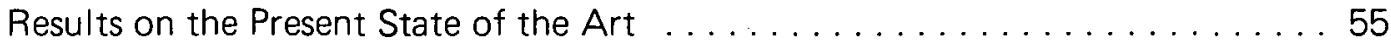

Conclusions ......................................... 56

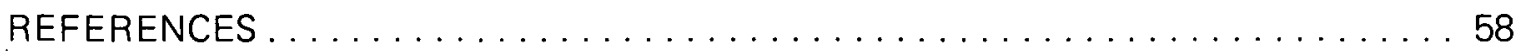

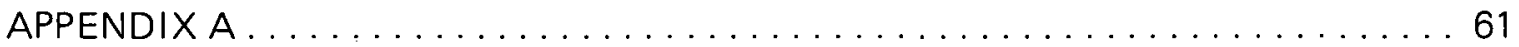

English-to-SI Conversion Factors $\ldots \ldots \ldots \ldots \ldots \ldots \ldots \ldots \ldots \ldots \ldots \ldots \ldots \ldots \ldots \ldots$

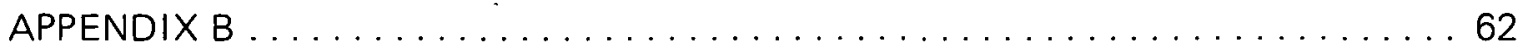

Derivation of the Theoretical Surface Finish $\ldots \ldots \ldots \ldots \ldots \ldots \ldots \ldots \ldots \ldots$

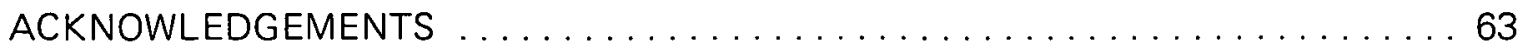




\section{SUMMARY}

This report was written as an introduction to the subject of the optical measurement of surface finishes. Diamond-turned surfaces are so smooth and so delicate that only cerfain specialized instruments have the capacity to reveal meaningful information about their characteristics. The report explains, first of all, the optical theory of some of the measuring instruments that can be used; then describes, in greater detail, the characteristics of each instrument: the double and multiple-beam interferometer, the FECO fringe interferometer, and the Nomarski polarization contrast interferometer. The report also lists the resolution of each objective that can be used with these microscopes, and then shows how the magnification varies with the photographic equipment. From this and some knowledge of the turning parameters used for a particular specimen, the engineer can judge whether a certain finish-measuring procedure will provide the information he needs.

In the data section, the report illustrates the use of interference fringes in measuring film thickness as an introduction to the measurement of surface finish. The information that can be obtained from the fringe system is illustrated with five different samples. These samples show first of all the cusps left by the tool; then, as the machining parameters are increased, the cusp spacing becomes smaller, often taxing the resolution of the microscope. Waves in the surface due to relative motion between the spindle and the part may be mistaken for tool cusps at low power. Data are then obtained from the fringes to provide a numerical value for the surface finish. It was shown that the displacement of the center of the fringe should be evaluated rather than the edge to obtain the most accurate data.

As a final example, the surface finish of a state-of-the-art, copper-plated, diamond-turned disc was evaluated. It was found to be 3.2 nanometers $(0.13$ microinch), AA. 


\section{INTRODUCTION}

The term "surface finish" is not new to engineers, nor is the microinch unit of measurement; for, conventionally, the roughness of a surface has been obtained with some type of stylus instrument and a dial-type or recorder readout, calibrated in microinches. The average person did not concern himself with the electronics and switches that converted the motion of the stylus to a peak-to-valley $(p-v)$, root mean square $(\mathrm{rms})$, or arithmetic average (AA) number for the surface.

Now, the era of the diamond-turned surface has arrived, and the roughness of the surface is so slight [see Figure 21 (a)] that only special stylus instruments can be used. The era of the high-energy laser has also arrived, so that most production diamond-turned surfaces are of soft copper or gold, and the track left by the stylus could be a damage site for the laser beam; if, indeed, the mirror were small enough to be used with a stylus instrument. How, then, can a surface finish be measured? Optical instruments can be used.

The specimens to be examined are highly reflective metals which appear specularly reflecting to the eye. The eye can see objects which differ in color or contrast (light and shadow), but these metal surfaces are uniform in color and contrast. The surface-finish microscope produces phase differences in the light reflected from the various elevations on the specimen, and interference makes these phase differences visible as a "fringe pattern".

In the past, optical-interference microscopes were not popular for surface-finish measurements in production areas because, generally, the fringe pattern must be photographed and then evaluated by eye. This process requires some training and the results are not unequivocal, such as a number from a meter.

The interference microscope and light scattering are two methods which can be used for evaluating surfaces of production size. Other methods, such as the transmission electron microscope (TEM) study of replicas, and the direct study of small sample surfaces with the scanning electron microscope (SEM), are practical only on a small number of specimens where some spccial information is desired.

Most engineers are not familiar with the principles of optical testing, yet these ideas are basic to understanding the information from various instruments so that these data can be used both for diagnosing the behavior of machines and interpreting the acceptance tests for the mirrors that were turned. This Oak Ridge $Y-12$ Plant (a) document reviews the optical theory of several instruments, and presents interference patterns and data which were obtained from diamond-turned surfaces. This information should be useful in interpreting test results and in deciding, beforehand, which instrument will provide the best data that are needed.

(a) Operated by the Union Carbide Corporation's Nuclear Division for the US Energy Research and Mevelnnment Administration. 


\section{SURFACE-FINISH MEASUREMENTS WITH INTERFERENCE MICROSCOPES}

\section{OPTICAL THEORY}

This report describes testing methods which use light to measure the quality of surfaces which are used to direct light of extremely high intensity, so some ideas of the nature of light should be presented first. The objective is to acquaint the reader with the meaning of such terms as: "coherence length", "phase difference", "diffraction", and "interference" which are used in this report.

Light is energy which has the characteristics both of discrete particles and electromagnetic waves. The particles are called "photons", and the energy in the photon depends upon the atom which emitted it. All of the laws of optics may be explained in terms of the interaction of this "electromagnetic wave" with the electrical properties of the surface upon which it impinges.

The photon is an electromagnetic wave emitted from an excited atom. (1) Since the photon is emitted from an atom, it has. a beginning and an end. In other words, it has a discrete lifetime. These "emission lines" of an atom are affected by a number of factors such as the temperature and pressure existing in the. source at the time of emission, the presence of neighboring atoms, and the atmosphere through which the light was transmitted. Thus, each photon (Figure 1) is a damped electromagnetic wave with slight variations in wavelength, a certain lifetime called "coherence time", and a specific length called "coherence length". For example, (2) Michelson found that the $6438 \AA$ line of cadmium has a path difference exceeding 500,000 wavelengths. Thus, the lifetime of this photon was approximately $10^{-9}$ second. An emitting source produces so many photons that the light appears to be continuous. When used to illuminate an interferometer, the coherence length is very important. A laser is a special device which stimulates excited atoms to emit photons in a time relationship such that the coherence length is greatly extended.

Figure 2 illustrates the meaning of wavelength; frequency is the number of waves that pass a point every second. The number of waves per second, times the length of each wave, $\lambda$, is equal to the velocity of light, or:

$$
c=f \lambda \text {. }
$$

The velocity of light is considered to be a fundamental constant of nature. (In vacuum it is 3 $\times 10^{8}$ meters per second.) The other fundamental property of electromagnetic radiation is frequency. When light travels through some medium other than vacuum it is slowed down. The refractive index, $n$, is the ratio of the speed of light in vacuum to the speed of light in a material. Since the frequency is constant, the wavelength must change with a change in refractive index. This relationship is expressed by the equation: (3)

$$
\lambda^{\prime}=\frac{\lambda}{n},
$$




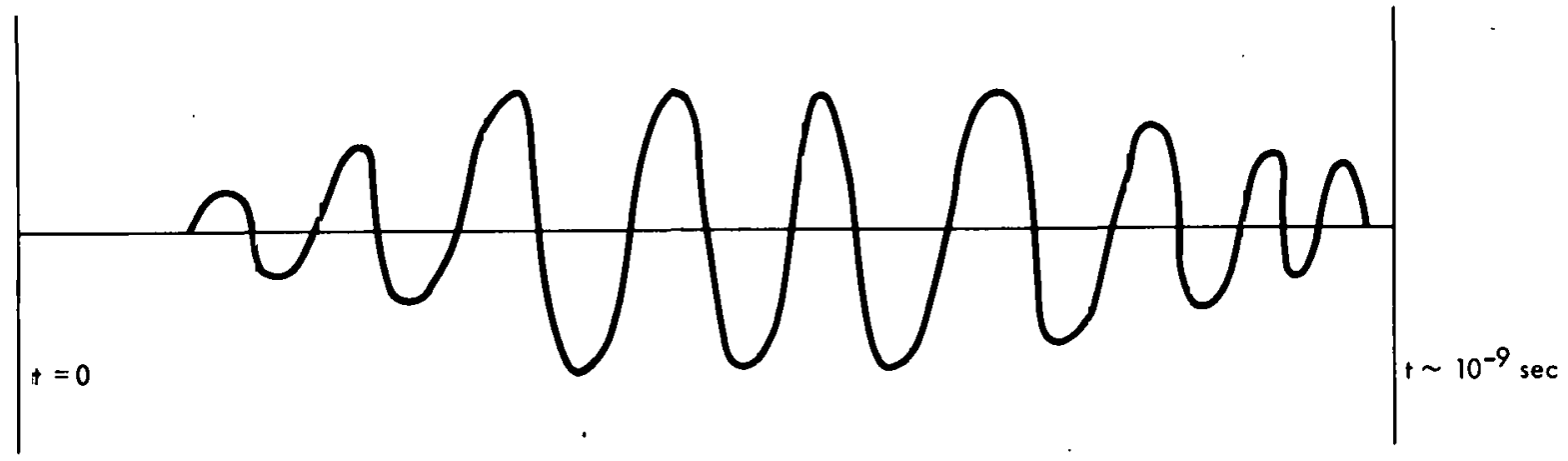

Figure 1. TYPICAL PHOTON IS A DAMPED ELECTROMAGNETIC WAVE. (Michelson Found that a Cadmium Photon was about 500,000 Wavelengiths Long; and, thus, had a Coherence Time of about $10^{-9}$ Second)

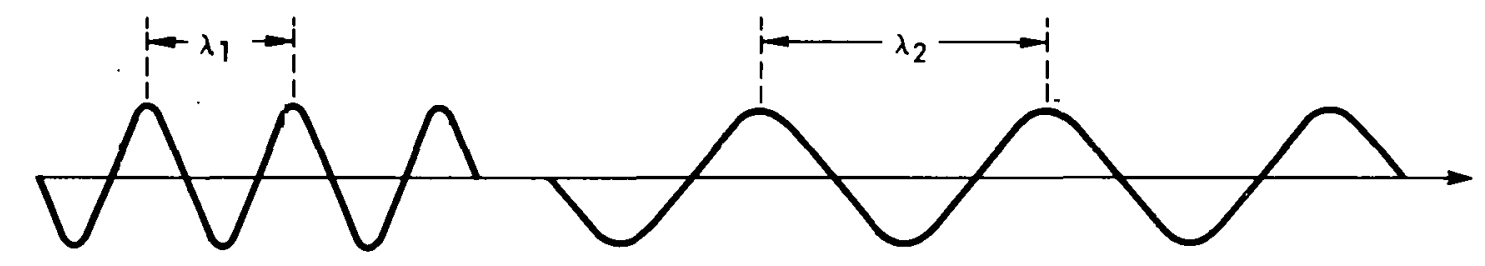

Figure 2. WAVELENGTH IS THE DISTANCE BETWEEN CORRESPONDING PARTS OF ADJACENT WAVES. 
where $\lambda$ represents the wavelength of light in vacuum and $\lambda^{\prime}$ the wavelength in some other medium. This equation shows why length-measuring interferometers must be corrected for variations in barometric pressure, but this is not required for surface-finish measurements.

The terms "phase" and "phase difference" have the same meaning in optics as in other fields dealing with wave motion. If two waves coincide; for example, reach a maximum simultaneously, they are said to be "in phase". Otherwise (Figure 3), they are considered "out of phase" and this phase difference is usually expressed in fractions of a wavelength. Optical-path difference is the product of linear distance times the refractive index of the medium.

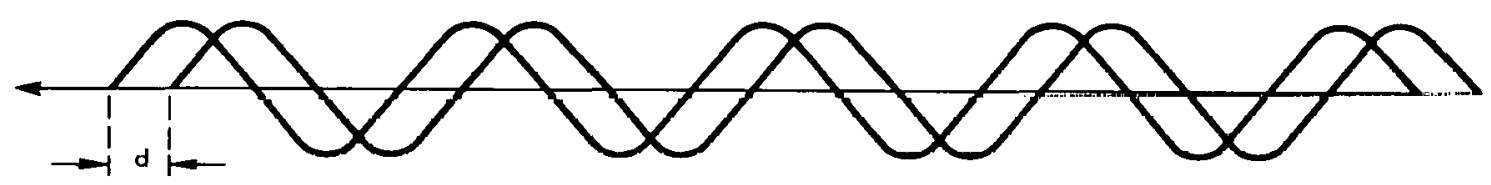

Figure 3. PHASE DIFFERENCE IS THE DISTANCE BY WHICH ONE WAVE LEADS OR LAGS ANOTHER IN PASSING A CERTAIN POINT. (It is Generally Expressed as a-Autltiple of the Wavelength)

The interferometer is an instrument that measures length by using variations in the intensity of light created by phase differences. This length can vary from angstroms, with interference microscopes, to meters, with laser interferometers. The interferometer consists of a device called a "beam divider" which causes a single beam of light to be divided into two or more beams which travel separate paths and are then reflected back to the beam divider where they are recombined. Since light is a form of wave motion, the amplitudes of the two reflected waves are added, with regard to phase. If they are "in phase", the amplitudes of the recombined wave is the sum of the two amplitudes, and they are said to interfere constructively; if they are "out of phase", they interfere destructively.

The practical interferometer consists of a light source and collimating and viewing lenses, in addition to the beam divider, and two end mirrors, Figure 4. The beam divider is necessary, rather than two individual sources, to ensure the proper coherence relations. Light from one photon can not interfere with light from another photon for this reason. In addition, the end mirrors must be nearly equidistant from the beam divider to remain within the coherence length of the light source that is used, (4) except when lasers are used.

Diffraction of light means the bending or spreading of a beam of light when it passes a sharp edge, or a small aperture such as a pinhole, or even a large aperture such as a camera lens or telescope. Theory states that every point on a wavefront gives rise to a new set of waves. These new waves then interfere with each other as they progress through space. An example is the double slit shown in Figure 5. Light from a single source falls upon two slits. The new wave fronts from each slit combine and interfere with each other to form an image of bright and dark lines. This consideration is important in the theory of the microscope.

White light consists of all visible wavelengths, although the intensity of these wavelengths depends upon the source of light. If an interferometer is illuminated with white light in the 


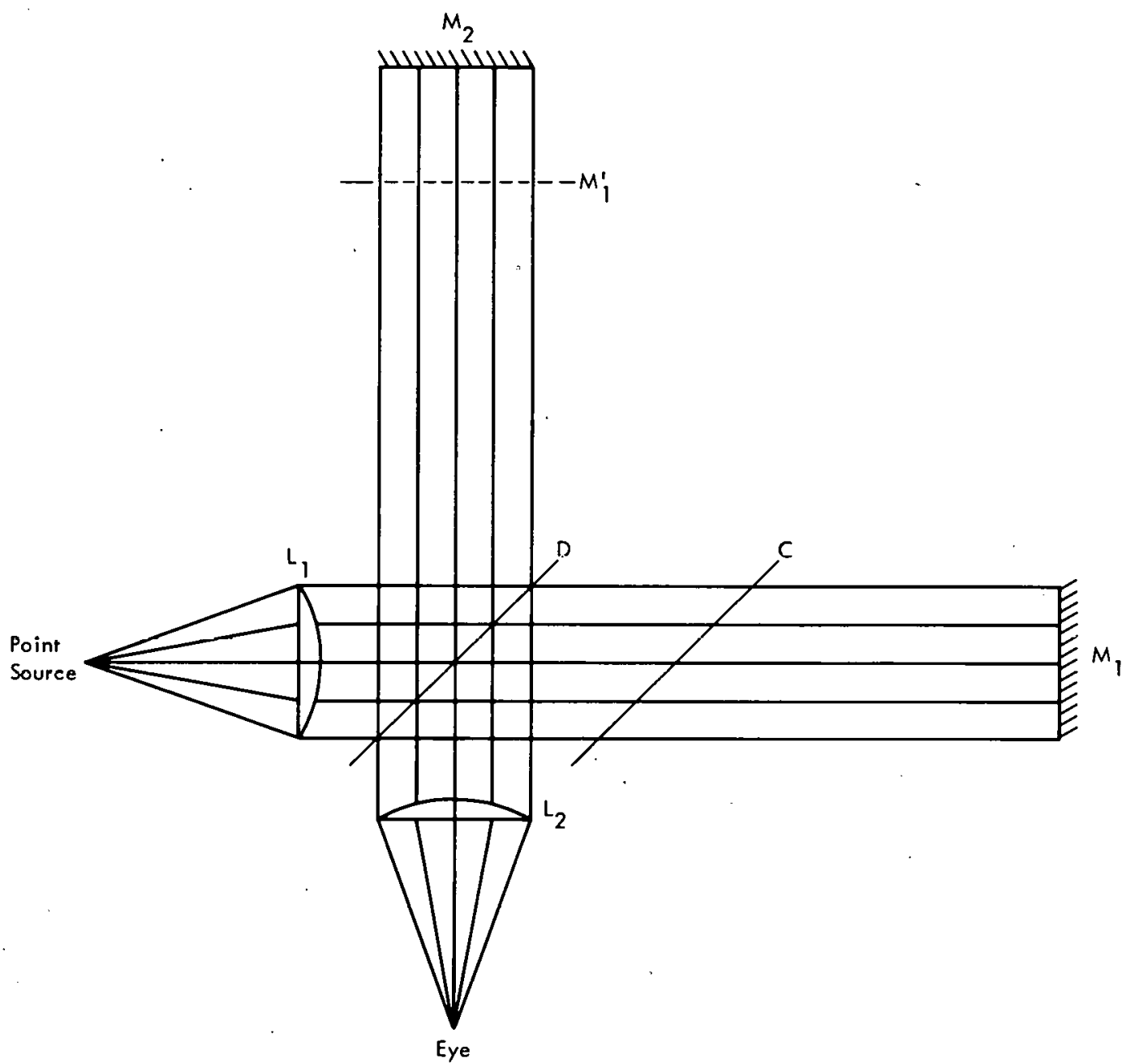

Figure 4. THE TWYMAN-GREEN INTERFEROMETER. (This Instrument Uses a Point Source, the Light is Accurately Collimated by Lens $L_{1}$; the Light is Divided into Two Beams by the Beam Divider, $D$; a Compensating Plate, C, is Necessary if White-Light Fringes are to be Obtained, but it is not Necessary for Monochromatic Light, such as a Laser; the Two Beams are Reflected Back from Mirrors $M_{1}$ and $M_{2}$; to the Viewer, $M_{1}$ Appears to be at Position $M_{1}^{\prime}$; the Eye Observes the Fringes as if they are at an Infinite Distance, because the light is Collimated; if a Laser is Used, the Fringes must be Observed on a Screen Instead of by the Eye)

area where the two optical paths are exactly equal, all wavelengths will be in phase and a white fringe will be observed. Where the path difference is close to $1 / 2$ wavelength, the fringe will be nearly black. As the path difference increases to several half wavelengths, the phase difference for each color or wavelength becomes different and the fringe pattern becomes a display of beautiful colors. Suppose that the phase difference is exactly half a wavelength for blue light. Then blue light is eliminated due to destructive interference. The other colors of which white light is composed will still be present, and the resulting color is white light minus blue light, which is yellow light in the subtractive list of primary colors. Unlike spectral yellow, this light does not have a specific wavelength, and cannot be used for quantitative measurements. The most important uses of white-light fringes are to determine the equality of two optical paths, and to determine the fringe shift in film.thickness 


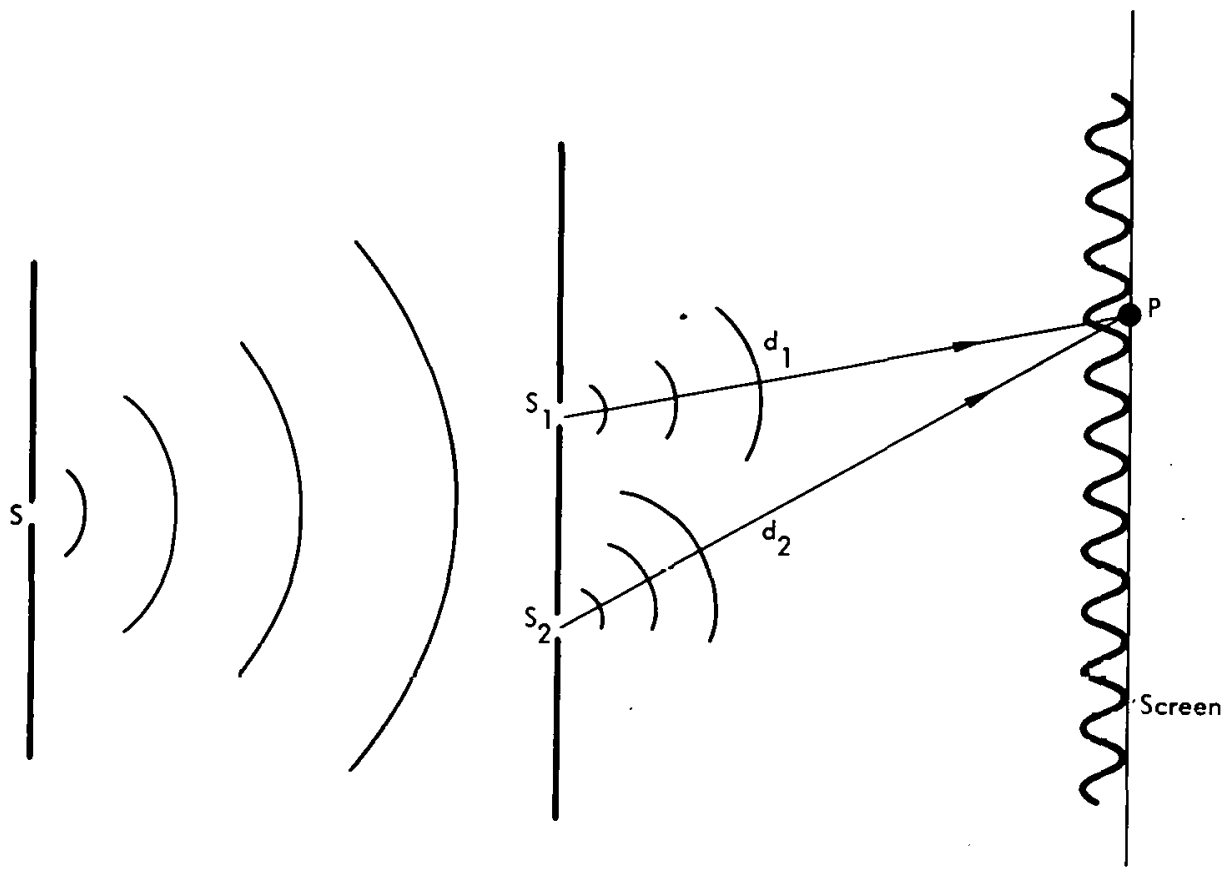

Figure 5. YOUNG's DOUBLE-SLIT EXPERIMENT. (This Arrangement Illustrates Diffraction and Interference; Light Falling upon the Slit, S, Forms a New Circular Wavefront; when this Wavefront Falls upon the Plate Containing the Slits, $S_{1}$ and $S_{2}$, Two New Wavefronts are Formed which have the Ability to Interfere; on the Screen, any Point, $P$, will be Bright if the Optical Paths, $d_{1}$ and $d_{2}$. are such that Constructive Interference will Occur)

measurements when it is not possible to follow monochromatic fringes. White-light fringes are not always easy to use, however, because the shade of the colors can be greatly altered by the color of the surface on which they appear.

\section{THEORY OF THE MICROSCOPE}

\section{General Comments}

The microscope consists of two sophisticated optical elements-the objective and the eyepiece. These items are sophisticated because of the great effort that has gone into the design and production, over the years, to develop instruments with very high magnification and very little distortion. The principle of reversibility applies to optics, namely: light will pass through a lens system in one direction and can then be reversed so that it will also pass the other way. However, every precise optical system is designed to operate under certain conditions and will not work as well under other conditions. That is, all the typical corrections-spherical aberration, chromatic aberration, coma, distortion, and curvature of field-are made to be a minimum under certain working conditions such as object and image distance and field of view. The microscope is highly corrected to give excellent results under certain conditions and that is why a knowledge of its capabilities and operation is important when examining surfaces. Francon's book $(5)$ provides an excellent in-depth study of the theoretical and practical sides of microscopy. 
First of all, consider a simple lens. The lens equation applies only to paraxial rays; that is, those that make a small angle with the axis of the lens. If $D_{O}$ is the distance from the object to the center of the lens (Figure 6) and $D_{i}$ is the distance from the center of the lens to the

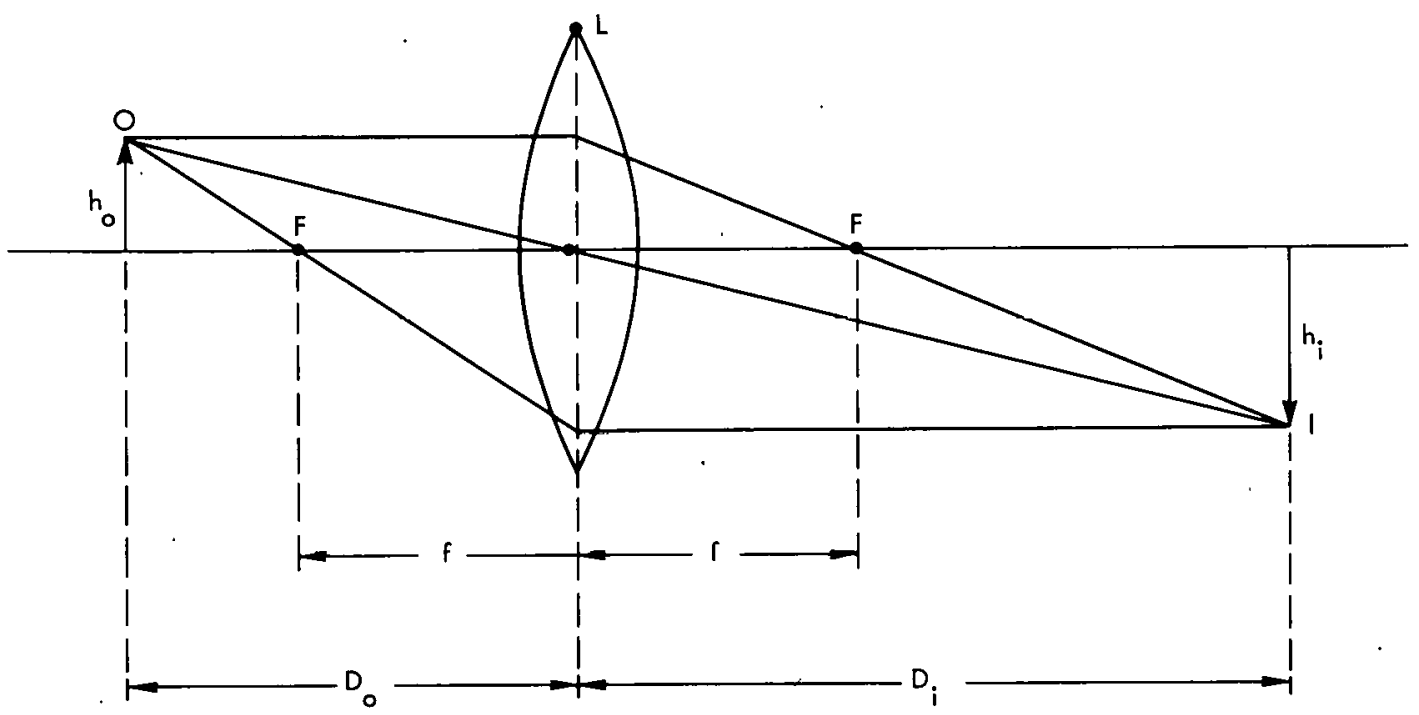

Figure 6. A RAY DIAGRAM, SHOWING HOW A LENS FORMS AN IMAGE. (The Object Distance is $D_{0}$, the Image Distance is $D_{i}$, and the Focal Length is $f$; as $D_{0}$ Approaches $f, D_{i}$ Increases, and the Image Size Increases, but not without Limit; when $D_{0}=f$, Parallel Rays are Formed; in the Microscope, $D_{0}$ is very Close to f)

image; and, if $f$ is the focal length of the lens, these three quantities are related by the equation:

$$
\frac{1}{D_{0}}+\frac{1}{D_{i}}=\frac{1}{f}
$$

There is an elaborate sign convention to be used with this equation; but, for the purpose of illustration, it is not necessary to discuss it here. The focal lengths of microscope objectives are always short, typical values: $25 \mathrm{~mm}$ for a $6 \mathrm{X}$ objective to $2 \mathrm{~mm}$ for an $80 \mathrm{x}$ objective. (b) These microscope objectives consist of several lens elements which are necessary for the corrections mentioned. In such cases, the focal length is not measured from the center of the lens, but from the principal planes, as noted in Figure 7. The object and image distances are also measured from these planes. However, the image distance is fixed by the length of the tube supplied by the manufacturer. A standard length is $160 \mathrm{~mm}$; but, in practice, this distance varies from about 150 to $200 \mathrm{~mm}$. The magnification of a lens can be calculated by dividing the image distance by the object distance:

$$
M=D_{i} / D_{0}
$$

Since the image distance is fixed by the tube length of the microscope, use of a shorter-focal-length lens results in a shorter object distance and, therefore, an increase in magnification. Increased magnification does not necessarily enable a microscope to reveal

(b) Measurement conversion factors that are pertinent to this report are presented in Appendix A. 
more detail. The smallness of detail that can be resolved is related to the diameter of the lens; which, in terms of a camera, means a low f/ number. That is, a faster lens can resolve more detail.

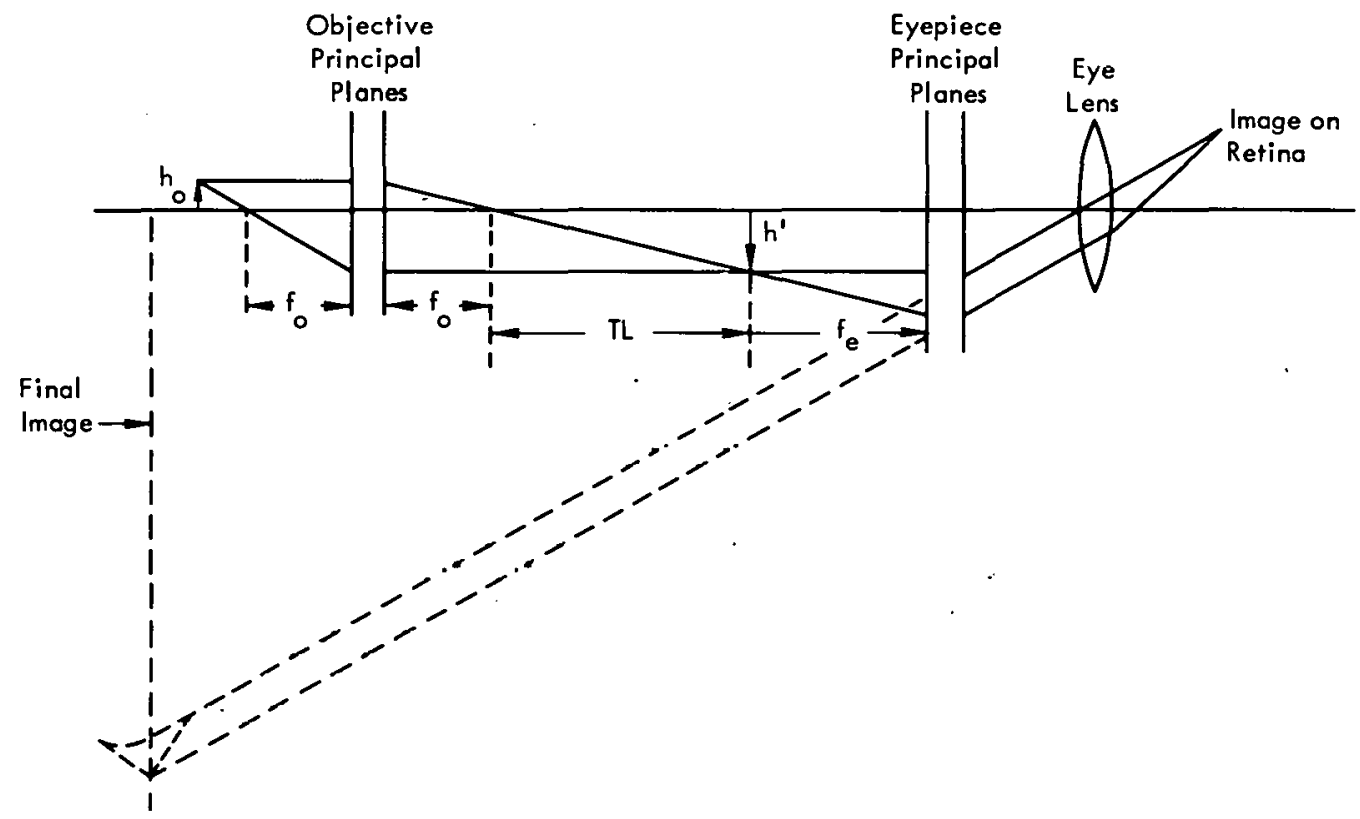

Figure 7. A RAY DIAGRAM OF THE COMPOUND MICROSCOPE, SHOWING THE PRINCIPAL. PLANES (PP) OF THE OBJECTIVE AND EYEPIECE. (The Optical Tube Length, TL, the Distance between the Focal Points of the Objective and Eyepiece, is Generally $150-160 \mathrm{~mm}$; this Distance, and the Focal Length of the Objective, Determine the Magnification that can be Obtained with the Objective; Note that the Image of the Objective is at the Focal Point of the Eyepiece, the Eve then Receives Parallel Light and its Muscles are Relaxed for Viewing Comfort)

The relation between diameter of the objective and resolution was explained by Ernst Abbe who discovered that an object of small size diffracts the light with which it is illuminated. $(6,7)$ To see all of the detail of the object, it is necessary to collect as much of the diffracted light as possible (Figure 8 ). This relationship is expressed by the formula for the numerical aperture (NA) of the objective:

$$
N A=n \sin A O B,
$$

where $n$ represents the refractive index of the medium between the lens and the object, and $A O B$ the half angle of the cone of light extending from a point object to the clear aperture of the lens.

Lord Rayleigh suggested that is should be possible to distinguish the images of two close objects as separate objects if the centers of the central bright discs lie directly over the centers of the first dark ring of the diffraction pattern. This conclusion leads to the formula for resolution for metallurgical microscopes: (8)

$$
R=\frac{1.22 \lambda}{2 N A} ; \text { for green light, } R=\frac{0.333 \times 10^{-6} \mathrm{~m}}{N A}=\frac{13 \mu \mathrm{in}}{N A}
$$


where the resolution is the distance between two features than can be resolved by the microscope. The distance will be in whatever unit is used to express the wavelength of light. Resolving power is the reciprocal of resolution; and, thus, is the number of lines/unit of length that can be separated by a system.

The magnification is a separate property of the objective, and it is possible to obtain objectives with the same magnification but different numerical apertures. An illustration will help to grasp the meaning of these properties: Suppose that there is available in the
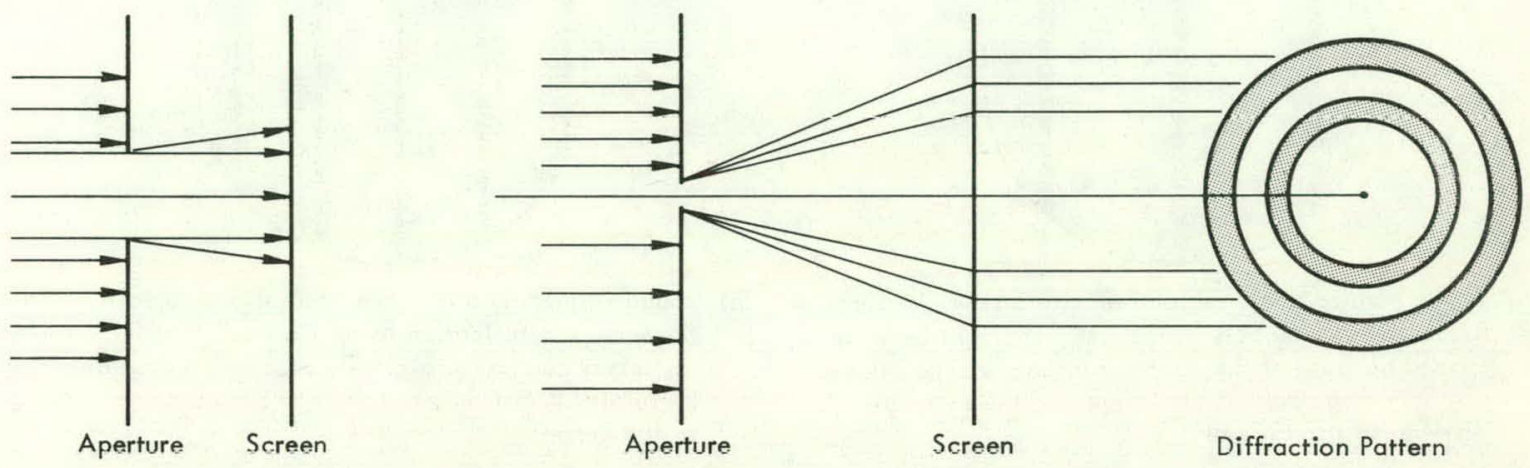

(a) Here is Shown that the Angular Extent of Diffraction Increases as the Size of the Diffracting Element becomes Smaller.

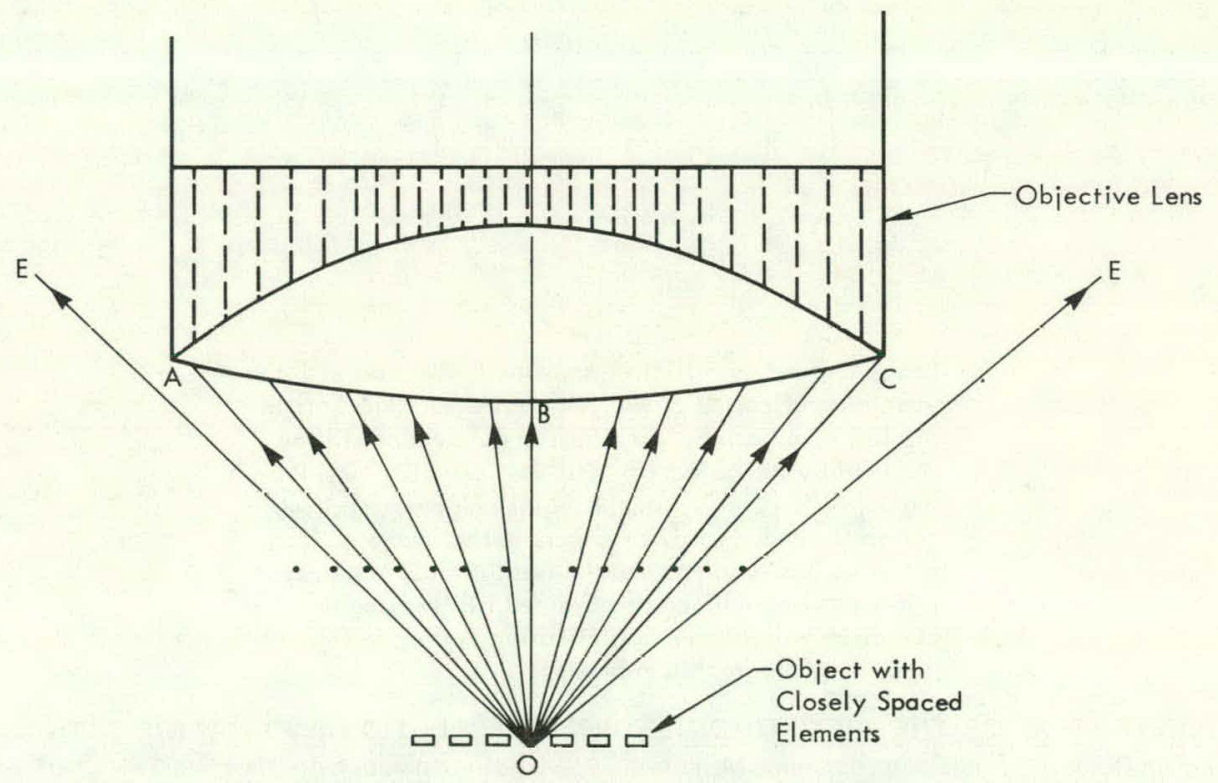

(b) Here is Illustrated the Concept of Numerical Aperture (NA) and the Part it Plays in Collecting All of the Light from an Object; an Object with Closely Spaced Elements Diffracts Light as Shown in View a; only the Diffracted Elements from $A$ to $C$ can Enter the Objective, the more Extreme Elements, $E$, Pass by; $N A=n \sin A O B$. [The refractive index of the medium ( $n$ ) is 1.0 for air, but greater if oil is used; more light can be collected with high numerical apertures, but the lens must then be closer to the work, or larger in diameter; the illustration shows only one point on the object, each point produces a similar cone of rays]

Figure 8. AN ILLUSTRATION OF THE PART THAT DIFFRACTION OF LIGHT AND NUMERICAL APERTURE PLAY IN THE FORMATION OF THE IMAGE OF A MICROSCOPE. 
laboratory a set of test objects which have been ruled with an increasing number of lines/unit width, and a set of microscope objectives with increasing numerical apertures (NA), but the same magnification-say 10X. If an objective did not have sufficient resolution for a test sample, the field would be uniform in color. An objective with a higher NA would be needed to resolve it. If another test object were used that had more bars/unit width, it might be necessary to use another objective with a higher NA to resolve it, etc. The images formed by the microscope would be as illustrated in Figure 9; where, as the number

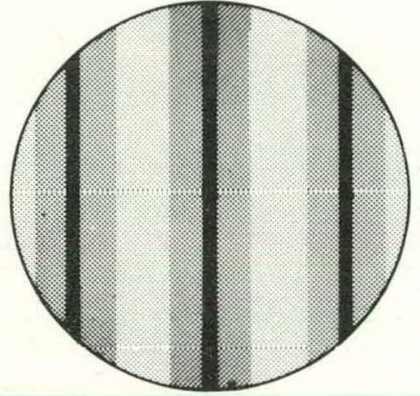

(a) Image Formed by an Objective with a Low NA and Low Resolution. (The bars in the test chart must be widely spaced because of the poor resolution; hence, there are only three bars in the image and the eye can distinguish them readily)

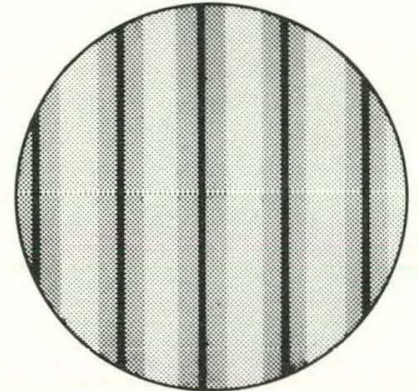

(b) Image Formed by a Medium-Resolution Objective with the same Magnification as in View a. (The bars in the test chart can be more closely spaced because they can be resolved, but they are therefore more closely spaced in the image)

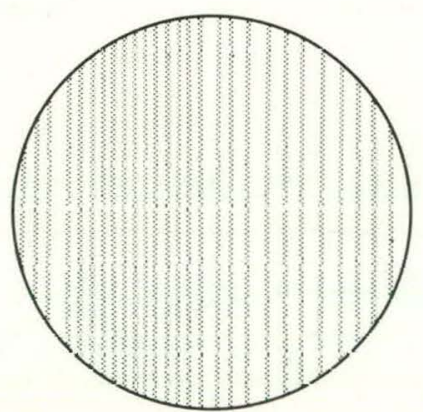

(c) Image Formed by a High-Resolution Objective with the same Magnification as in Views a and b. (The bars in the test chart can be very closely spaced and still be resolved by the objective, but they are very closely spaced in the image; at this point, higher magnification is needed so that the bars in the image will not have less spacing than the resolution of the eye; this magnification can be obtained by choosing an objective with higher magnification, using an eyepiece or photographic enlarging)

Figure 9. ILLUSTRATION OF THE DISTINCTION BETWEEN RESOLUTION AND MAGNIFICATION. IObjectives Capable of Higher Resolution, but with the Same Magnifying Power, can Separate more Bars in a Test Chart, or Grooves in a Specimen, if they Exist; if there are Closely Spaced Artifacts that can be Resolved by the Objective, it may be Necessary to Increase the Magnification to Meet the Resolution Requirements of the Eye)

of bars in the object increased and obviously the spacing between bars has decreased, the spacing of the bars in the image has decreased because the magnification of the three objectives was the same-10X. But, because of the 10X, the bars of the image have 10 times the separation of the bars of the object. Nevertheless, the bars in the image are becoming 
closer together; and, at this point, it is necessary to introduce a new concept-the resolution of the eye. It is the eye which examines the image of the objective through the eyepiece. Thus, it is now apparent that, as the resolution capability of the objective increases, the increase is limited by the ability of the eye to resolve the image. It is necessary to increase the magnification so that the eye can utilize the increased resolution of the objective. Since the resolution of the eye (called visual acuity) is about one minute of arc; and, since the resolution of the objective is limited by the wavelength of light that is used and the diameter of the objective lens, there is a limit to the useful magnification of the optical microscope. Any greater magnification is termed "empty magnification" because it only makes the image larger without increasing the detail that can be resolved. Abbe's rule states that the upper useful limit of magnification of any objective may be found by multiplying the NA by 1000 .

These concepts are embodied in an equation that can be derived from Equations 4 and 6. Consider the image size to be the smallest dimension that can be resolved by the eye. (This value varies somewhat with the individual and conditions, but a generally accepted figure is one minute of arc which is 0.000291 radian.) The distance of distinct vision, $D_{V}$, is $250 \mathrm{~mm}$. The smallest linear spacing the eye can resolve can be found using the conventional formula that the length of arc of a circle is equal to the product of the radius times the angle, in radians. The result is $0.000291 \times 250 \mathrm{~mm}=0.0727 \mathrm{~mm}(0.0029 \mathrm{in})$. If the objective can resolve lines or points such that the spacing in the image is less than this figure, then the eyepiece must have sufficient power to increase the separation. The separation between two objects that can be resolved by the objective is given by Equation 6 . The resulting equation is: $(8,9)$

$$
\begin{aligned}
& \text { Necessary Magnification }>\frac{V \text { isual Acuity } \times D_{V}}{1.22 \lambda / 2 \mathrm{NA}} \\
& =218 \mathrm{NA} \text { for green light, or } \\
& =188 \mathrm{NA} \text { for red light. }
\end{aligned}
$$

Ihis result is the minimum magnification necessary for the eye to resolve what can be resolved by the objective. The maximum useful magnification is usually taken to be three times this amount; that is, figured on three minutes of arc. For example, if a typical $10 \mathrm{X}$ objective with an NA of 0.18 is used in green light, the necessary magnification is $40 \mathrm{X}$ (minimum) or $120 \mathrm{X}$ (maximum). This spread means that, since the magnification of the objective is $10 X$, an eyepiece should be used that has a magnification between 4 and $12 X$. (Magnification greater than this is empty magnification.) Additional comments will be made later, after the reader has had the opportunity to examine some of the photographs in this report.

For photomicrography, the film is the important element instead of the eye. (8) High-speed films, such as Polaroid Type 57 (3000 speed), have a resolution about the same as the eye, so the necessary magnification is about the same as for visual work. Most samples that are 
examined in the laboratory for surface finish are photographed. In this case, an eyepiece may be used as part of the camera system. The only accurate way to determine the resulting magnification is with a stage micrometer. The magnification may change unintentionally by several power with the adjustment of the microscope. In this report, photomicrographs appear which are basically the same setup, but slightly different powers may be noted with the pictures.

The various objectives in the laboratory are listed in Table 1 with the NA of each objective and the calculated resolution (necessary magnification for visual and photomicrographic work) and the typical magnification on a photomicrograph. Photomicrographs of a stage micrometer are shown in Figure 10 to present a concrete example of magnification of each microscope. From Table 1 and Figure 10 it should be

Table 1

CHARACTERISTICS OF THE SURFACE-FINISH MICROSCOPE OBJECTIVES AND COMPLETE INSTRUMENTS

\begin{tabular}{|c|c|c|c|c|c|c|c|c|c|c|}
\hline \multirow{4}{*}{$\begin{array}{c}\text { Microscope } \\
\text { Type }\end{array}$} & \multirow{4}{*}{$\begin{array}{c}\text { Objective } \\
\text { Power }\end{array}$} & \multirow{4}{*}{$\begin{array}{c}\text { Numerical } \\
\text { Aperture }\end{array}$} & \multicolumn{4}{|c|}{ Green Light, $5461 \AA$} & \multicolumn{4}{|c|}{ Red Light, $6328 \AA$} \\
\hline & & & \multirow{2}{*}{\multicolumn{2}{|c|}{ Resolution (1) }} & \multicolumn{2}{|c|}{ Magnification } & & & \multicolumn{2}{|c|}{ Magnification } \\
\hline & & & & & \multirow{2}{*}{$\begin{array}{c}\text { Mınımum } \\
\text { Needed, } \\
\text { Visual }\end{array}$} & \multirow{2}{*}{$\begin{array}{c}\text { I ypical } \\
\text { Obtained, } \\
\text { Photograph }\end{array}$} & \multicolumn{2}{|c|}{ Resolution } & \multirow{2}{*}{$\begin{array}{c}\text { Mınımum } \\
\text { Needed, } \\
\text { Visual }\end{array}$} & \multirow{2}{*}{$\begin{array}{c}\text { I ypical } \\
\text { Obtained, } \\
\text { Photograph }\end{array}$} \\
\hline & & & $(\mu \mathrm{m})$ & $(\mu \mathrm{in})$ & & & $(\mu \mathrm{m})$ & $(\mu \mathrm{in})$ & & \\
\hline Leitz & $10 x$ & 0.18 & 1.85 & 73 & $39 x$ & $51 x$ & & & & \\
\hline Double & $20 x$ & 0.35 & 0.92 & 37 & $76 x$ & $102 X$ & & & & \\
\hline \multirow[t]{3}{*}{ Beam } & $50 x$ & 0.85 & 0.39 & 16 & $185 x$ & $260 x$ & & & & \\
\hline & $100 \times(2)$ & 0.95 & 0.35 & 14 & $207 x$ & & & & & \\
\hline & $100 \times(2)$ & 1.3 (oil) & 0.25 & 10 & $296 x$ & & & & & \\
\hline Leitz & $3.2 \times(2)$ & 0.06 & 5.55 & 218 & $13 x$ & & 6.43 & 253 & $11 X$ & \\
\hline Multiple & $5.0 x$ & 0.09 & 3.70 & 146 & $20 x$ & & 4.29 & 169 & $17 x$ & \\
\hline \multirow[t]{3}{*}{ Beam } & $10.0 \times(2)$ & 0.18 & 1.85 & 13 & $39 x$ & & 2.14 & 84 & $34 x$ & \\
\hline & $2 n x$ & 0.40 & 0.83 & 3.3 & $87 x$ & $352 \times(3)$ & $\cap .97$ & 38 & $75 x$ & $352 \times(3)$ \\
\hline & $32 x$ & 0.60 & 0.56 & 22 & $131 x$ & $533 x^{(3)}$ & 0.64 & 25 & $113 x$ & \\
\hline Nikon & $6.4 X$ & 0.18 & 1.85 & 73 & $39 x$ & $164 x$ & 2.14 & 84 & $34 x$ & $164 x$ \\
\hline $\begin{array}{l}\text { Multiple } \\
\text { Beam }\end{array}$ & $13 x$ & 0.25 & 1.33 & 52 & $55 x$ & $328 x$ & 1.54 & 61 & $47 x$ & $328 x$ \\
\hline Reichert & $8 x$ & 0.15 & 2.22 & 87 & $33 x$ & & & & & \\
\hline Nomarski & $16 x$ & 0.25 & 1.33 & 52 & $55 x$ & $203 x$ & & & & \\
\hline \multirow[t]{4}{*}{ Technique } & $32 x$ & 0.40 & 0.83 & 33 & $87 x$ & $395 X$ & & & & \\
\hline & $45 x$ & 0.65 & 0.51 & 20 & $142 x$ & $567 x$ & & & & \\
\hline & $80 x$ & 0.85 & 0.39 & 16 & $185 x$ & $960 x$ & & & & \\
\hline & $140 x$ & 1.30 (oil) & 0.26 & 10 & $283 x$ & & & & & \\
\hline Zeiss & $10 x$ & 0.16 & 2.1 & 82 & $35 x$ & $69 x$ & & & & \\
\hline Double & $25 x$ & 0.32 & 1.0 & 41 & $10 x$ & $1 / 1 x$ & & & & \\
\hline Beam 1 & $60 x$ & 0.64 & 0.5 & 20 & $140 x$ & $450 x$ & & & & \\
\hline Zeiss & $10 x$ & 0.16 & 2.1 & 82 & $35 x$ & $41 x$ & & & & \\
\hline Double & $25 x$ & 0.32 & 1.0 & 41 & $70 x$ & $105 x$ & & & & \\
\hline Beam 2 & $60 x$ & 0.64 & 0.5 & 20 & $140 x$ & $267 x$ & & & & \\
\hline
\end{tabular}

(1) Resolution is the separation between two lines which can be resolved by the objective.

(2) This objective is not available at $Y-12$ at present.

(3) This objective was used on the Nikon multiple-beam microscope. 
possible to judge whether or not the laboratory work fulfills the requirements of the person submitting the sample.

The magnification discussed thus far is linear magnification, which is necessary to resolve the features on a surface, but it does not improve the visibility of a colorless, featureless surface. In fact, it is difficult to focus on such a surface unless a dust particle can be located. The interference effect makes the surface features visible, and these special microscopes will be discussed in the next section.

The numbers in Table 1 will be more meaningful if illustrated. The best specimen for this purpose was a spectrographic diffraction grating. The views of Figure 11 were taken with the Leitz double-beam interference microscope with 10X, 20X, and 50X objective lenses. (These are pictures using the interference effect to bring out the lines in the grating.) With the $10 \mathrm{X}$ objective, the grooves are not visible; they are barely visible with the $20 \mathrm{X}$ objective, and very plain with the $50 \mathrm{X}$ objective. This grating has 570.0 (grooves $/ \mathrm{mm})(14,500$ grooves/in) so that the groove spacing is $0.0018 \mathrm{~mm}$ (69 $\mu \mathrm{in})$. Hence, the $20 \mathrm{X}$ objective should resolve the grooves, and it does, but it is really impossible to tell anything about the surface. Table 1 lists the minimum magnification for the $20 \mathrm{X}$ objective as 76 . The magnification of Figure 11, View $b$ is 102; thus, it is apparent that resolved lines will be marginally visible. The $50 \mathrm{X}$ objective (View c) provides a much clearer view; but, in all cases, to obtain the most information it is necessary to produce a large, clear photograph of the surface. This objective was achieved for the illustrations by photographing the fringes on $35-\mathrm{mm}$ Panatomic- $X$ film and making a $19.4 X$ enlargement. The enlargements show that the 10X objective (View d) does not resolve the grating; it is resolved with the $20 \mathrm{X}$ objective (Viewe), and with the 50X objective (View f). The extra magnification obtained by photographic enlargement is really useful because that obtained using the Polaroid camera is the minimum needed. The problem with using $35-\mathrm{mm}$ film is the additional time and inconvenience required for processing the film and making the enlargements. The same problem is encountered with the Zeiss Double-Beam Microscope 2, which has a different Polaroid camera from Zeiss Microscope 1.

The $13 \mathrm{X}$ objective of the multiple-beam interference microscope is capable of resolving the diffraction grating (Figure 11, View g), and the magnification on the Polaroid print is adequate and about as high as should be used. The Leitz lenses, used on the Nikon, provide even higher resolution and magnification (Views $h$ and i). The dimensions of the picture are larger because of a different camera. This substitution did not increase the magnification, but it did increase the field of view.

\section{Double-Beam Interference Microscope}

Applications Note-This surface-finish microscope is a noncontact instrument and, therefore, provides a nondestructive method for measuring surface finish. The fringes are broad, so that a light and a dark area are about equal in width. Sensitivity is generally about $30 \mathrm{~nm}(1.2 \mu \mathrm{in})$, but may he as low as $14 \mathrm{~nm}(0.5 \mu \mathrm{in})$ under good 


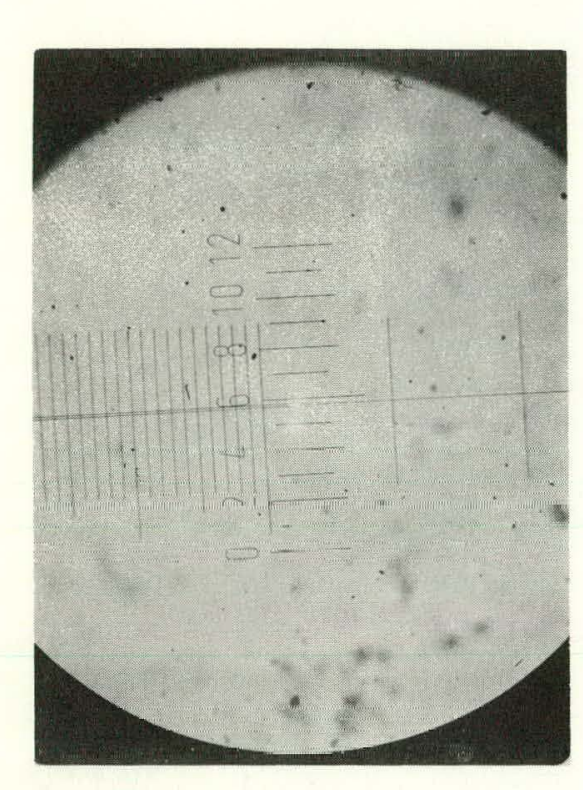

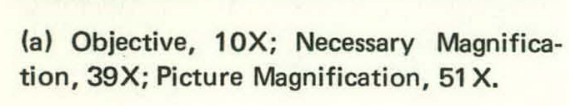

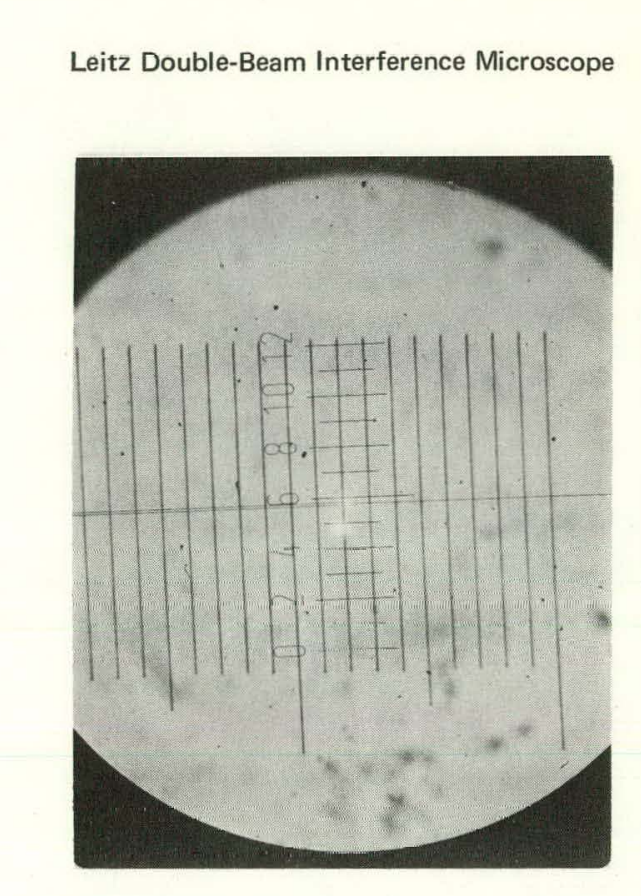

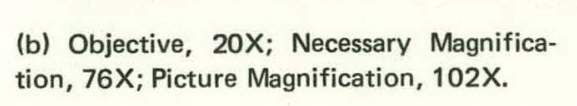

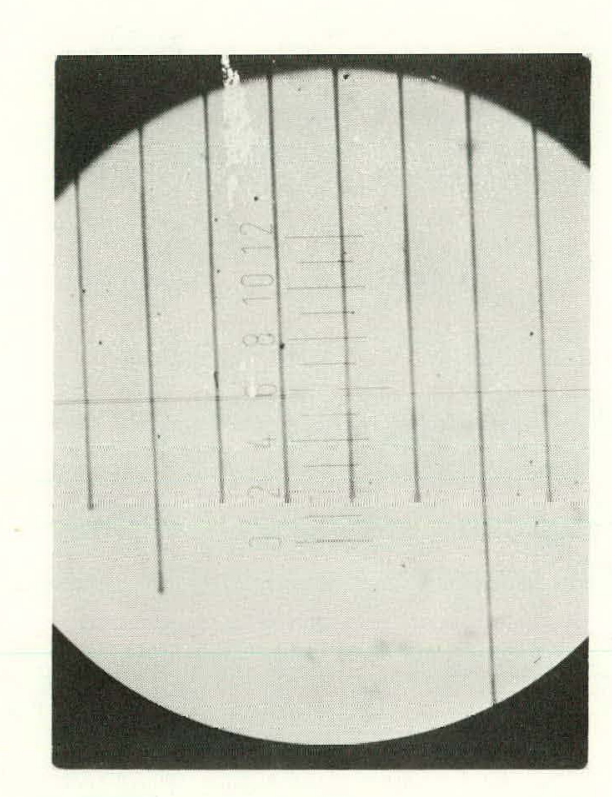

(c) Objective, 50x; Necessary Magniticas.
tion, 185x; Picture Magnitication, $200 \times$.

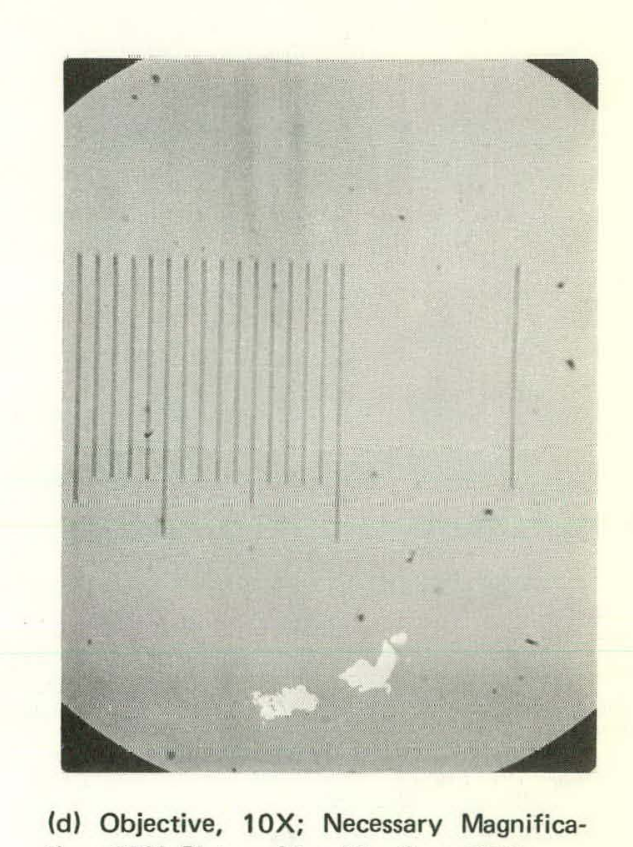

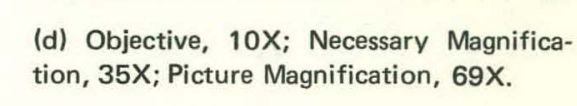

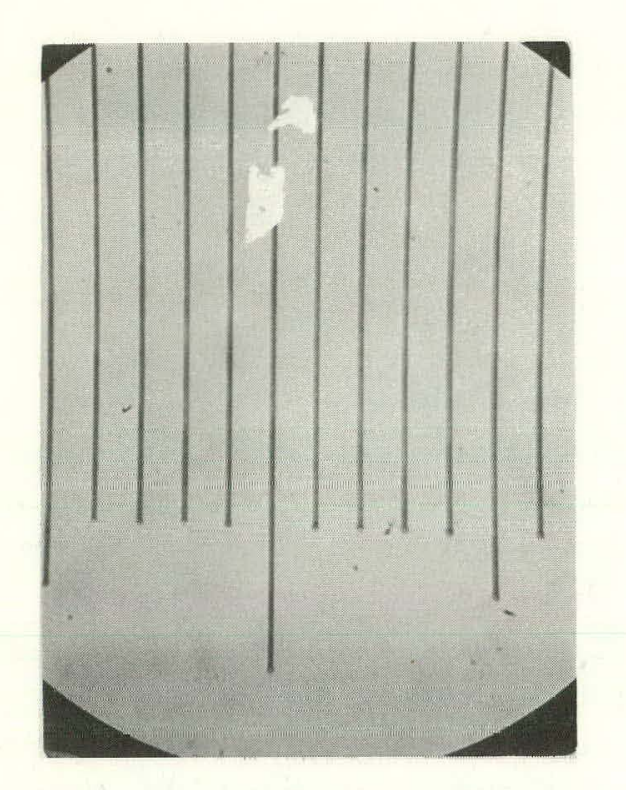

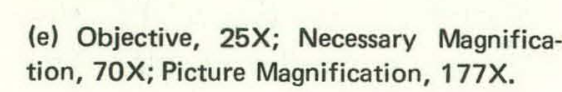

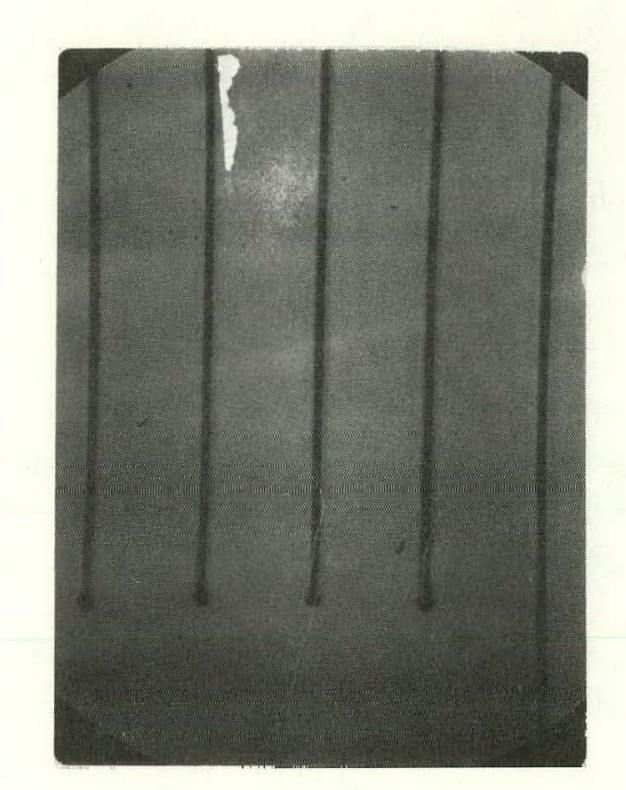

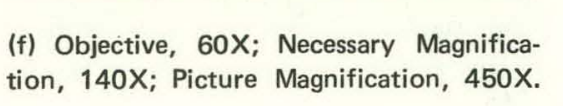

Nikon Multiple-Beam Interference Microscope

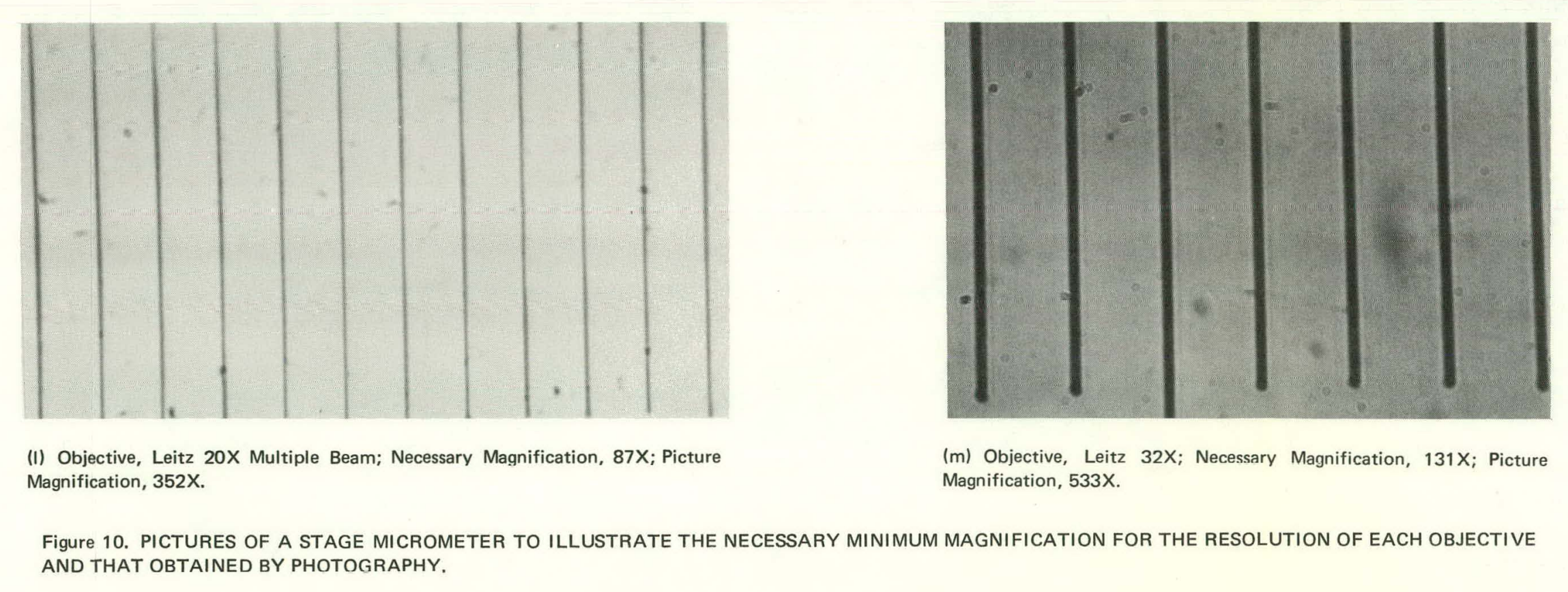



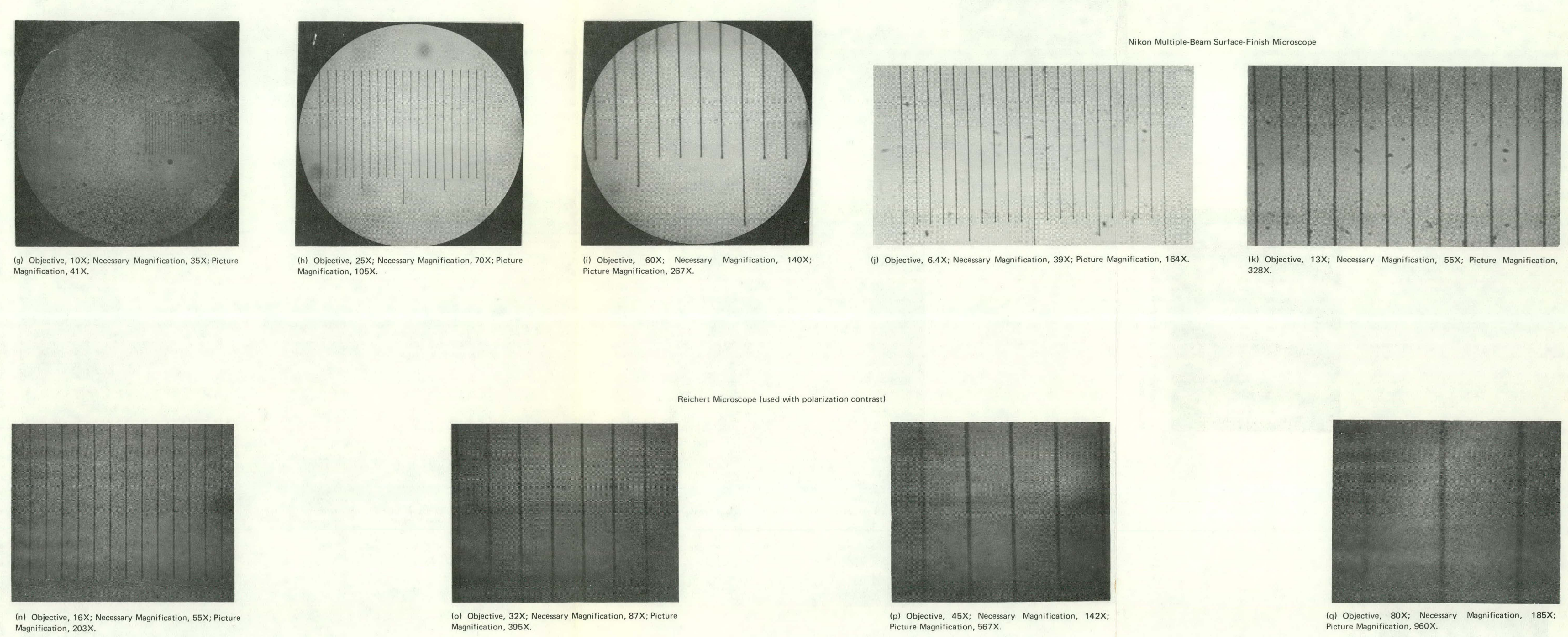


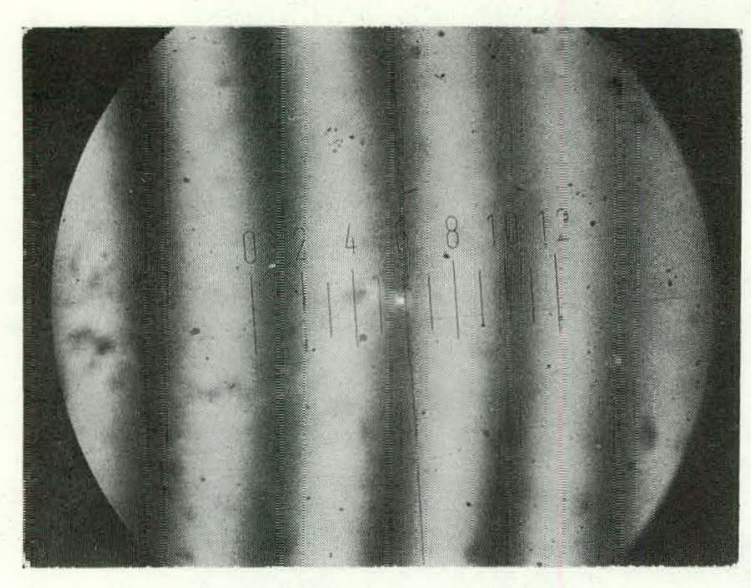

(a) Object ve, 10X; NA, 0.13; Resolution, 73 pin; Pictur Magnification, $51 X$

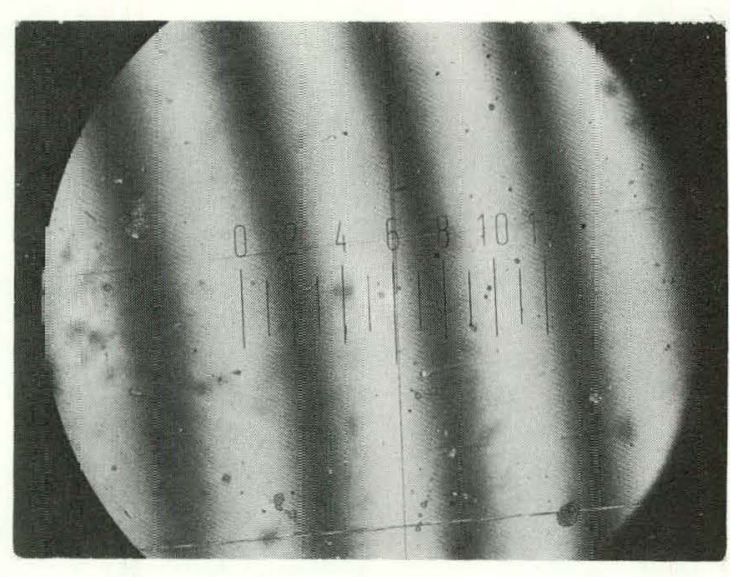
(b) Objective, 20x; N.A, 0.35; Resolution, 37 pin; Picture
Magrification, 102X.

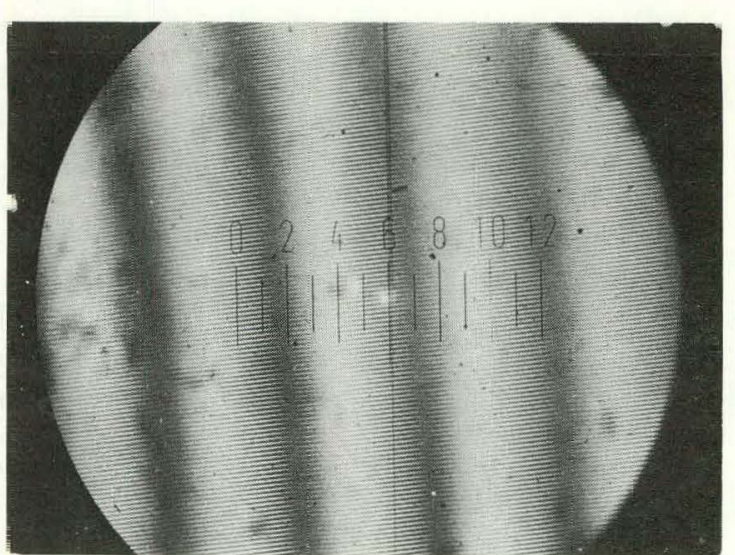

(c) Objective, 50X; NA, 0.85; Resolution, 16 pin; Pictura Magnification, 260X

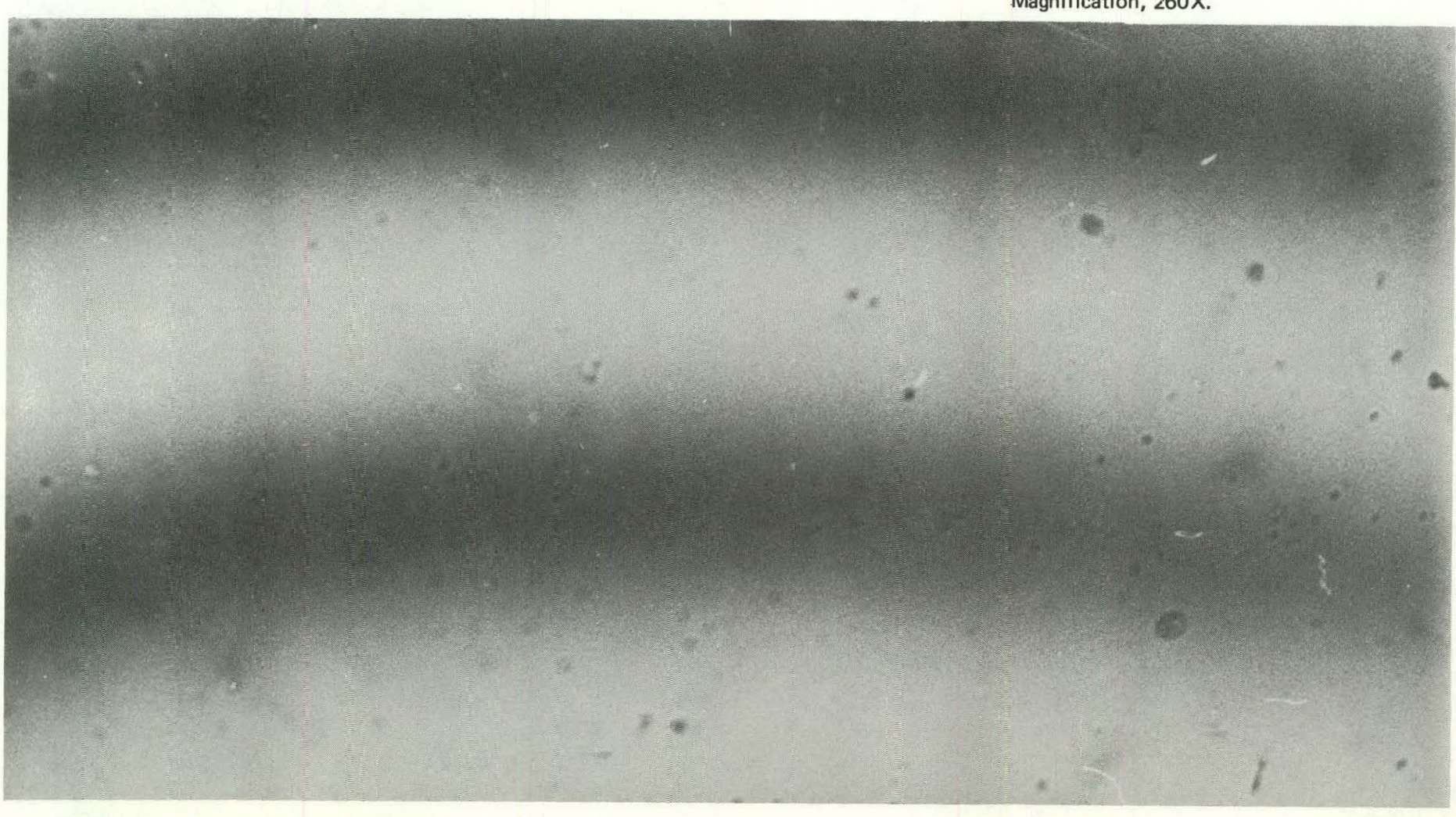

(d) Objective, Leitz 10X; VA, 0.18 Resolution, 73 min; Picture Magrification, 194X.

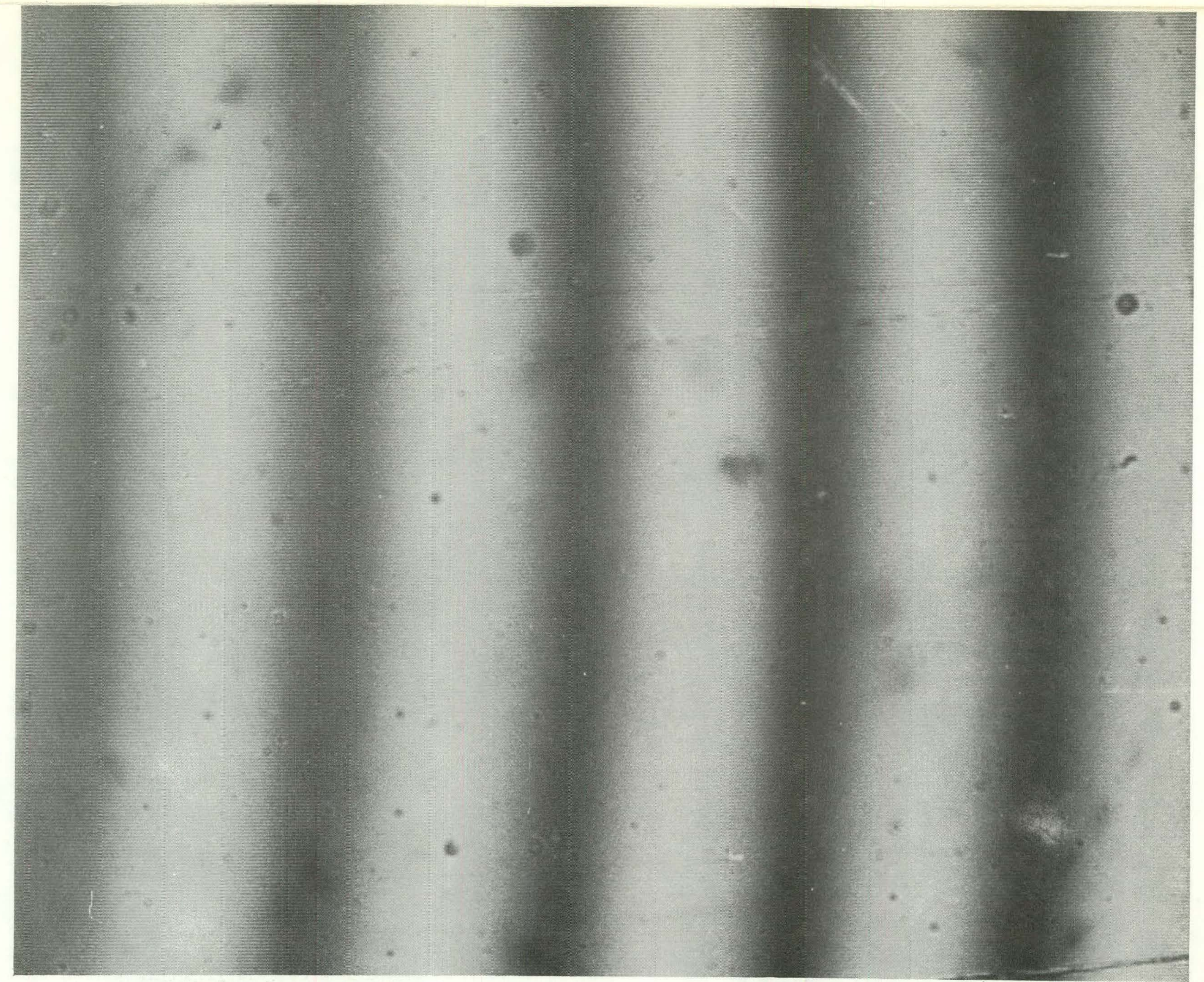

(e) Objective, Leitz 20X; NA, 0.35; Resslution, 35 pin; Picture Magnif cation, 388X. 


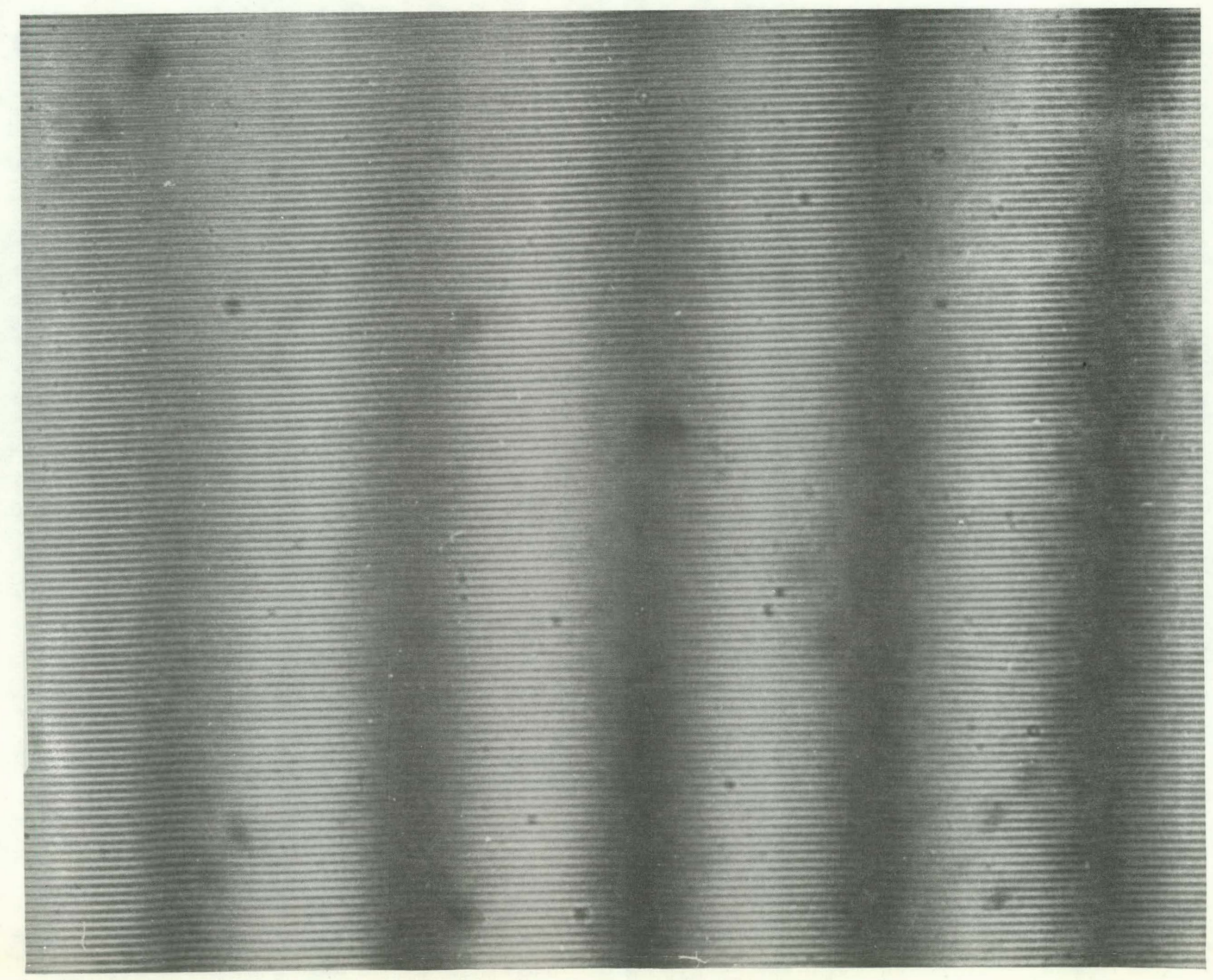

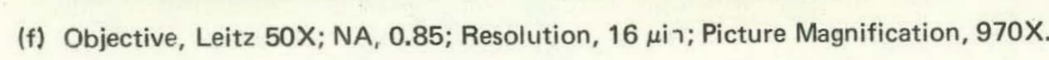

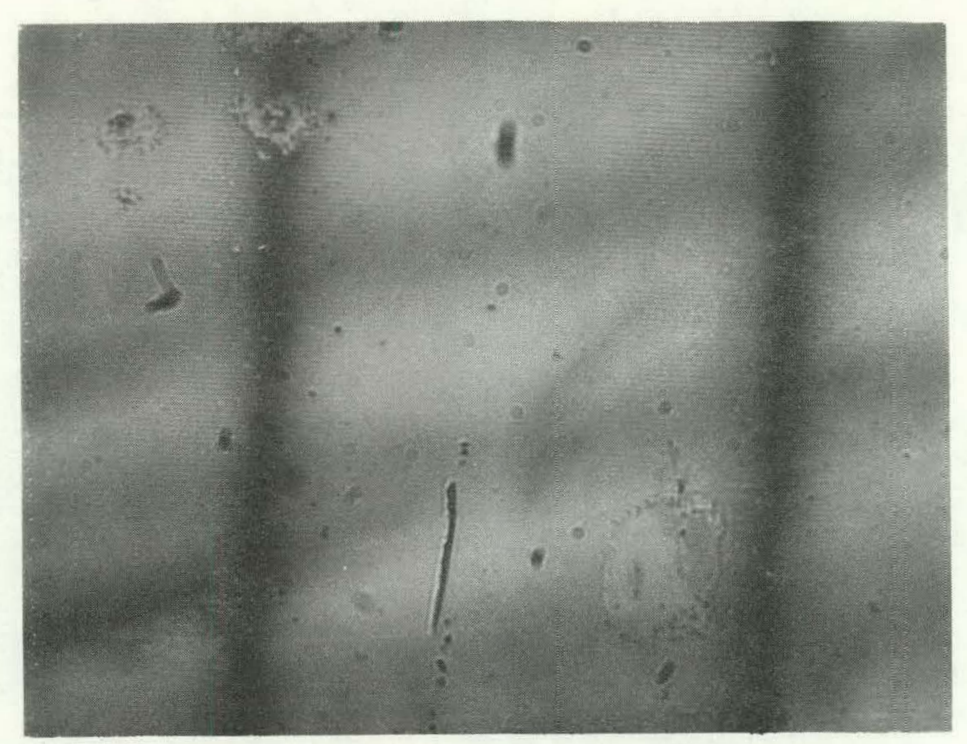

(g) Objective, Nikon 13X; NA, 0.25; Resolution, $52 \mu$ in (green); Picture Macnification, 311X.

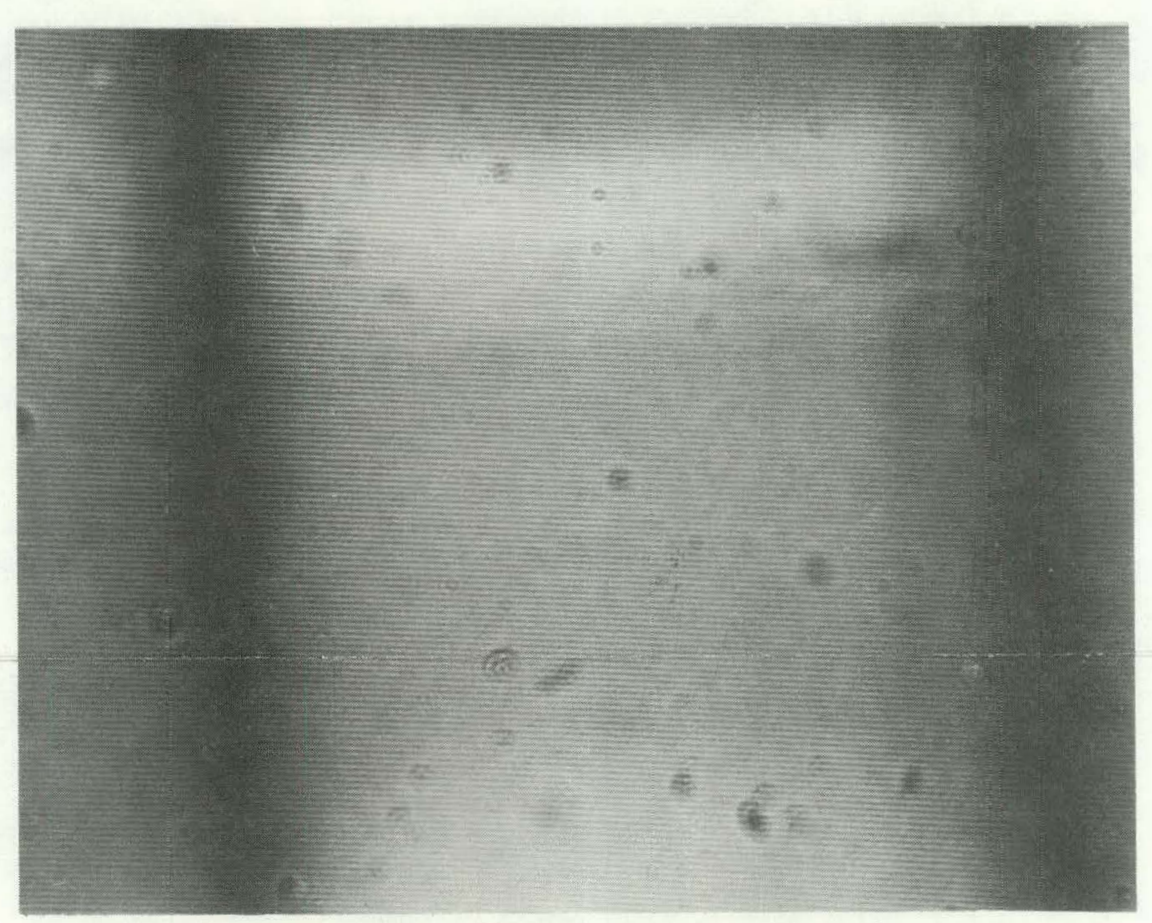

(h) Objective, Leitz 20X on Nikon Microscope; NA, 0.40; Resolution, 33 min (green) Picture Magnification, 352X.

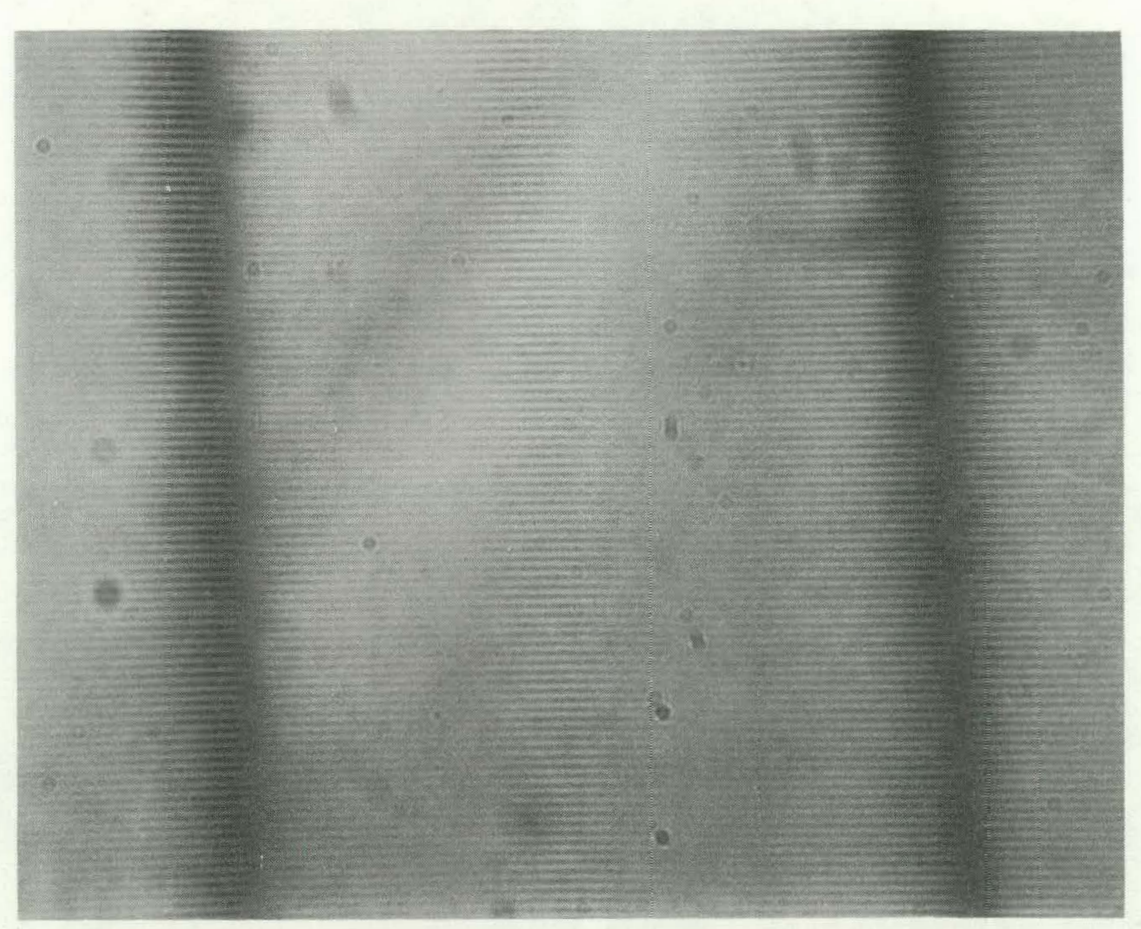

(i) Objective, Leitz $32 \mathrm{X}$ on Nikon Microscope; NA, 0.60: Resolution, 25 uin (red): Picture Magnification, 533X. 
conditions. High-resolution objectives are available. Some instruments can be used with very large and heavy specimens, or even used with vertical specimens mounted on a machine spindle.

The double-beam microscope is a Twyman-Green interferometer in which microscope objectives have been inserted before the mirrors, and which are focused on the surface of the mirrors (Figure 12). The microscope incorporates a small beam divider for division of amplitude of the incident beam, and which sends one beam to the reference objective. There are other types of objectives (Mireau) in which the beam divider and reference flat are combined with the objective so that only one objective is needed. After the beams have been reflected from the sample and reference surfaces, they return to the beam divider where recombination occurs and interference takes place. The objectives must he matched to obtain white-light fringes because of the short coherence length of white light, as explained before. The optical system also includes either a special lamp to produce monochromatic light or an interference filter to approximate monochromatic light.

The objectives must be focused accurately on the sample surface and the reference surface to obtain fringes. Artifacts that are usually used for focusing, such as spots, dust, and scratches, change the amplitude of the light and are called "amplitude objects". A smooth, clean mirror or diamond-turned surface has no such artifacts upon which to focus, only changes of elevation or inclination due to slopes of the shallow grooves on the surface. The reflected light is changed in phase, not amplitude-such objects are called "phase objects". The eye cannot detect changes of phase and, therefore, cannot focus the microscope on such a surface. The microscope may be inadvertently adjusted out of focus if the user attempts to set sharply on some lines that may look like machıne grooves, but are actually diffraction patterns formed by surface structures. The best approach to obtaining fringes with phase objects appears to be to set up the microscope first on an amplitude object, such as a surface with a thin film boundary or a sligh̨t scratch. Next, adjust the reterence-mmior lucusmly cunliuls to obtain the sharpest white-light fringes with the greatest contrast. Finally, upon switching to the phase object, focus on the edge of the surface if possible with the coarse controls and then use the fine controls to obtain fringes with the maximum contrast and definition.

Theory of the double-beam fringes is given in the text by Born and Wolf, $(10)$ and other books. Figure 13 shows why double-beam fringes are broad. These fringos are a $\cos ^{2} \delta$ function, where $\delta$ is the phase difference between the two interfering beams. The fringes have the greatest visibility when both the sample and reference have the same reflectivity, which should be as high as possible.

The principle of the Zeiss double-beam microscope is similar to that of the Leitz; however, the controls are quite different. In addition, the Zeiss is an inverted microscope; that is, the objective looks up. The objective of the Leitz is pointed down toward the base and, thus, this microscope can be used with very heavy specimens (Figure 14). The microscope was adapted for vertical specimens also, as indicated in Figure 15. 


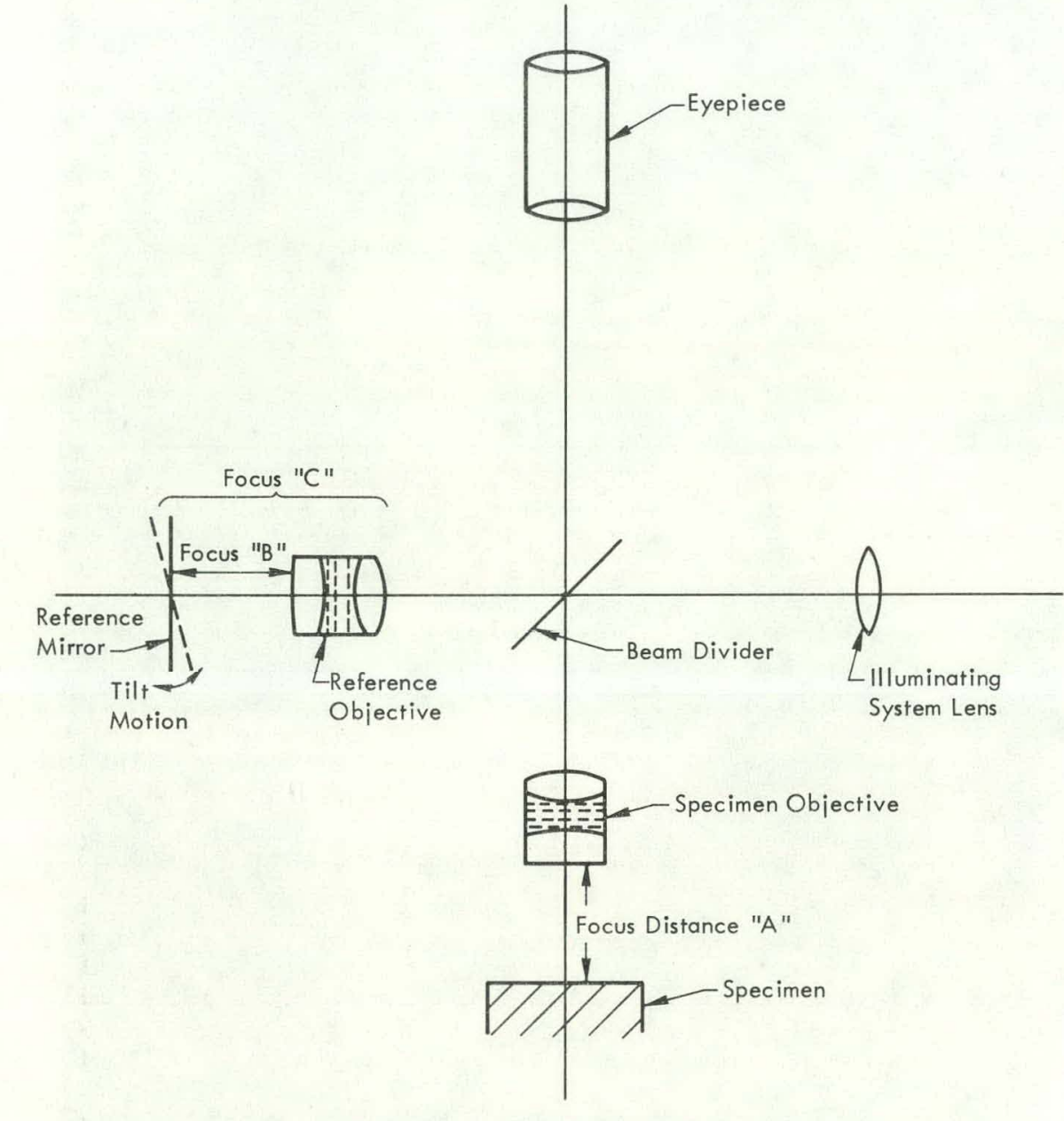

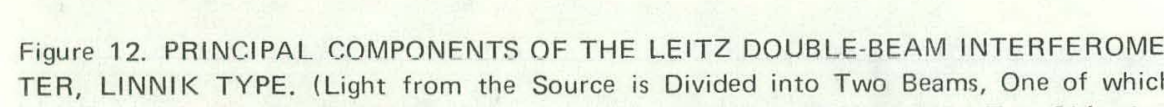

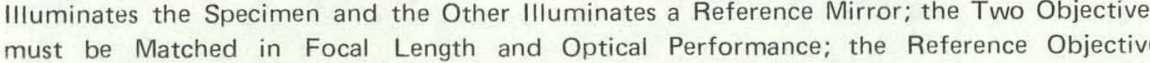

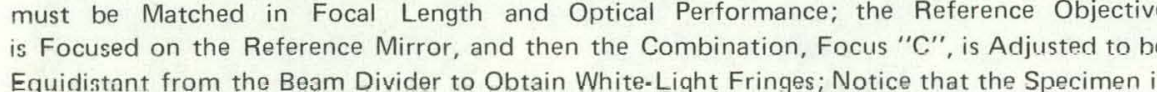
Magnified beforer Fringes are Obtained by the Recombination of Light Beams)

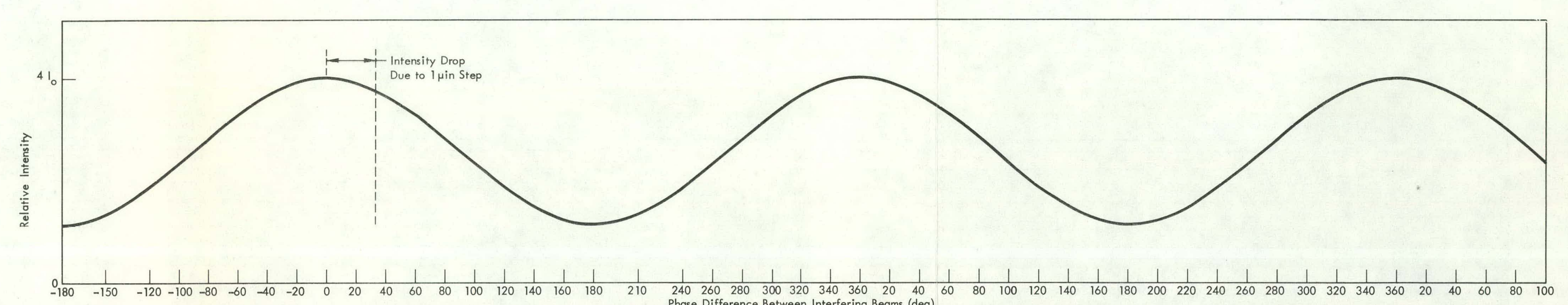

Figure 13. GRAPH, SHOWING THAT DOUBLE-BEAM FRINGES ARE EQUAL IN WIDTH TO THE SPACE BETWEEN THE FRINGES. (This Graph hs of the

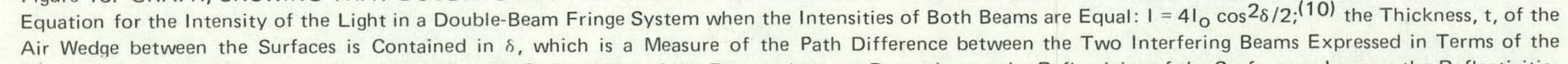

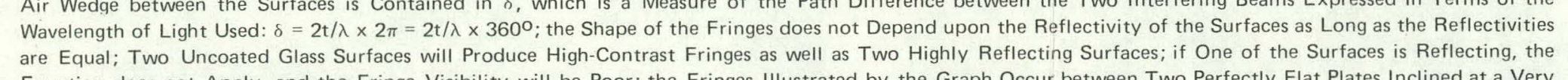

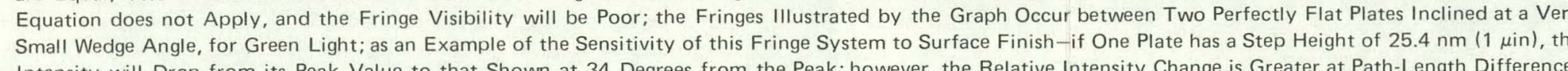

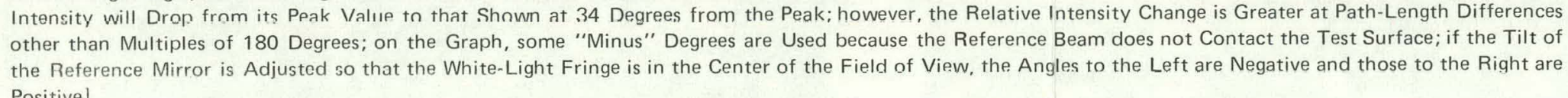




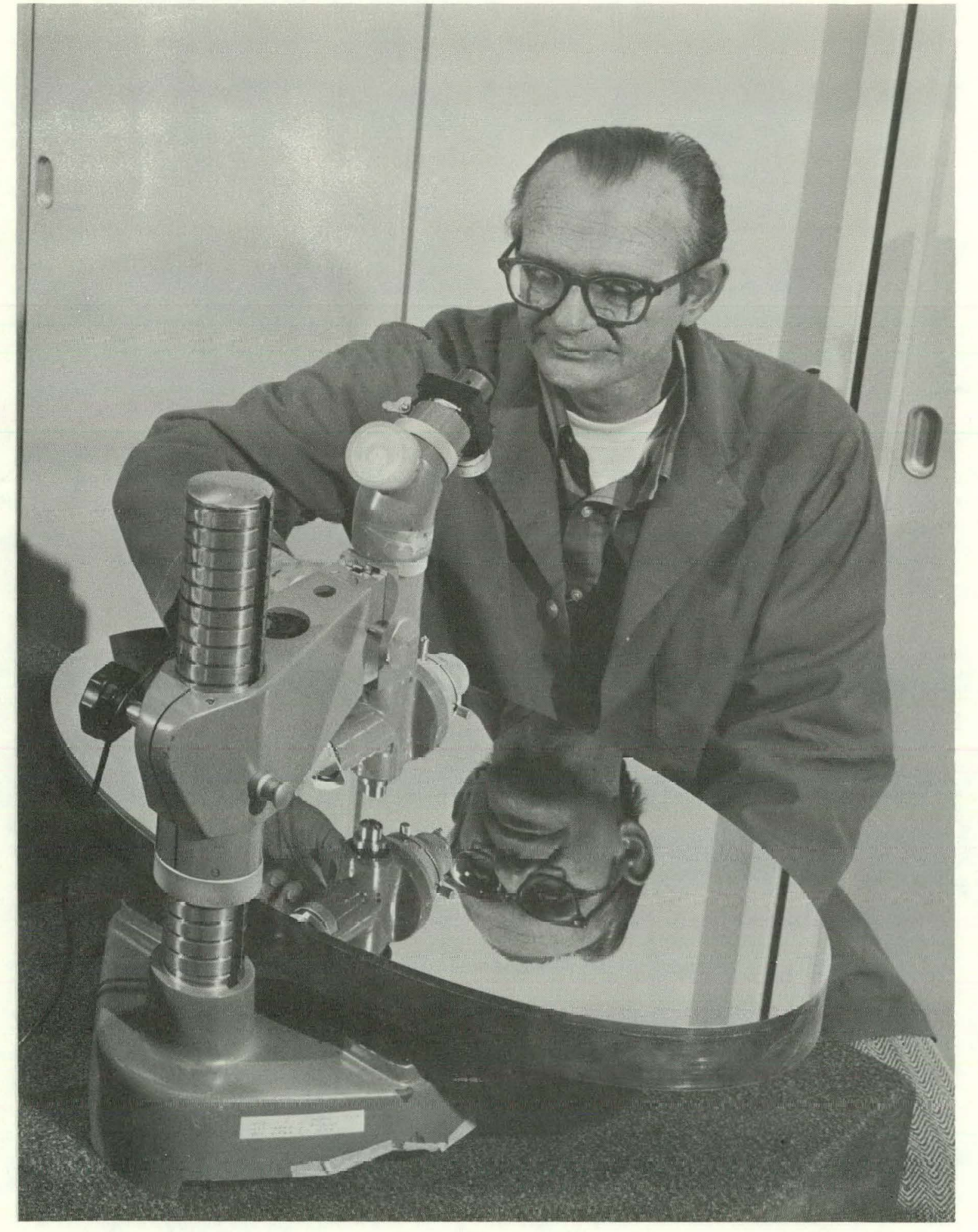

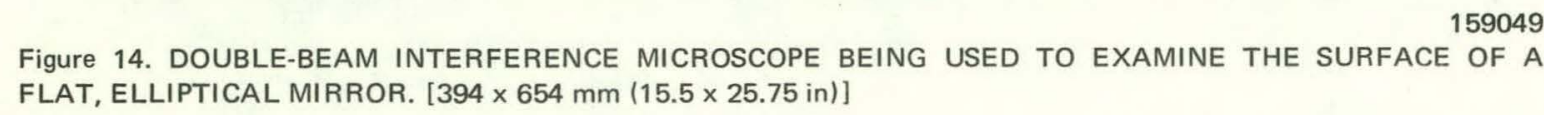

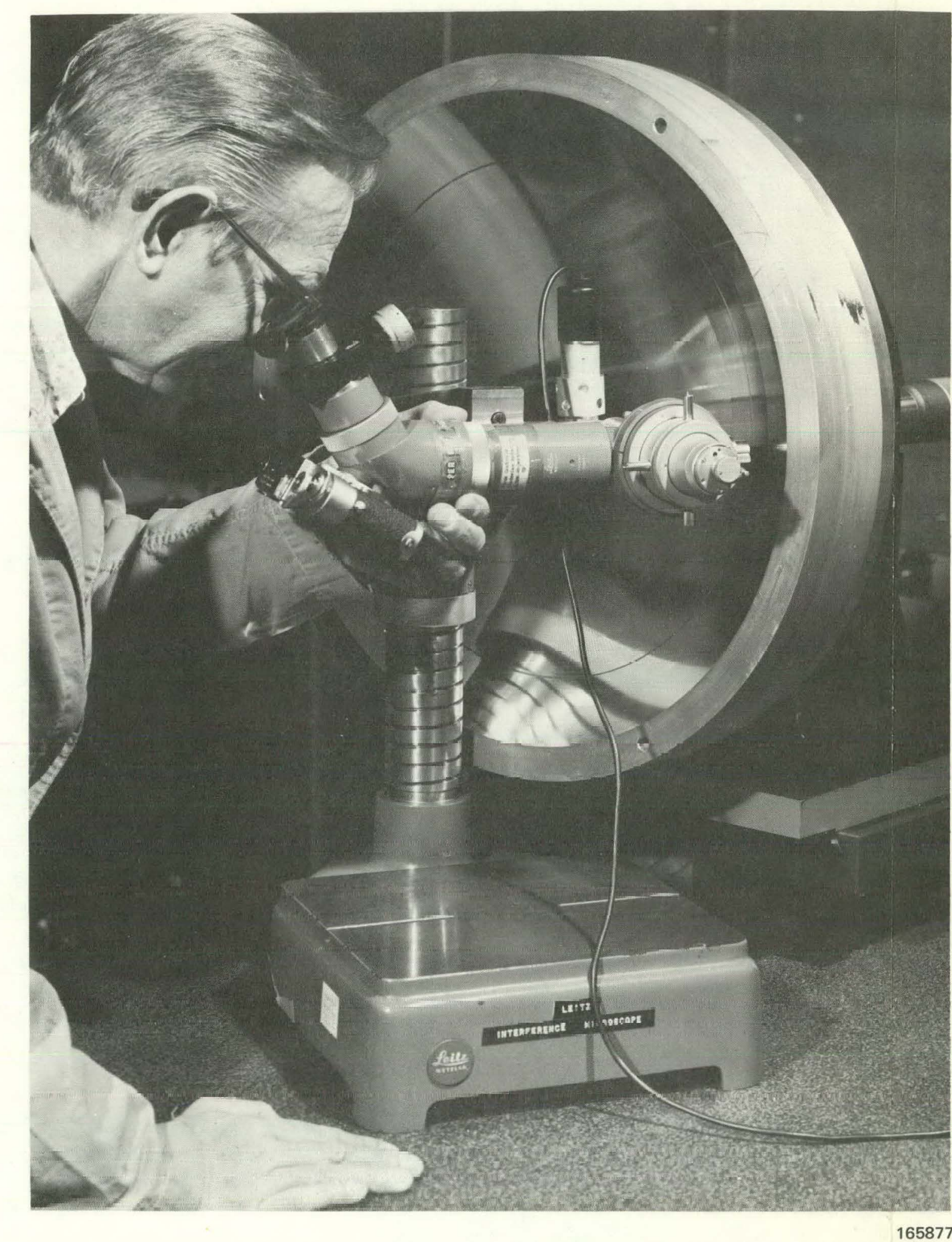

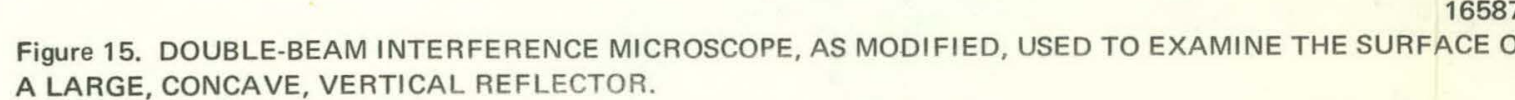

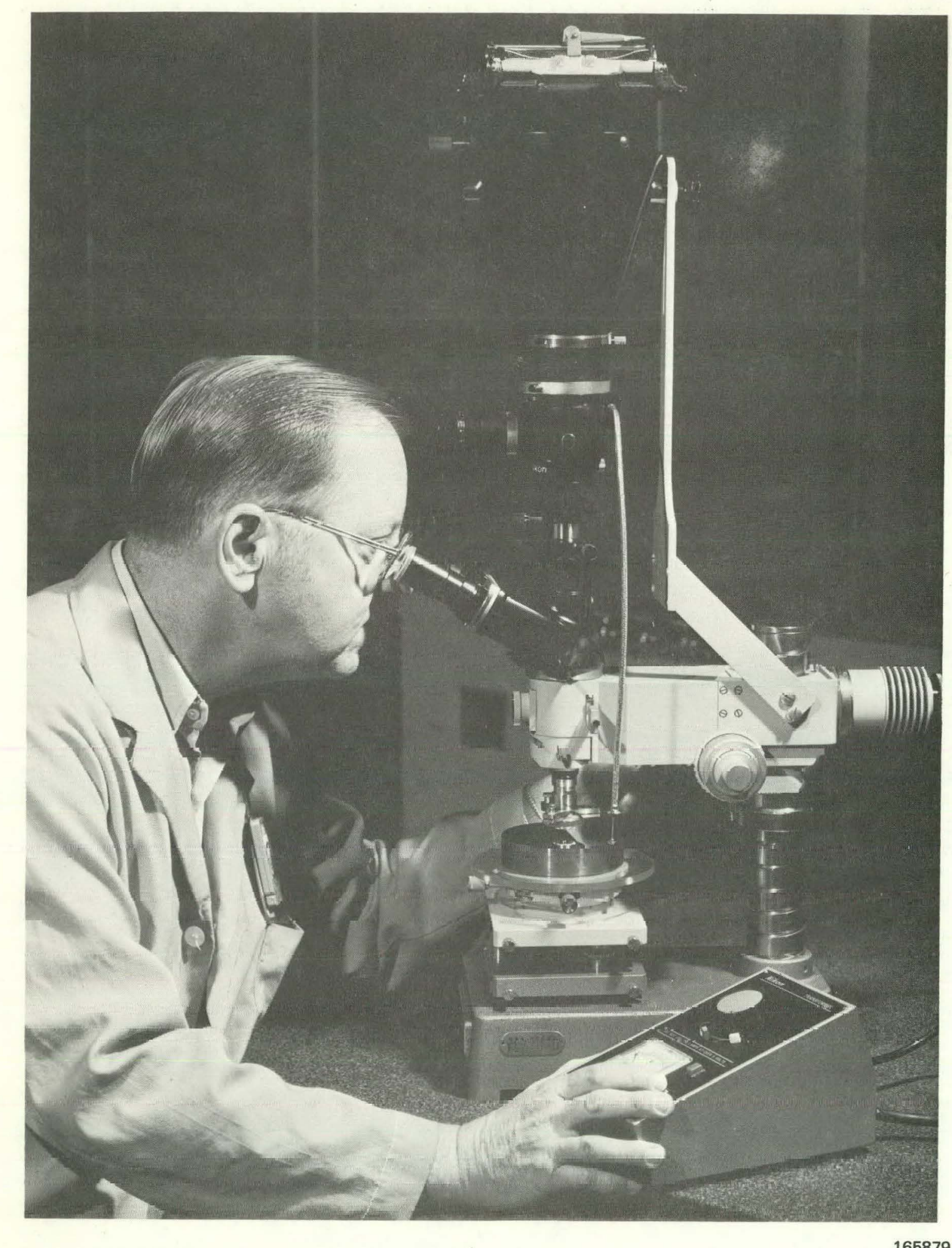

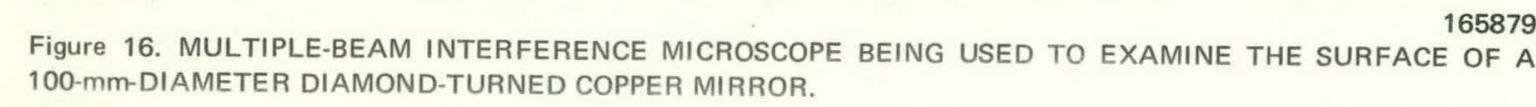




\section{Multiple-Beam Interference Microscope}

Applications Note-The multiple-beam fringes are a powerful source of quantitative information on surfaces that are very smooth and highly reflecting. The sensitivity of a Y-12 Nikon multiple-beam interference microscope (Figure 16) is about $0.8 \mathrm{~nm}(0.03 \mu \mathrm{in})$. The maximum sample size is about $125 \mathrm{~mm}$ ( $5 \mathrm{in}$ ) square and $75 \mathrm{~mm}$ (3in) thick. Only specimens which can tolerate a small mark (perhaps on the edge) should be used with this instrument.

A multiple-beam interference microscope ${ }^{(11)}$ consists of a microscope with a built-in illuminator such that the objective will transmit collimated monochromatic light to the specimen (Figure 17, View a). A small, highly polished and silvered glass flat is placed on the sample. Because both the specimen and the reference are flat (or have the same curvature) and are highly reflecting, a ray of light that passes through the flat is reflected between the flat and specimen many times before the intensity becomes insignificant (Figure 17, View b). At each reflection, a small amount of light passes out through the flat and back into the microscope to become part of the "multiple-beam" system. Tolansky (12) said that 60 reflections are desirable. The fringes are viewed with the objective. An added refinement is the provision for tilting the specimen or reference flat to vary the fringe spacing and orientation. This test is destructive of highly polished surfaces because the flat is in contact with the surface and very likely will mark the surface, if the metal is soft.

Obviously, if there are to be 60 reflections, the reference and sample surfaces must be closely parallel(13) or the beam would "walk out" of the mirror space (Figure 17, View b); or, as in the multiple-bounce reflectometer, it would change direction and "walk back" to the entrance side. In addition, the microscope lens aperture must be large enough in diameter to permit all of the reflected beams to enter and yet must be long enough in focal length to permit the insertion of the thin, flat reference surface between the objective and the test specimen. Therefore, multiple-beam and FECO (fringes of equal chromatic order) fringes are usually possible only at low primary magnifications.

It is possible (using some estimations about the spacing and parallelism of the interferometer plates and the angle of incidence and wavelength of the light) to calculate the linear distance on the specimen necessary for 60 reflections to occur. The result was: $(12) \mathrm{D}=0.002 \mathrm{~mm}(79 \mu \mathrm{in})$, which is comparable to the resolution of a $10 \mathrm{X}$ objective. Thus, the 60 beams appear to come from one point on the specimen and there is an identity between the object viewed and the local fringe corresponding to that object.

However, the important assumption was made that the reflecting surfaces were perfect. When the surfaces are less than perfect, there are small variations in the separation distance and angular orientation. Then, definition is inferior, the fringe is broadened, and interpretation is difficult or even meaningless.

The theory of the multiple-beam interferometer was also discussed by Born and Wolf. (14) The multiple-beam fringes (Figure 18) are $\sin ^{2} \delta$ functiun, in whlich the vidth of the fringe 


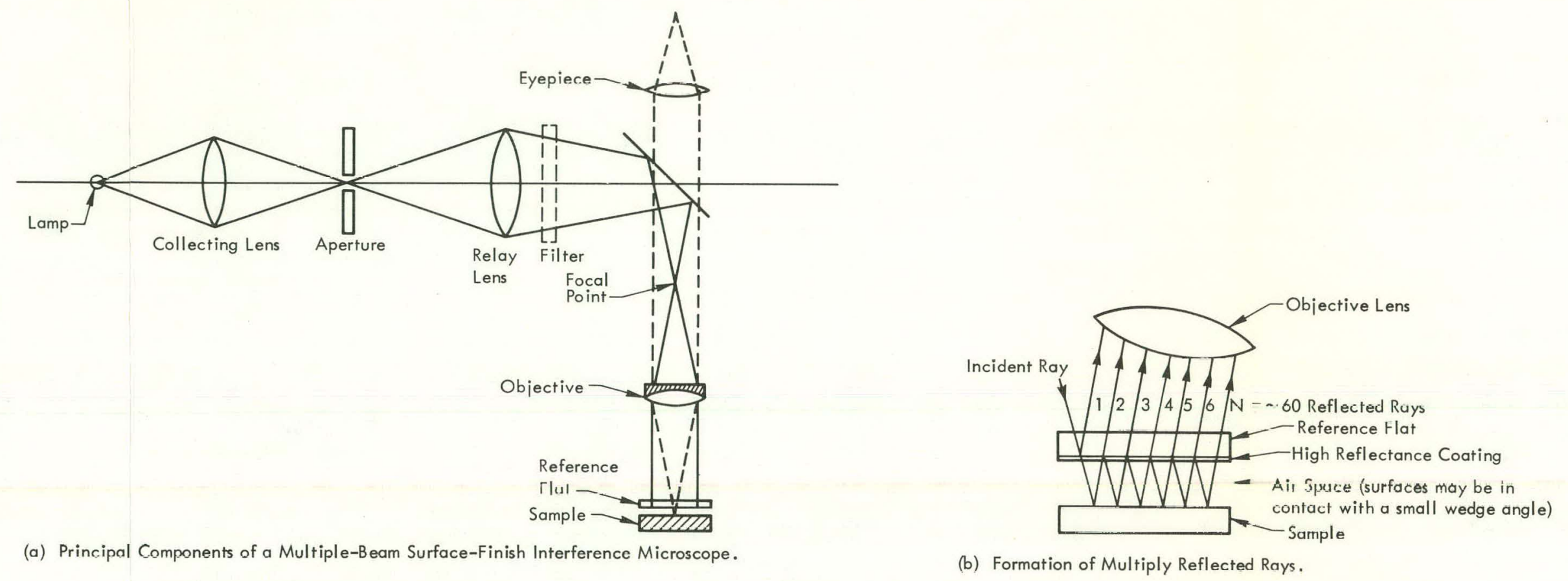

Figure 17. SCHEMATIC PRINCIPLES OF THE MULTIPLE-BEAM MICROSCOPE AND THE FORMATION OF THE FRINGES. IView a Shows that the
Reference Flat and the Sample are IIIUminated with Collimated Light, the Fringes that are Formed are then Observed with the Objective Lens; View b Shows the Formation of Multiple Reflected Rays, but the Figure is Grossly Distorted; the Incident Ray, of course, comes through the Microscope Objective; since the Light is

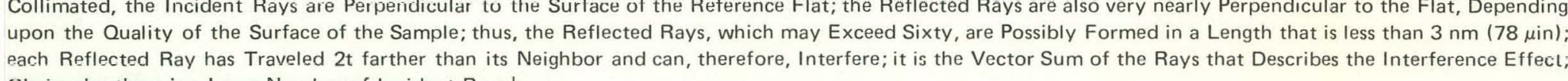

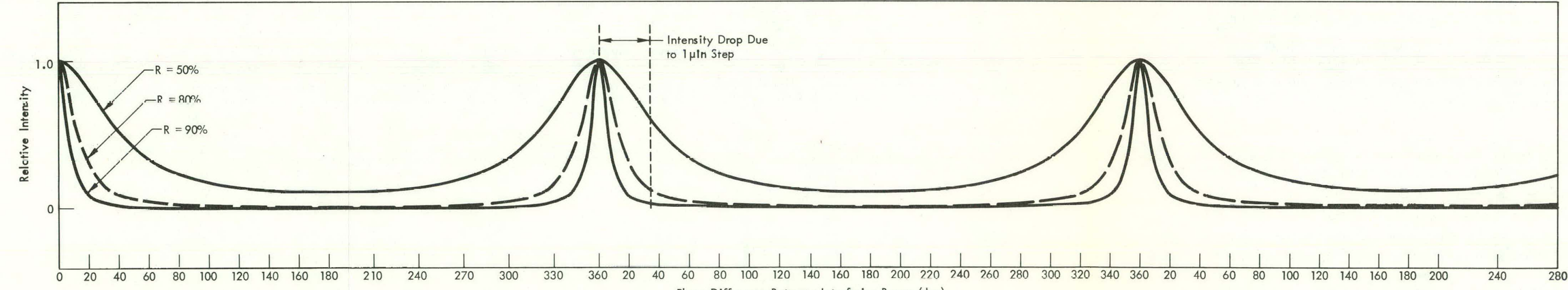

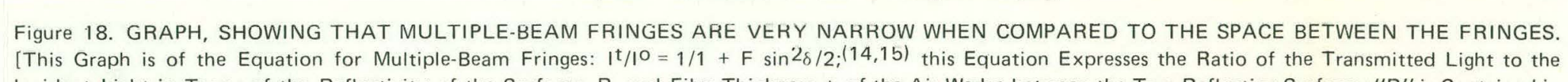

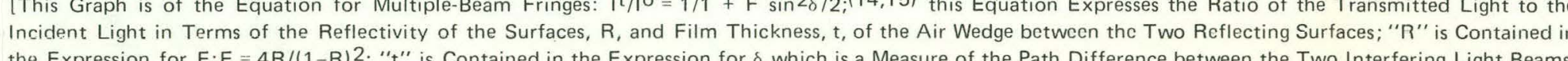

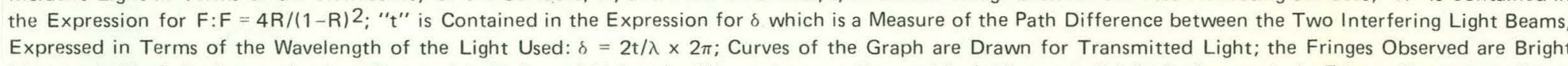

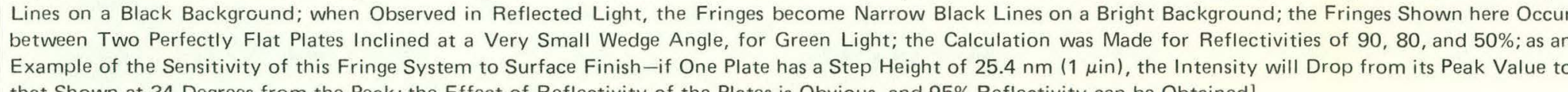


depends upon the reflectivity of the surfaces. If the reflectivity is 0.27 , the fringes may be more broad than the double-beam fringes; but, increasing the reflectivity to 0.87 or higher makes the fringes very narrow, as seen in Figures 19 through 21.

It is well known in interferometry that, for the greatest fringe contrast, both of the reflecting surfaces should have about equal reflectivities; and, for multiple-beam fringes, it should be as high as possible. Thus, only aluminum and silver meet this requirement in the visible. A copper or gold surface would have to be silvered to obtain good fringes when the standard mercury green interference filter is used. As a second choice, the reference filter could be used with a lower reflectivity $(60 \%)$, with some fringe broadening, of course. An interference filter was obtained for the $\mathrm{Ne} 6328 \AA$ line, where the reflectivity of copper is about $95 \%$ and that of gold is about $93 \%$. There is a little loss of resolution, as noted in Table 1, but it is possible to obtain excellent fringes without coating the surface, and the $90 \%$ reflectivity reference mirror can be used.

When the microscope is focused on a sample, there are usually quite a few fringes in the field of view. By adjusting the tilt (or angular orientation of the surfaces), the fringe spacing can be increased so that only two will fill the field of view that can be photographed. In this regard, the Nikon can be used with a 35- $\mathrm{mm}$ camera, a Polaroid film-pack camera, or a graphic back that accepts the Polaroid $4 \times 5$ processor or other $4 \times 5$-cut film. This larger format permits photographing the largest fringe spacing and thus offers the greatest sensitivity. The smallest fringe deviation currently measured at the $\mathrm{Y}-12$ Plant is 0.01 inch (10 mils). Obviously, the greater the fringe spacing on the photograph, the greater the sensitivity will be, within the limits of empty magnification and photographic contrast that can be obtained. At the fringe spacing shown in Figure 20, this is a height of $10 \AA$. The fringes can be spread out farther so that only one fringe fills the field of view (Figure 22), and then probably the most qualitative information can be obtained from the surface. As the tilt is continually adjusted, more fringes again appear in the field of view. The reference surface now is being tilted in the opposite sense. From this observation it is evident how the microscope can be used to indicate high and low areas on the surface. Using a specimen that has been plated with a step for film-thickness measurement, the tilt is adjusted so that the reference is one fringe from parallel. It will be observed that, at the film step, the fringe will bend downward as it goes from the unplated to the plated surface. Thus, by observing which way the tilt is adjusted on the reference, the operator can correlate fringe direction with the surface peaks and valleys.

\section{Fringes of Equal Chromatic Order}

Applications Note-The fringes of equal chromatic order (FECO) fringe system is mentioned so frequently in the literature $(15-18)$ that it is appropriate to mention it at this time. The Nikon multiple-beam interference microscope was adapted to produce FECO fringes. FECO fringes have even more sensitivity than multiple-beam fringes $(2.5 \AA(19))$, but the same limitations apply to their utilization. They are formed by using white light in a multiple-beam microscope and then passing the light through a spectrometer to obtain fringes (Figure 23) These fringes provide 

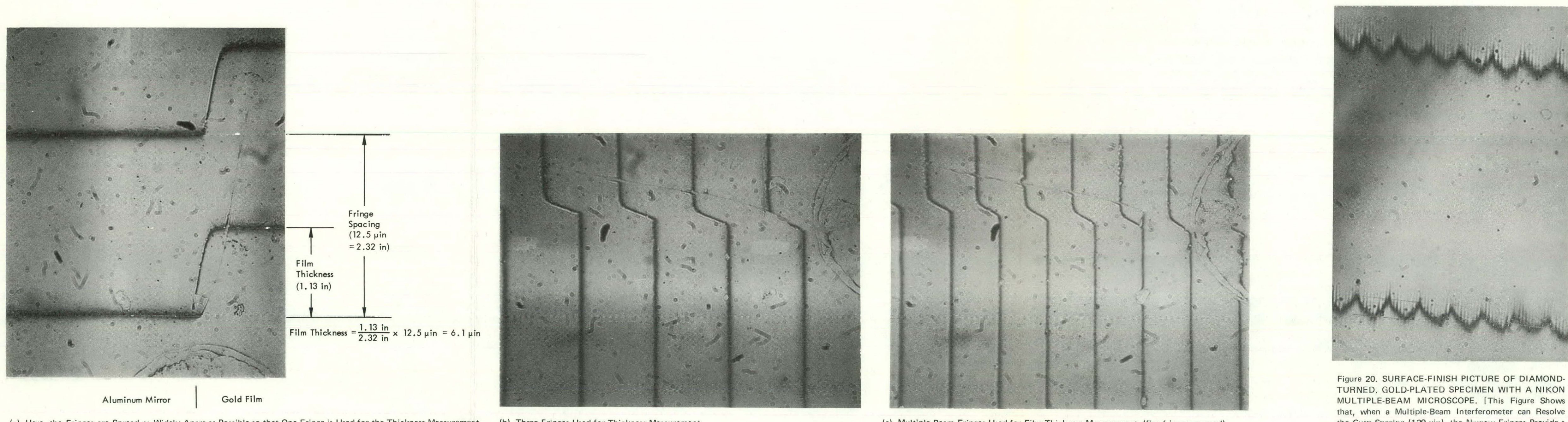

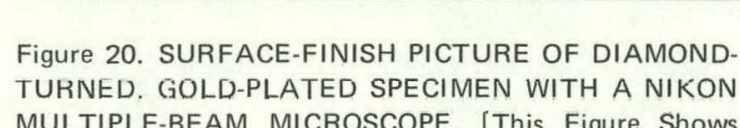

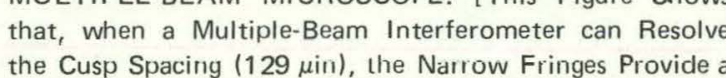
Better Picture of the Surface than Double-Beam Fringer

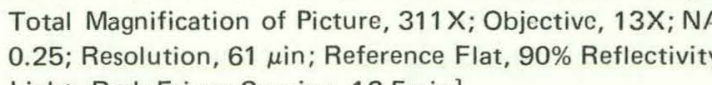

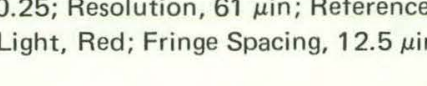




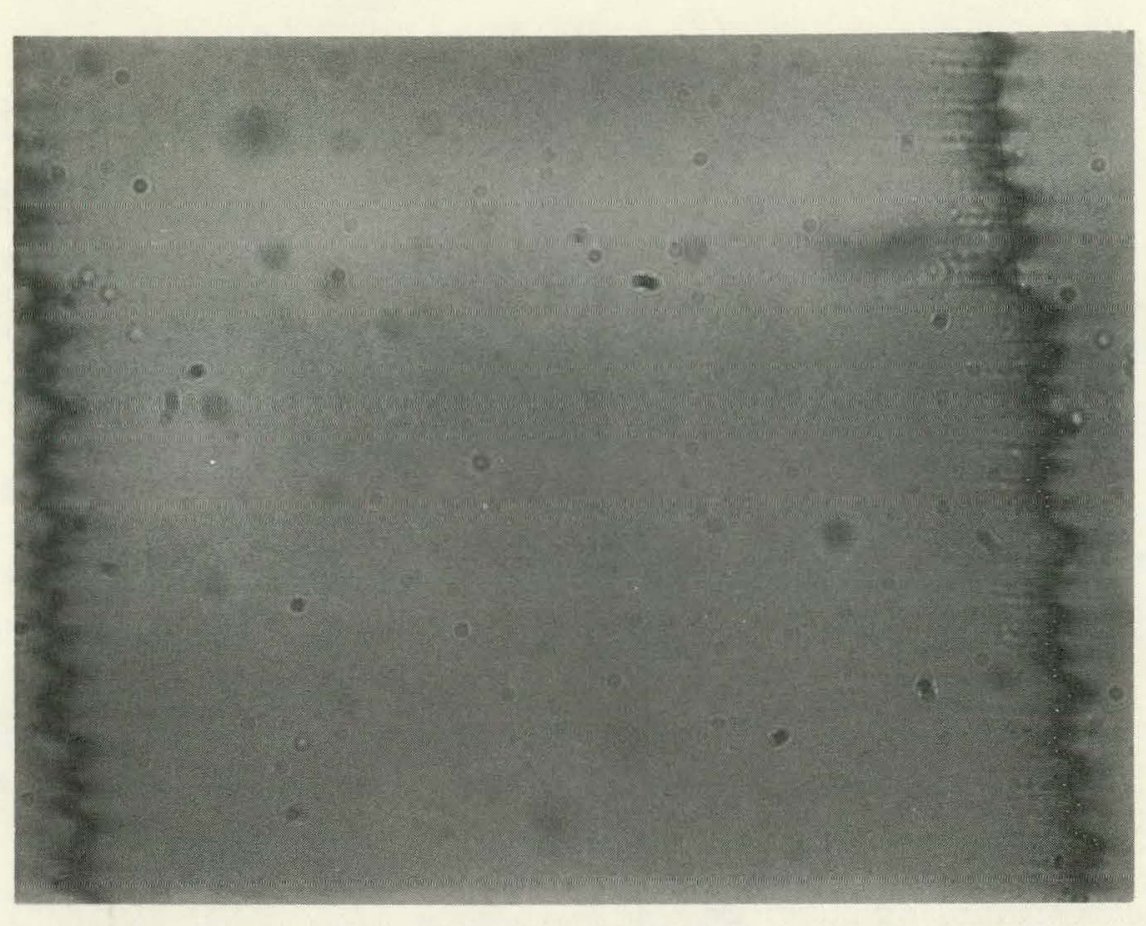

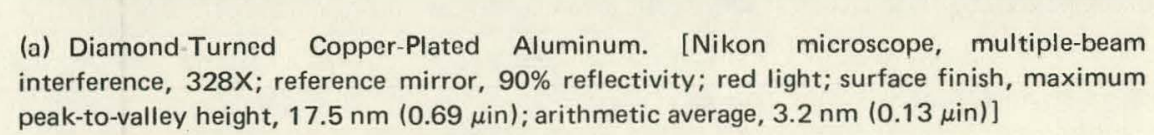

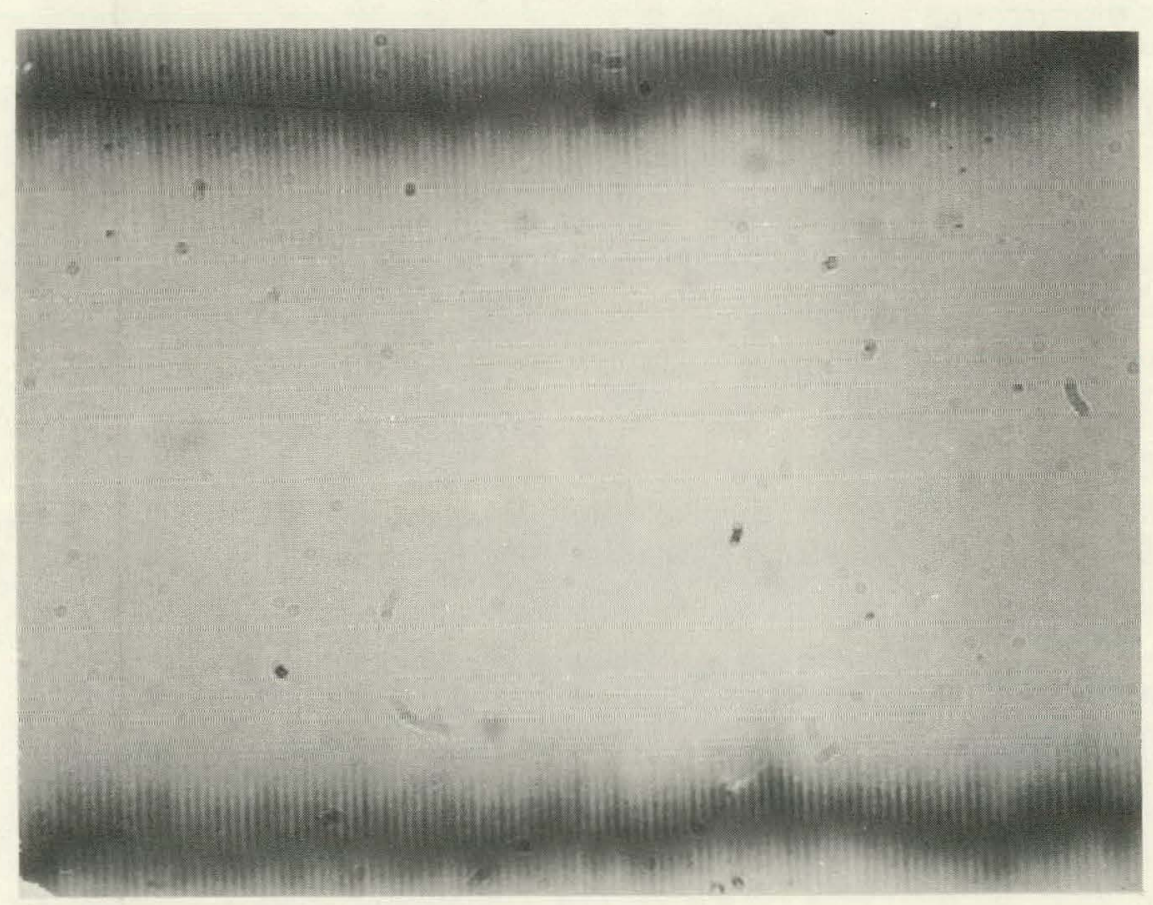

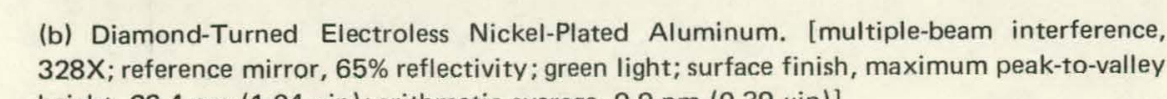

Figure 21 STTATE-OF-THEART DIAMOND-TURNED COPPER AND NICKEL
SURFACES.

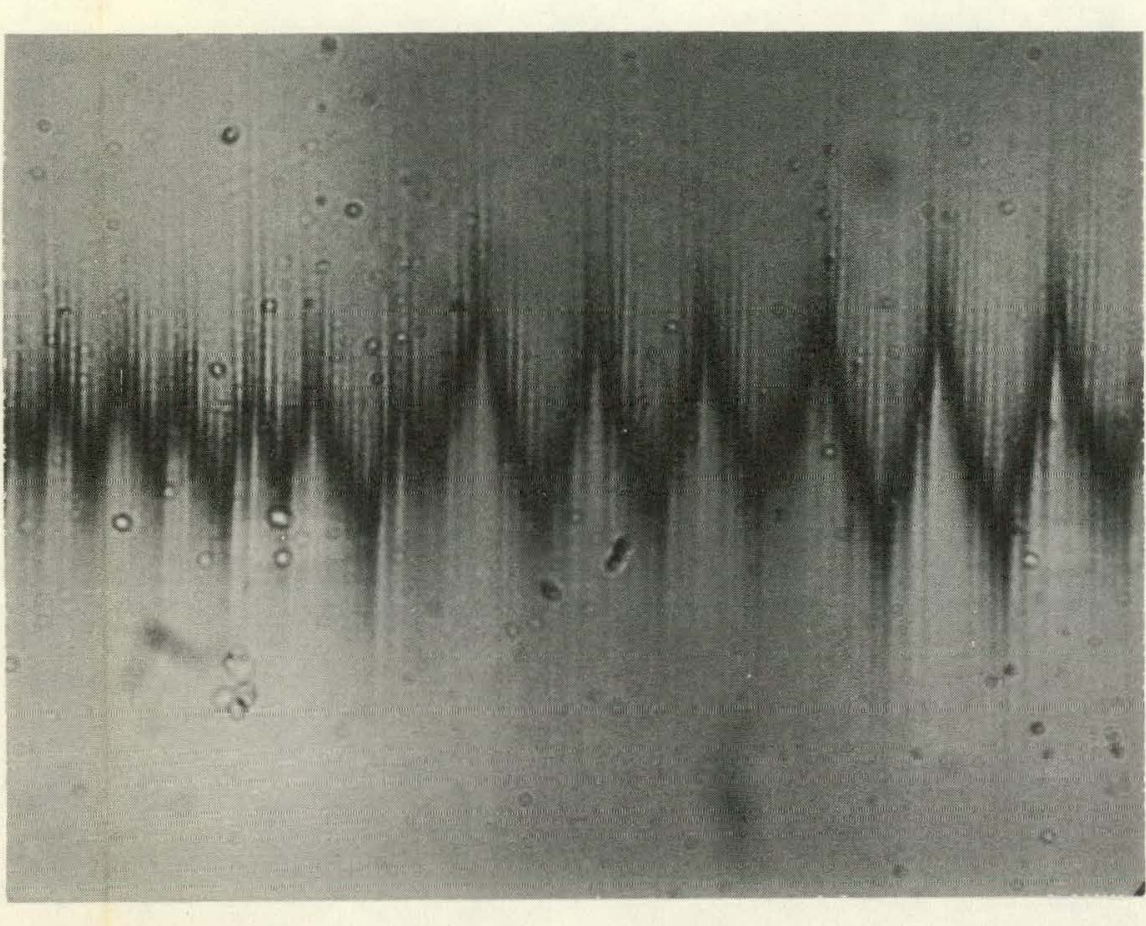

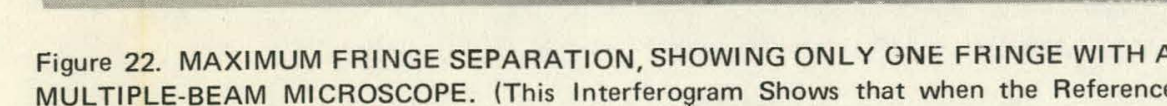

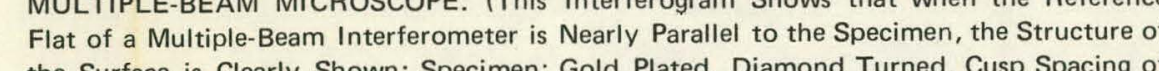

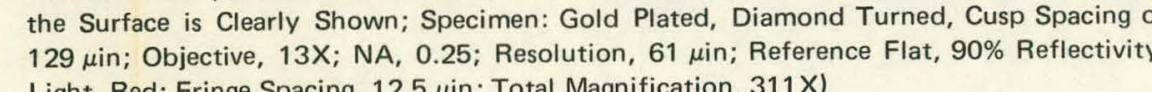

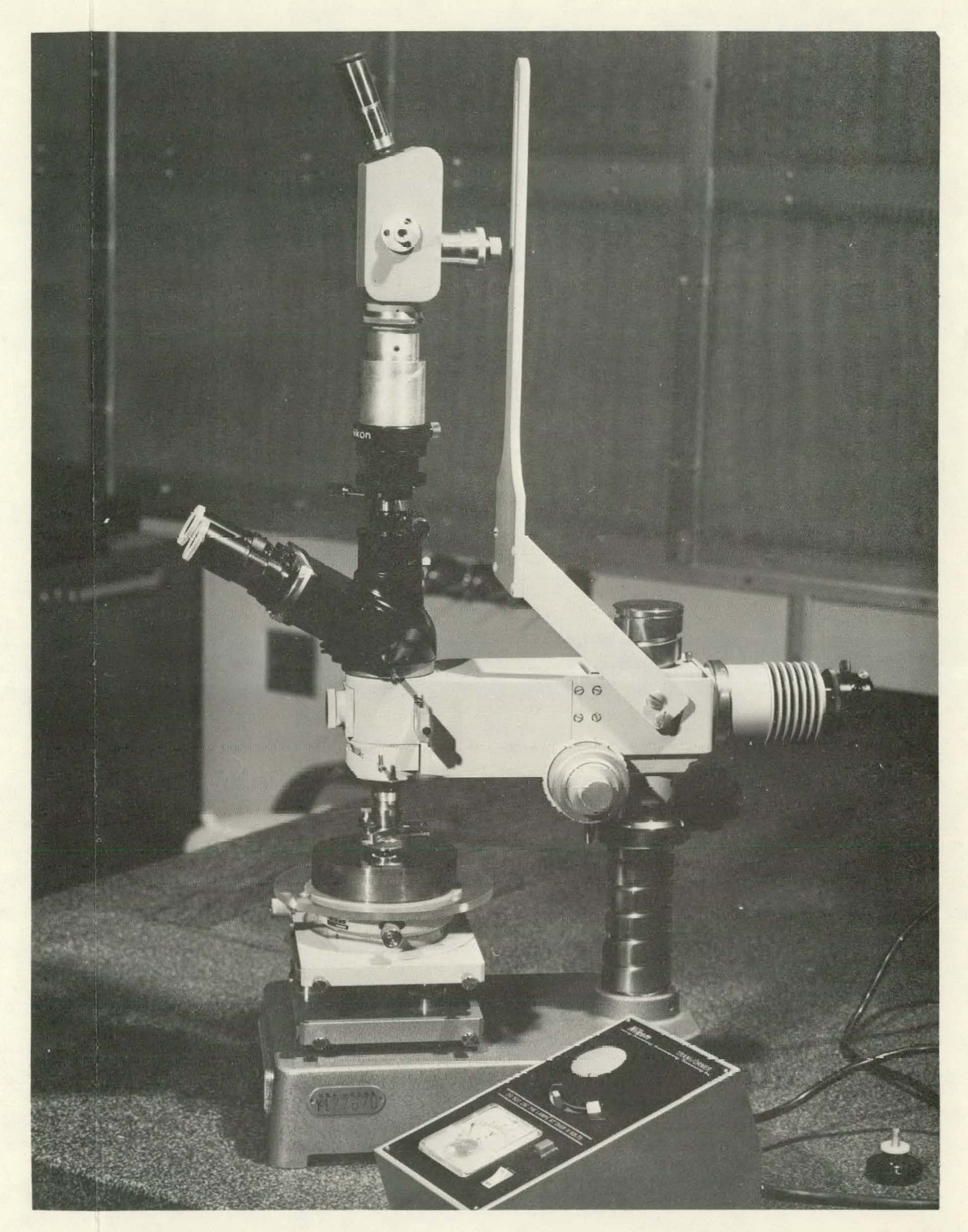

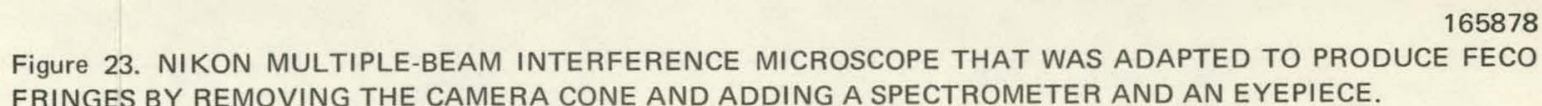


an unambiguous picture of the high and low points of the surface. To take full advantage of FECO fringes it is necessary to use automatic scanning of the fringe picture. With such equipment and a computer program (available at the Naval Weapons Center, China Lake, California), it is possible to obtain statistical information about a surface such as the slope-distribution function and the autocorrelation function.

The expression controlling the fringe shape for multiple-beam and FECO fringes is the Airy formula: (15)

$$
I=\frac{I_{\max }}{1+F \sin ^{2} \pi\left[\frac{2 \mu t}{\lambda} \cos \beta\right]}
$$

where:

I represents the intensity of the fringe,

Imax the incident intensity,

F a function of the reflectivity of the surfaces,

$\mu \quad$ the index of refraction of air (usually, 1.0),

$\mathrm{t}$ the separation of the plates of the interferometer (the thickness of the air wedge between surfaces),

$\lambda \quad$ the wavelength of the light used (generally, 5461 or $6328 \AA$ ), and

$\beta \quad$ the angle of incidence of the light (preferably close to 0 degree so that cos $\beta=1)$.

For multiple-beam fringes, monochromatic light is used and $\lambda$ is a constant at one of two wavelengths ( 5460 or $63^{\prime 2} 28 \AA$ ). Then, the fringe shape is a function only of the thickness, $t$, in the Airy equation

Fringes of cqual chromatic order are produced when white light is used; that is, $\lambda$ in the Airy squation is alsn allowed to vary, in addition to $t$. So, the fringe intensity is a maximum when the denominator of the equation is equal to one, that is:

$$
\sin ^{2} \frac{2 \pi t}{\lambda}=0
$$

This equality happens when $t / \lambda=n$, and $n=0,1,2, \ldots$ Thus, $n$, the order number $=t / \lambda$. 
Since $t / \lambda$ must remain constant for any fringe which has a particular order number, $n$, the wavelength must decrease if the thickness increases. The thickness, $t$, is the thickness of the air wedge between the specimen and the reference surface. Theory assumes that the reference is perfect and all error is in the specimen, or that the reference surface is known and suitable corrections can be made. Variations in thickness of the air wedge introduce variations in phase difference which, as was explained before for white-light fringes, cause destructive interference for a certain wavelength. This wavelength, which is eliminated from white light, shows up as a dark fringe on a light background. Thus, the color shifts of the FECO fringes are an unambiguous indication of the slopes of the surface. If the fringe shifts to the red, the thickness has increased and the surface has a groove or valley; if the fringe shifts to the blue, the thickness has decreased and the surface has a high spot.

Before data can be obtained from a set of FECO fringes, the order number, $n$, must be known. This value can be obtained from two adjacent fringes, as illustrated in Figure 24. However, the exact interpretation of FECO fringes for the attainment of high accuracy when thin films are being measured requires measurement of possible phase shifts of the reflected light. $(20-22)$ This information is not necessary with low orders of interference.

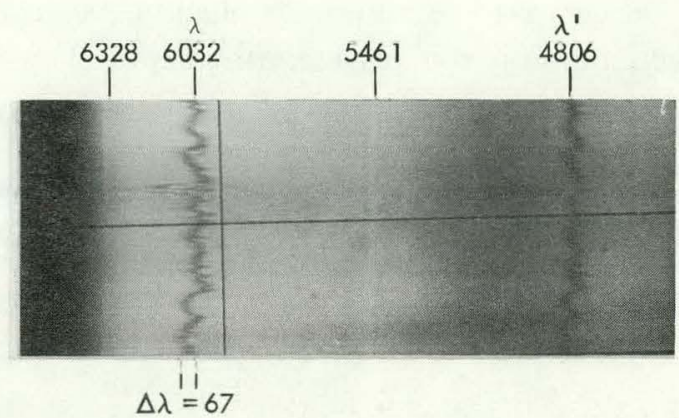

Equation for FECO fringes: $n \lambda=2 t ; n=2 t / \lambda$

where:

$n$ is the order of the fringes,

$t$ is the thickness of the space between specimen and reference, and

$\lambda$ is the wavelength of the fringe.

$n=\frac{\lambda^{\prime}}{\lambda-\lambda^{\prime}}=\frac{4806}{1226}=3.9$

$\Delta t=\frac{n}{2} \Delta \lambda=\frac{4}{2} \times 67=135 \AA$, peak in valley

Surface Finish $=135 / 4=34 \AA$, AA

Figure 24. A PHOTOGRAPH OF FECO FRINGES AND AN ILLUSTRATION OF THE METHOD OF CALCULATING SURFACE FINISH. (Specimen, Silver-Plated Copper; Microscope, Multiple Beam; Ohjective, 13X: $90 \%$ Reflectivity Reference Flat) 
The Nikon microscope was adapted (Figure 23) to produce FECO fringes by removing the camera cone from the trinocular eyepiece and adding a spectrometer. To do this, an Ealing reversion spectrometer was used by removing the reversion apparatus. Then it becomes a direct-vision grating spectrometer equipped with a cylindrical entrance lens, an adjustable slit, and a wavelength drum calibrated in angstroms. A Gaertner 20X eyepiece and adapter with a hairline was used for setting on the fringe. An aluminum adapter was made to fit this unit over the 10X Nikon eyepiece. The camera cone, with its monocular eyepiece, shutter, and Polaroid pack, can be mounted on a separate study tripod for photographing the FECO fringes. Exposure time was 75 seconds, using 3200-speed film and the Nikon white-light lamp.

To obtain FECO tringes, the microscope is set up, as for double-beam tringes; and, the binocular eyepiece is used for adjustment until only a few fringes are in the field of view, using the red filter. Orientation of the grooves in the sample should be such that the fringes are parallel to the slit of the spectrometer. To observe FECO fringes, the red filter is removed for white-light illumination, and the binocular field is switched to the monocular. The FECO fringes can then be observed through the eyepiece of the monochromator. The tilt of the specimen can be adjusted to vary the number of fringes in the field, and the wavelength of each fringe can be measured by placing the hairline of the eyepiece at the desired location and then reading the wavelength drum. If measurements are to be taken from the photographs, it is necessary to have some known wavelengths recorded. This measurement was made by making a triple exposure. First, the red $6328 \AA$ interference filter was inserted, and a 90-second exposure was made. The field of view was dark except for the one bright line. This operation was repeated with the green $5461 \AA$ filter. Finally, the $\vdash E C U$ tringe system itselt was exposed tor $/ b$ seconds.

Several experimental points should be clarified:

1. The FECO fringe pattern, shown in Figure 24, was obtained from a diamond-turned copper disc that had been silvered; the reason why a fringe is visible in the red and blue regions. (Unsilvered copper and gold do not have sufficient reflectivity outside of the red region of the spectrum to produce fringes.)

2. It was stated earlier that, by adjusting the tilt, the number of FECO fringes in the field of view could be controlled. This maneuver works, of course, but that is not the way it is ordinarily done. When equipment permits, the reference plate is lined up parallel to the specimen surface and separated only by the dust particles between the surfaces. At this time there is a minimum number of fringes in the field of view. To increase the number of fringes, the separation of the plates is increased while maintaining their parallelism as well as possible. In the tilt method used here, more fringes are introduced at the expense of an increased angle between the surfaces. This limitation can seriously reduce the number of reflections between the surfaces and should be avoided by keeping the number of fringes to a minimum. The sensitivity is also greater with a smaller number of fringes. 
3. If the tilt adjustment is made to reduce the number of fringes to one, and then the reference plate is tilted to the opposite angle, the sense of the fringes with respect to hills and valleys does not change, as it does with multiple-beam fringes.

4. A narrow slit is used to define the beam of light going from the eyepiece of the microscope into the spectrometer. Using now the principle of reversibility of an optical system that was mentioned earlier, the lenses of the eyepiece and objective "project" the size of the slit onto the specimen. This slit size constitutes the surface area of the specimen that is examined by the entire FECO fringe system. It is very small; and, therefore, if there are several fringes on the FECOgram, their shape is identical and nothing is gained by evaluating more than one. When double or multiple-beam fringes are used, the entire field of view will give rise to fringes. If the shape of the surface is different over several areas in the field, adjoining fringes will have a different appearance and may produce different values of surface finish.

\section{Nomarski Polarization-Contrast Technique}

Applications Note - Polarization-contrast microscopes have about the same sensitivity as multiple-beam fringes, but are not quantitative. However, the advantage of this technique is that it does not require contact with the surface and, thus, is nondestructive. It can be used with any reflectivity surface, including uncoated glass or salt surfaces, because one portion of the surface is the reference for an adjoining portion. But, because of this requirement, it is only effective when a surface is fairly smooth. The process is sensitive to changes in slope; flat surfaces with slopeless changes in elevation are not detected.

Several optical systems are described in the literature(23-25) and they are available from the manufacturers of microscopic equipment. A Reichert inverted microscope (used at the Y-12 Plant) will be described briefly.

The microscope has the attachments to use polarized light; that is, a polarizer and an analyzer. The unit that is added for polarization contrast is a modified Wollaston prism (Figure 25). The Wollaston prism is cut from a birefringent crystal-a natural crystal which has two refractive indices. This prism has the property that when a single beam of light is incident upon it, two beams emerge: (1) the ordinary (O) beam that is displaced proportionally to the normal refractive index, and (2) the extraordinary (E) beam. The prism is located at the back focal plane of the objective so that polarized light from the source is brought to a focus at Point I (Figure 24). The $O$ and $E$ beams diverge from the crystal, pass through the objective, and illuminate the specimen. If the specimen is absolutely flat, the beams are reflected back to the Woliaston prism at Point J. Since the Wollaston prism is symmetrical, both the $O$ and $E$ beams travel equal optical paths and no phase difference is introduced. If the analyzer is crossed with the polarizer, the field of view is dark. This result also occurs if there are abrupt, cliff-like changes in elevation of the surface (Figure 26). But, if there are variations in slope, leading from one elevation to another, the sloping surface reflects light away from Point $\mathrm{J}$, this light is no longer equalized, and a bright spot or line appears. 


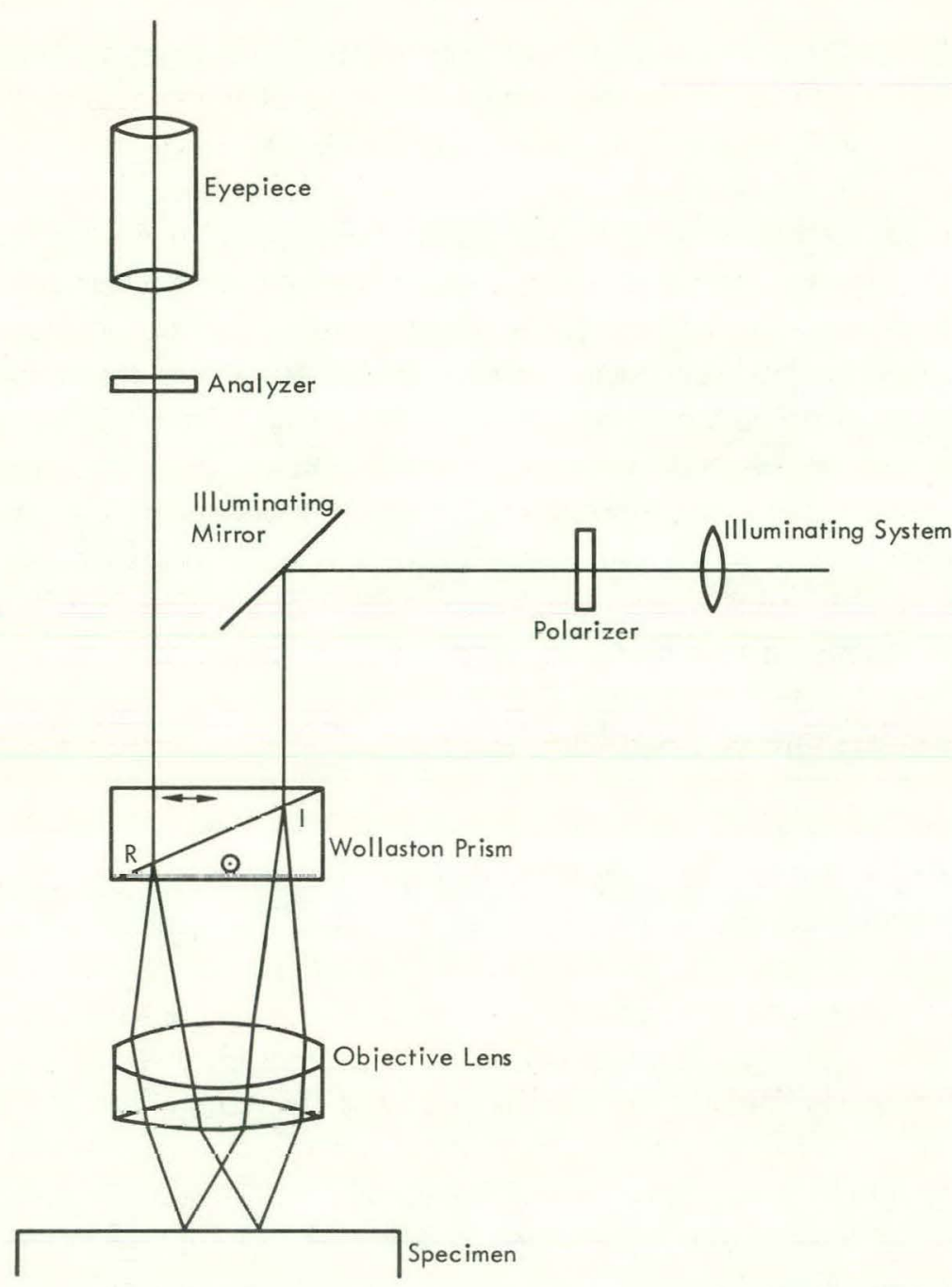

Figure 25. OPTICAL COMPONENTS OF THE NOMARSKI INTERFERENCE CONTRAST MICROSCOPE. (Polarized Light from the Source Falls on the Wollaston Prism where it is Exactly Focused at "I"; the Plane of Polarization is not Along the Coordinate Axes, but at an Angle of 45 Degrees; hence, Two Polarized Beams Emerge from the Wollaston; these Two Beams Illuminate Slightly Separated Areas of the Sample and One Area thus becomes the Reference for the Other; the Two Beams are Reflected Back to the Wollaston where they are Recombined and Interference can Take Place)

Several points should be made:

1. Since one area of a surface is the standard for another, the result will be meaningless if a surface is too rough.

2. The technique is directional. (22) If there are regular grooves in a surface, the doubling must be accomplished in a direction normal to the grooves. If the sample is not rotated to the optimum direction, the grooves may be missed completely, as seen in Figure 27. 


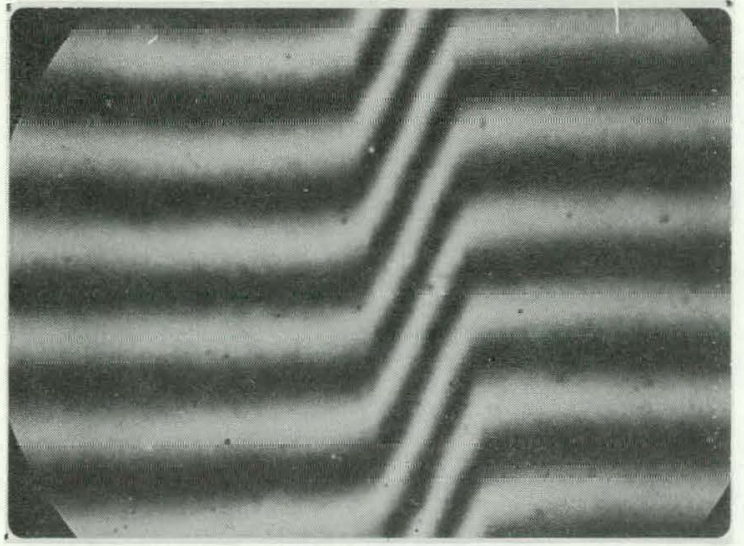

(a) Double-Beam Interference Microscope Picture. (view of a gold coating on a polished metal substrate; picture magnification, $66 \mathrm{X}$; step height, $23 \mu \mathrm{in}$ )

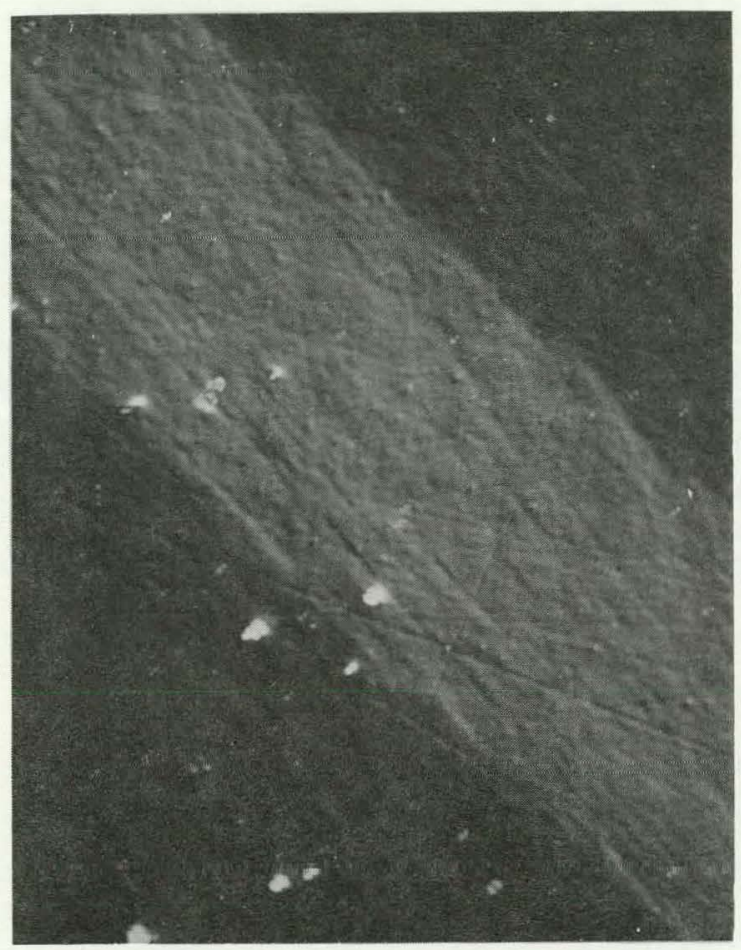

(b) Same Coating as in View a, but Taken with a Nomarski Polarization Contrast Attachment nn a Reichert Microscope. (this condition is also called "differential interference"; note that the level above and below the step is the same intensity, but the slope is bright and uniform; the step was turned so that it is parallel to the doubling produced by the Wollaston prism, as ohserved hy the twinning of the dust particles; picture magnification, 247X)

Figure 26. DIFFERENCE IN APPEARANCE OF A SLOPING STEP AS PRESENTED BY THE DOUBLE-BEAM AND POLARIZATION-CONTRAST METHODS.

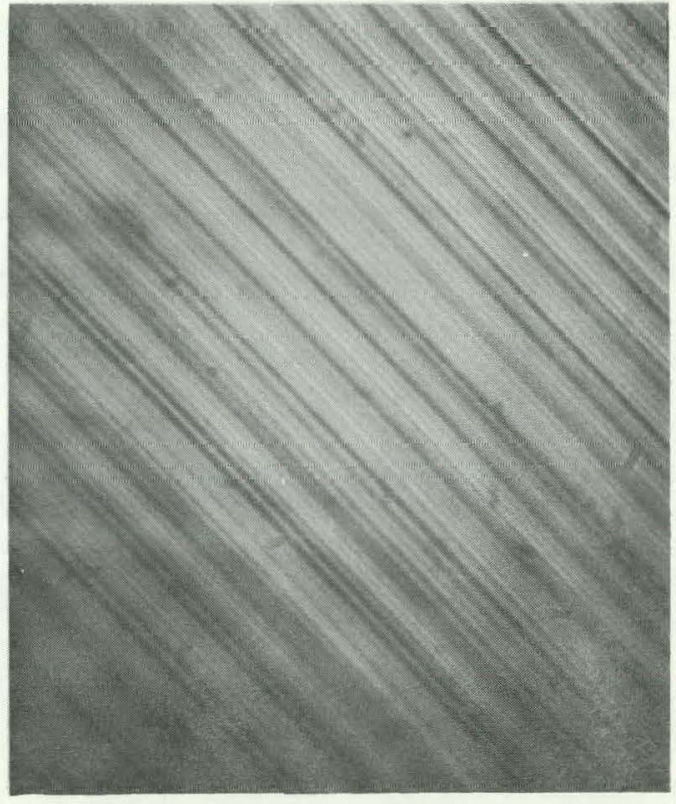

(a) Illustration of a Proper Alignment.

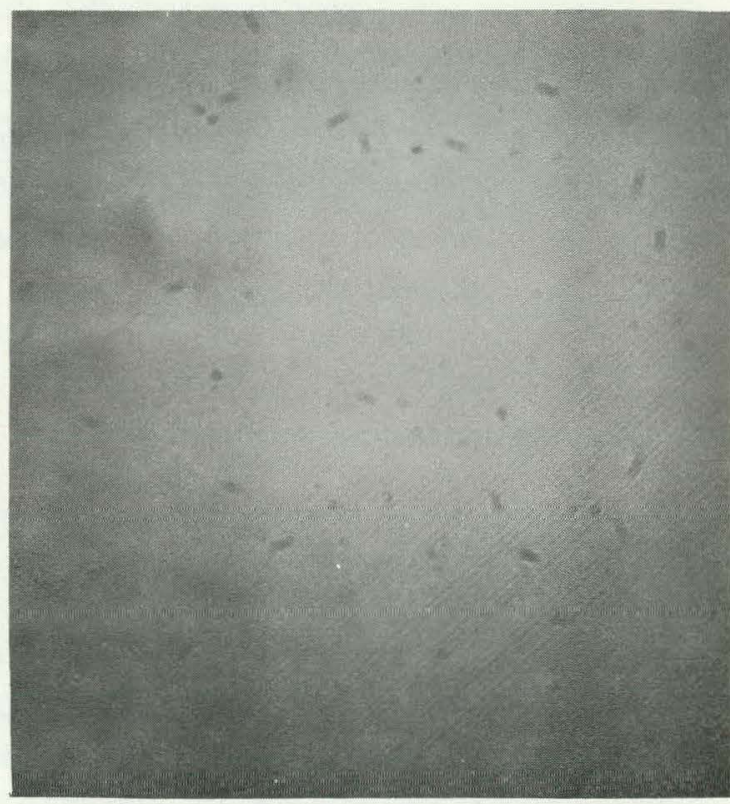

(b) View after the Sample in View a was Rotated 90 Degrees.

Figure 27. VIEWS TO SHOW THE IMPORTANCE OF PROPER SAMPLE ORIENTATION WHEN NOMARSKI POLARIZATION CONTRAST IS USED TO ENHANCE THE APPEARANCE OF GROOVES ON A SURFACE. (A Gold-Plated, Diamond-Turned Disc; Picture Magnification, 203X) 
3. This method is also called "differential interference contrast" (DIC) because the interference effect is generated by the difference in phase of the slopes of the doubled image. (25) If the difference is zero, the field of view is black; if it is very small, it is some shade of gray; if it is larger, some color is visible. These colors are the "subtractive" colors that were mentioned before. It is possible to use these colors for slope-height measurements; but, shades of gray are most sensitive to small slope differences. Peak-to-valley heights of less than $25 \mathrm{~nm}(1 \mu \mathrm{in})$ are in the gray area. A method of calibration for crystals has been reported by Gifkins. (23)

4. A wide variety of objective powers with a high resolving power can be used without contacting the surface, and oil-immersion objectives can also be used. However, there is less image contrast with the high-power objectives because the increased linear magnification decreases the slopes. (25) (Figure 28).

5. Another similar type of attachment called "polarization interference" produces interference fringes instead of variations in the level of illumination. This device must be used with an interference filter to produce fringes with a known spacing, and the sensitivity of these fringes is about $25 \mathrm{~nm}(1 \mu \mathrm{in})$. The advantage of this attachment is that the results are quantitative and can be used on transparent surfaces, but the sensitivity is limited (Figure 29).

\section{INFORMATION AND NUMERICAL DATA OBTAINED FROM THE FRINGES}

Interferometers are used to obtain many types of data. The two types to be discussed here are: (1) the thickness of films that have been deposited on a surface, and (2) the surface tinish of a specimen that has been lapped and polıshed or diamond turned. Although this report is about the latter application, an illustration of the former will help to demonstrate some of the advantages and disadvantages of the systems that are available.

\section{Film-Thickness Measurement}

To make quantitative measurements of film thickness or surface finish, the surface must be highly polished and specularly reflecting. The technique used for film-thickness measurements is to start with a high-quality mirror-preferably about $6 \mathrm{~mm}(1 / 4 \mathrm{in})$ thick. An aluminized microscope slide is sometimes used; but it may bend, giving rise to curved tringes which are difficult to measure. A gradual slope is needed between the filmed and unfilmed surfaces, so that the fringes will follow visibly to permit measurement of the displacement. A razor blade or fine wire may be used to form the sloping edge. When observed in the microscope, the fringe system which is formed on the substrate follows the sloping surface up to the top of the filmed surface. Sometimes the specimen is completely overcoated with silver or aluminum so that differences in reflectivity or color between the base and the film will not adversely affect the accuracy of the measurement, especially if FECO tringes are used. The tringe spacing is one halt the wavelength of the light used. The film thickness is obtained by measuring the linear separation between a pair of fringes (Figure 19, View a) on the substrate and the linear shift as the fringe progresses to the top of the film. This fraction times one half the wavelength is the film thickness. 


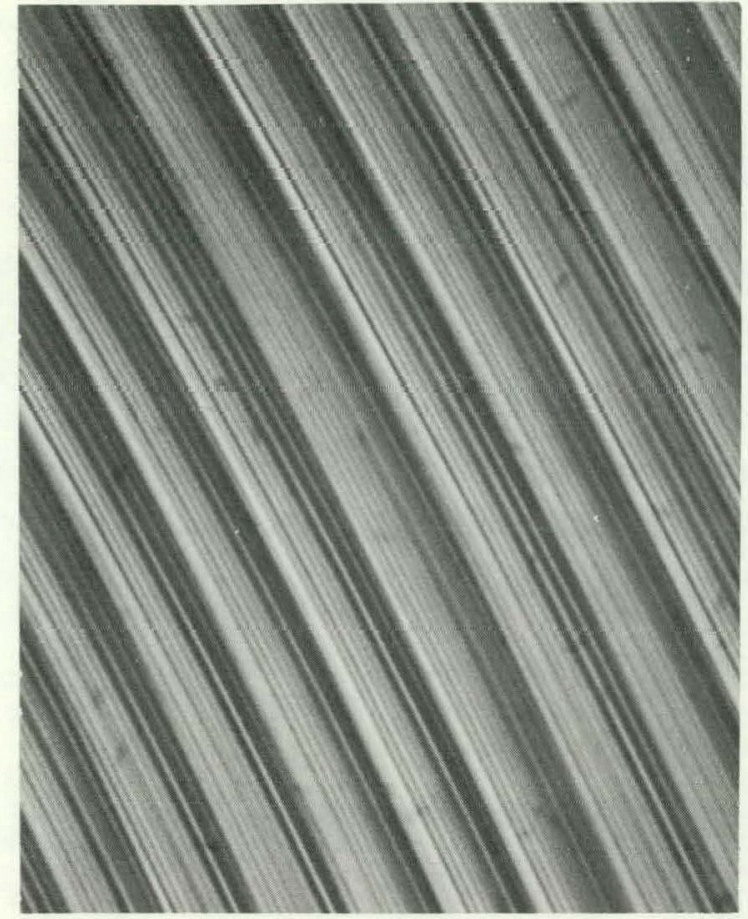

(a) Objective, 16X; Picture Magnification, 203X.

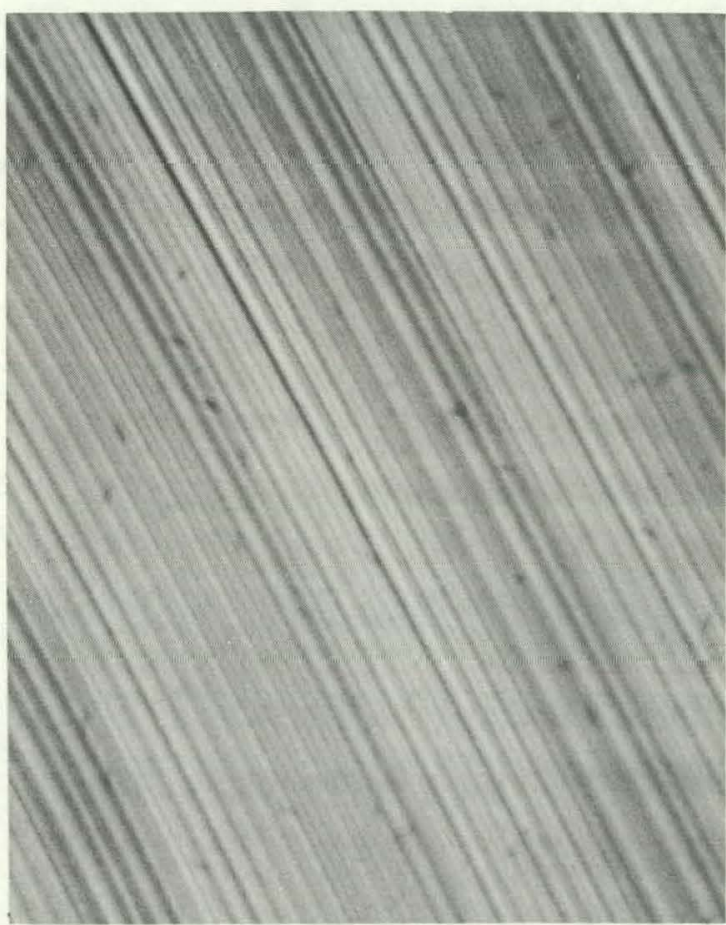

(c) Objective, 45X; Picture Magnification, 567X.

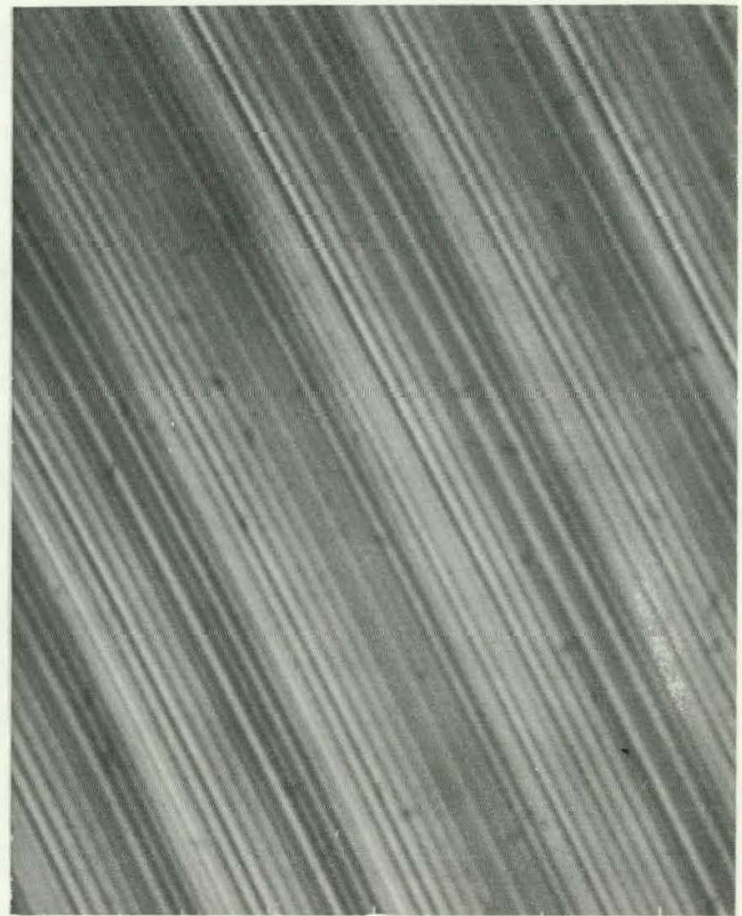

(b) Objective, 32X; Picture Magnification, 395X.

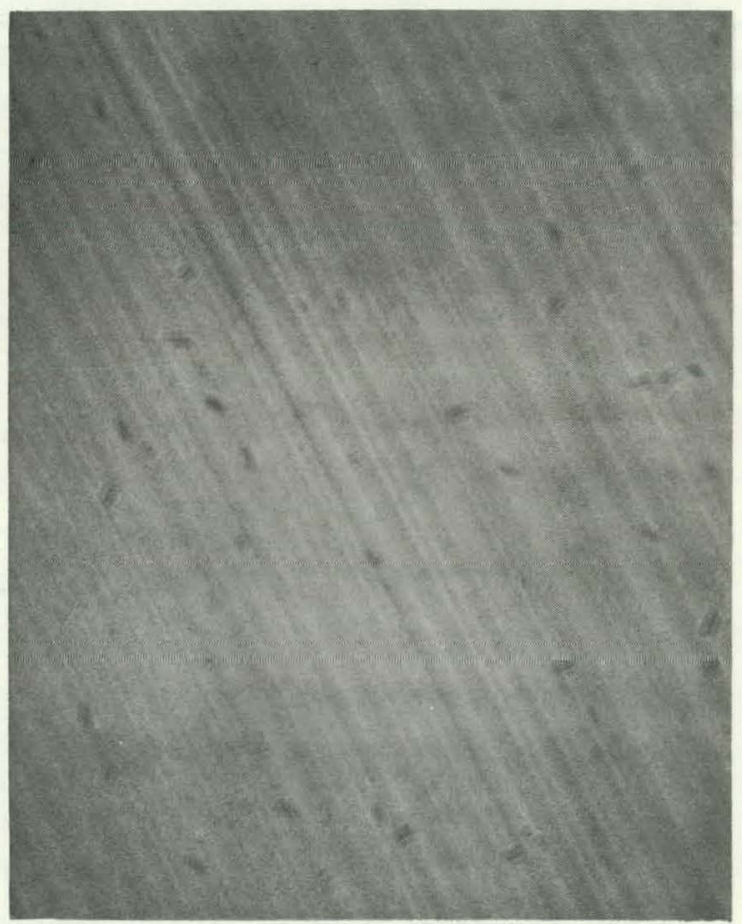

(d) Objective, 80X; Picture Magnification, 960X.

Figure 28. EFFECT OF USING INCREASING POWERS OF THE MICROSCOPE OBJECTIVE WITH NOMARSKI POLARIZATION CONTRAST. (A Gold-Plated, Diamond-Turned Specimen) 
The sample used in this study consisted of a gold film plated on a thick, aluminized substrate. It was examined with multiple-beam fringes using the $6.4 \mathrm{X}$ objective (Figure 19) and the $13 \mathrm{X}$ objective. It was also examined with double-beam fringes, using the $10 \mathrm{X}$ objective (Figure 30), the $25 \mathrm{X}$ objective, and the $60 \mathrm{X}$ objective (Figure 31 ). In all of these cases, the reference mirror was adjusted so that measurements could be made with one, three, and five fringes. The data are summarized in Table 2. From the raw data it was apparent that more precise data could be obtained from the multiple-beam fringes. The narrow width of the individual fringes and the wide spacing of adjacent fringes provide a smaller chance of error in making the linear measurements with a rule. Again it should be pointed out that the multiple-beam method involves contact with the surface and may cause damage.

It was demonstrated earlier in this report that the high resolution which is obtained from high NA objectives with high initial magnification is necessary to resolve small grooves in the surface. (For film thickness measurements, low magnification is usually adequate.) The data in Table 2 show that when the film thickness is measured with the 60X objective, it is about one microinch less than when measured with the $10 X$ or $25 X$ objectives. Studies $(25-32)$ have shown that the measured surface finish is about $10 \%$ less with objectives of higher numerical aperture because of the oblique light coming from the surface. The table also shows that there is more variation in the data between one, three, and five fringes at $60 \mathrm{X}$ than' at a lower power; and, also, the agreement is better between the multiple-beam results at $13 \mathrm{X}$ and the double beam at $60 \mathrm{X}$. The field of view for these two objectives is about the same, but is less than for the other two objectives. Changing the number of fringes in the picture does not change the size of the field of view.

\section{General Discussion of Diamond-Turned Surfaces}

The diamond-turning process consists of a highly refined, state-of-the-art lathe which uses a single-point diamond tool to produce mirror surfaces. In this process, the mirror blank may be mounted on an air-bearing spindle and rotated at any suitable speed up to about $2100 \mathrm{rpm}$ while the tool is mounted on the cross slide of the machine; or, the tool may be rotated on the spindle and the mirror mounted on the cross slide (fly cutting). In both cases, the surface finish is measured to have a method of evaluating the quality of the mirror, and to furnish diagnostic information to the machıne development engineers.

I he turnıng process leaves a spiral cusp or ridge on the surface of the disc. The height and spacing of the cusps depend upon the tool advance (TA) and the radius of the cutting tool (see Appendix B) and are part of the surface finish. Generally, the cusp height is theoretically much less than a microinch and should hardly be observed. In practice, a noticable surface finish is observed on the part. This section presents data and photomicrographs to illustrate what has been seen and how it has been interpreted.

The turning statistics given in the discussion to follow were used in the samples selected for illustration. These values may vary considerably at the discretion of the 

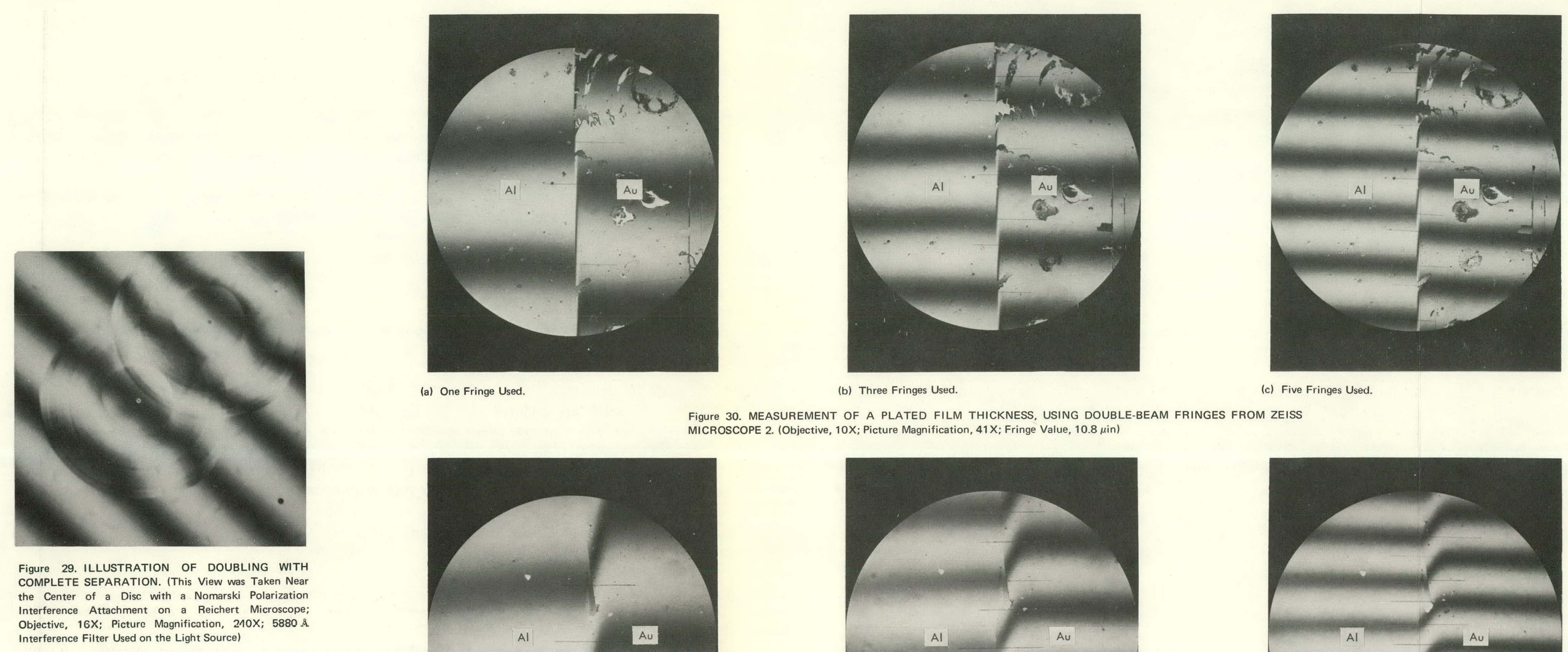

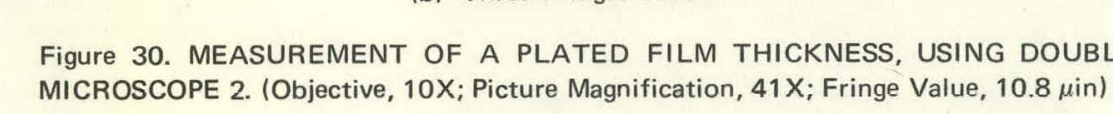
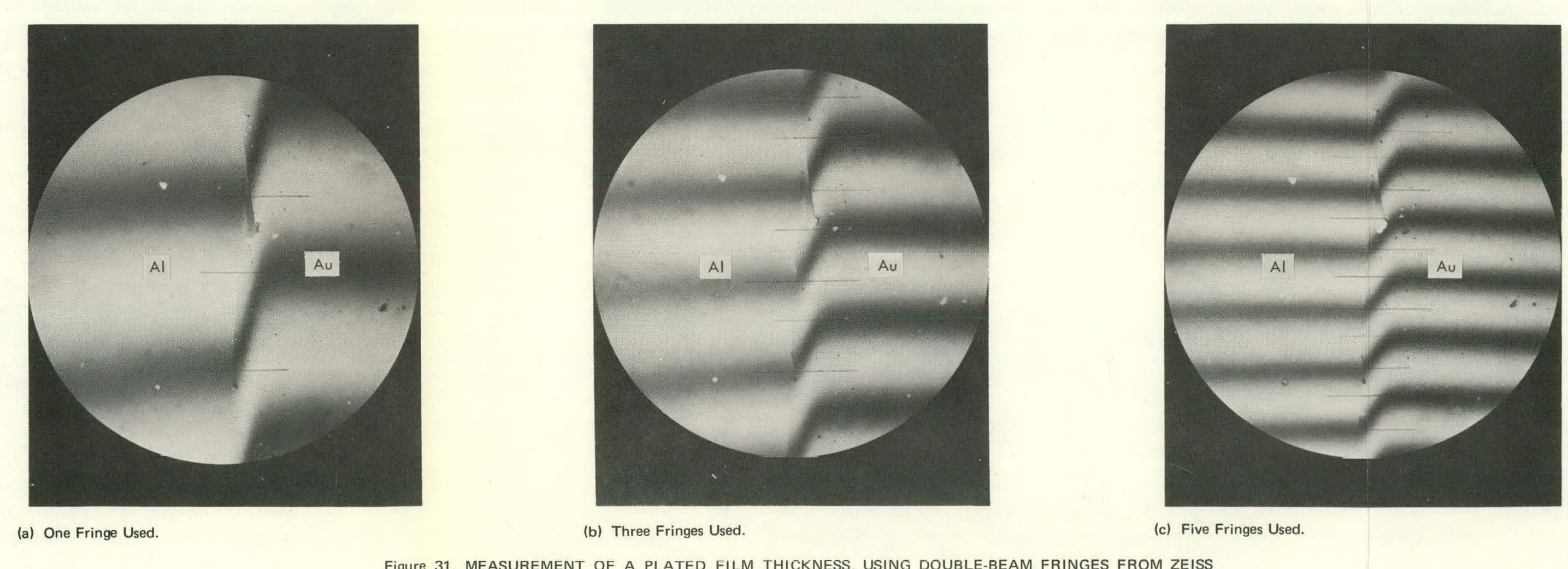

Table 2
COMPARIISON OFF FLM-TIICKNESS DATA FOR
MULTTPLE-BEAM AND DOUBLE-AEAM

\begin{tabular}{|c|c|c|c|}
\hline Microscope & $\begin{array}{l}\frac{\text { Magnifica }}{\text { Objective }} \\
\text { Ob }\end{array}$ & on $(x)$ & $\begin{array}{c}\text { Number of } \\
\text { Fringes ssed }(1) \\
1\end{array}$ \\
\hline $\begin{array}{l}\text { Nikon, } \\
\text { Multiple } \\
\text { Beam }\end{array}$ & $\begin{array}{l}6.4 \\
13\end{array}$ & $\begin{array}{l}155 \\
311\end{array}$ & $\begin{array}{lll}6.1 & 5.8 & 5 . . \\
5.8 & 5.8 & 5 .\end{array}$ \\
\hline $\begin{array}{l}\begin{array}{l}\text { Zeiss } 2, \\
\text { Double } \\
\text { Beam }\end{array} \\
\text { Bear }\end{array}$ & $\begin{array}{l}10 \\
25 \\
60\end{array}$ & $\begin{array}{r}41 \\
105 \\
267\end{array}$ & $\begin{array}{ccc}7.1 & 7.0 & 7 . \\
7.0 & 7.3 & 7 . \\
6.5 & 6.1 & 5 . \\
\end{array}$ \\
\hline
\end{tabular}


engineers. The discussion concerns the following five mirrors which were examined to illustrate certain points:

1. A solid copper mirror which was fly cut with a TA of 1 mil. This mirror is used to illustrate actual tool cusps, which are generally much closer spaced.

2. A disc which was gold plated and then diamond turned. The TA was $129 \mu$ in. This disc illustrates a fine-grained surface with cusps and waves, and one which does not oxidize.

3. A solid copper disc which was diamond turned with a TA of $225 \mu$ in and later coated with silver to enhance its reflectivity. This disc shows the effects of grain structure, oxidation, and reflectivity over a wide spectral range.

4. A copper-plated, diamond-turned disc. This surface shows almost no waves or cusps and illustrates state-of-the-art turning.

5. An electroless-nickel-plated aluminum disc. This disc illustrates a turned surface of material that is harder than copper and gold, and also of lower reflectivity so that the trınges are broadened.

Solid Copper Mirror - The first specimen to be discussed was a copper mirror, $100 \mathrm{~mm}$ (4 in) outside diameter, which was fly cut. The feed rate was $0.255 \mathrm{in} / \mathrm{min}$ and the spindle speed was $255 \mathrm{rpm}$. Tool advance (TA) is the ratio of slide speed to spindle speed; which, in this case, is $1 \mathrm{mil} / \mathrm{rev}$. This means that the turning process wili leave a ridge or cusp on the surface every I mil (see Figure 3'2 and also Appendix B). The height of these cusps, if the

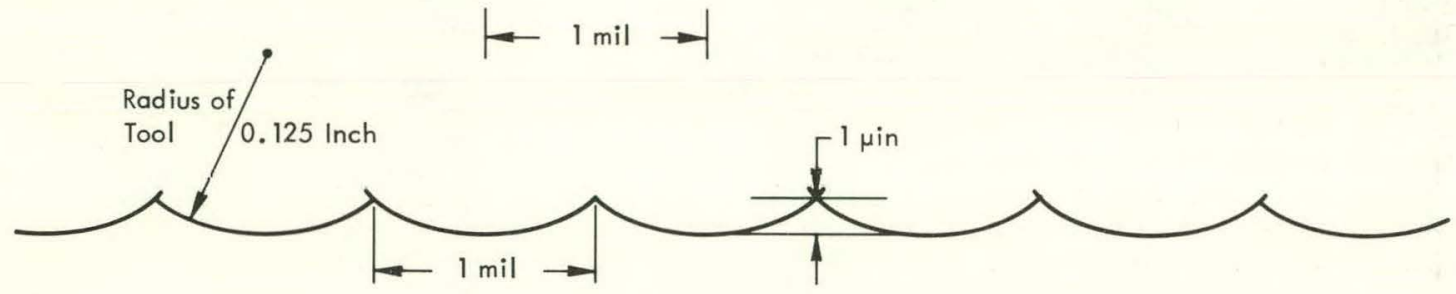

Figure 32. ILLUSTRATION OF THE THEORETICAL CALCULATION OF CUSP SPACING AND SURFACE FINISH, BASED ON THE MACHINING PARAMETERS. IAlso Illustrated is the Fact that, although the Cusp Spacing is Wide (1000 $\mu \mathrm{in}$, in this case), the Actual Cusp or Point where Two Adjoining Cuts Contact each other is very Narrow; if there is any Folding or Tearing of Metal in this Area, the Resolution to See it must be much Lower than that Based on the Cusp Spacing; Specimen, Solid Copper Disc; Feed Rate, $0.255 \mathrm{in} / \mathrm{min}$; Spindle Speed, 255 $\mathrm{rpm}$ (fly cut); Tool Advance, 0.255/255 = $1 \mathrm{mil} / \mathrm{rev}$; Surface Finish, $1 \mu \mathrm{in}$ ]

tool has a radius of curvature of $1 / 8$ inch, is equal to $\mathrm{TA}^{2}$; and, in this case, it is one microinch. When this surface was examined with the multiple-beam microscope at $311 \mathrm{X}$, the cusps were obvious with the nominally correct spacing of 1 mil (Figure 33), but they were not uniform. This nonuniformity is due to relative motion between the tool and mirror as it is turned. If the machine is less than perfect, the only thing that can happen is that the tool can plunge more deeply into the surface or withdraw somewhat from the surface. Angular motions would show no different effect because the tool has a radius. An angular 
motion is equivalent to a plunge or withdrawal. This concept is illustrated (under both theoretical and actual conditions) in Figure 34 and is a gross exaggeration of the dimensions. It shows what happens if the tool moves in or out. If the tool plunges into the surface, the cut is increased in depth equal to the depth of the plunge. The width is also increased, making the previous and following cuts narrow. Similarly, a withdrawal makes the cut more shallow and narrow and the adjoining cuts wider. Both cases also make the cusps unsymmetrical.

Gold-Plated Copper Disc - The second specimen, a gold-plated copper disc [31.8 mm (1.25 in) in diameter] was diamond turned with a slide speed of $0.2 \mathrm{in} / \mathrm{min}$ at $1550 \mathrm{rpm}$. The TA was, therefore, 129 microinches per revolution, Figure 35, Example (a), which could be resolved by any of the objectives. First of all, note that at 10X, Figure 35, View a, each fringe is distinct, with many little peaks called "grass" on each edge. If the $20 \mathrm{X}$ objective is used (View b), the grass turns into arches and a few fine lines appear. If the $50 \mathrm{X}$ objective is used (View c), with its much greater resolving power, many fine lines appear, especially if the fringe system is expanded so that only two fringes fill the field of view (View d). The arches are now less apparent, but it can be seen that the fringe line is not straight; that is, there is some waviness in the surface.

Table 1 shows that the magnification on the photograph for these three Leitz double-beam objectives is about the minimum necessary for the eye to detect what the objective can resolve. So, the fringes were photographed with $35-\mathrm{mm}$ film also and enlargements made. Even the $10 \mathrm{X}$ objective should be able to resolve the $129 \mu$ in TA (Figure 36, View a). On this picture, the cusps should be spaced $0.6 \mathrm{~mm}(0.025 \mathrm{in})$, but nothing can be discerned at this spacing. At $20 X$ ( View b), there is again no certain indication of cusp spacing. The cusp spacing is evident with the $50 \mathrm{X}$ objective, $970 \mathrm{X}$ total magnification (View c); however, focus and contrast are soft.

It is not possible to get a very clear idea of the nature of the surface waviness, surface finish, or slopes from the double-beam interference picture, even with its high resolution, because much information is obscured by fringe broadening; and, as is explained in the following paragraph, the tool cusps are generally not as deep as the waves in the surface.

The multiple-beam fringe provides a much better description of the surface. Figures 20 and 22 show that the surface consists of a number of fine cusps superimposed upon much larger arches. Measurements made on the picture show that the fine cusps have the proper spacing [3.28 $\mu \mathrm{m}(129 \mu \mathrm{in})]$ to be the marks left by the tool. The arches themselves have a spacing of $33.5 \mu \mathrm{m}(1321 \mu \mathrm{in})$ and are due to some periodic motion in the turning machine. From measurements using the fringe spacing of $318 \mu \mathrm{m}$ (12.5 $\mu \mathrm{in}$ ), it was found that the height of the arches varies from 14 to $24 \mathrm{~nm}$ ( 0.54 to $0.94 \mu \mathrm{in}$ ) and the depth of the tool cusps varies from 7.6 to $15.2 \mathrm{~nm}$ (0.3 to $0.6 \mu \mathrm{in})$. The turned surface, then, is generated (as indicated in Figure 37) vvlıere (liere is a basic vvave, or an iri-and-out movement, with approximately 10 tool advances or grooves for every wave. The actual surface finish is about 20 times the theoretical surface finish. 


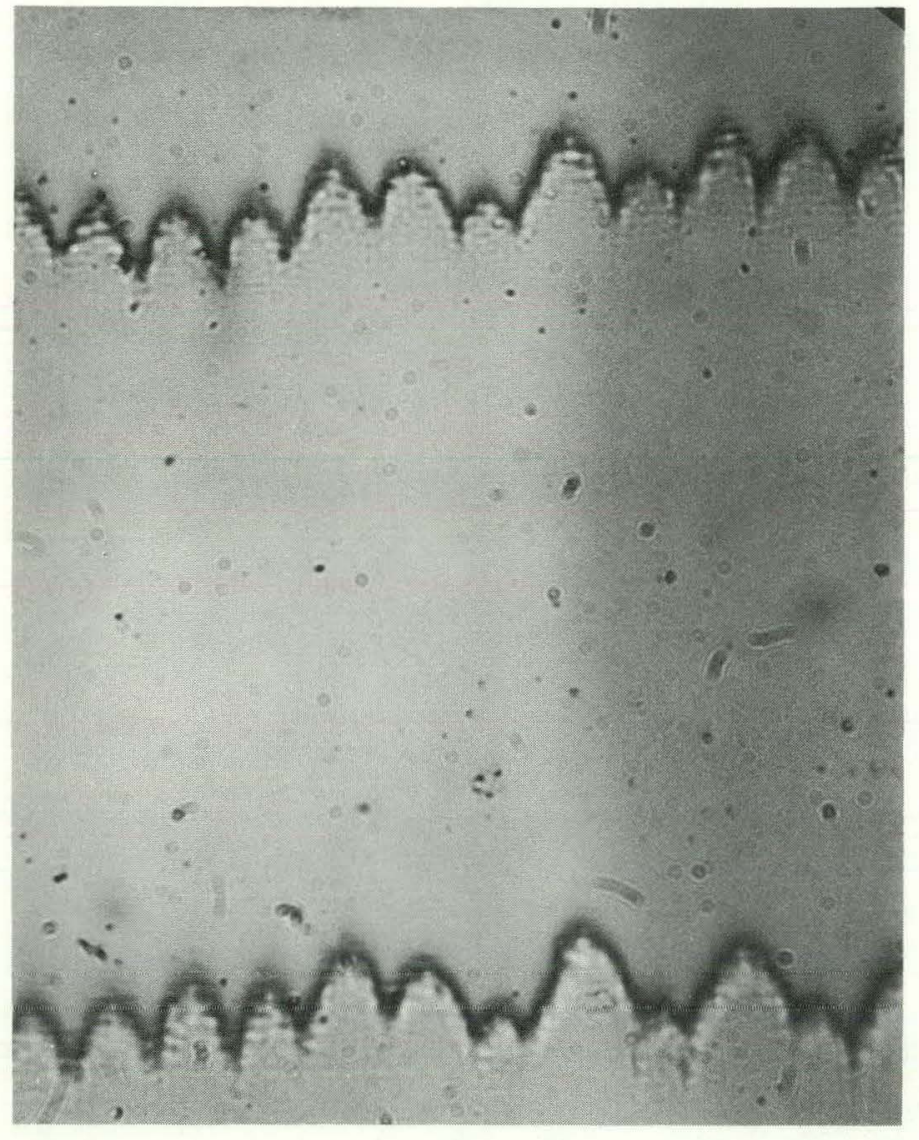

Figure 33. MULTIPLE-BEAM FRINGES OF A DIAMOND-TURNED

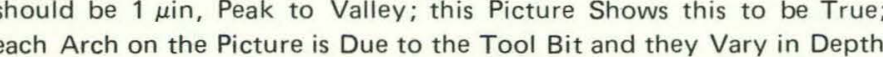
Due to the Relative Motion between the Tool and the Copper Surface,

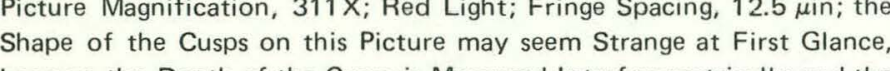

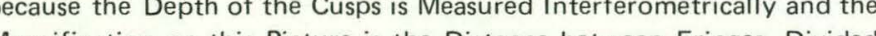

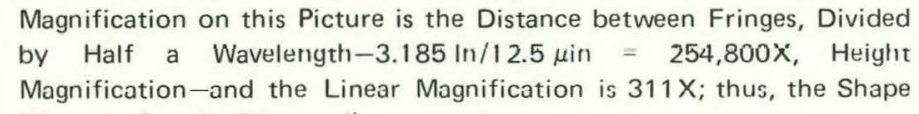
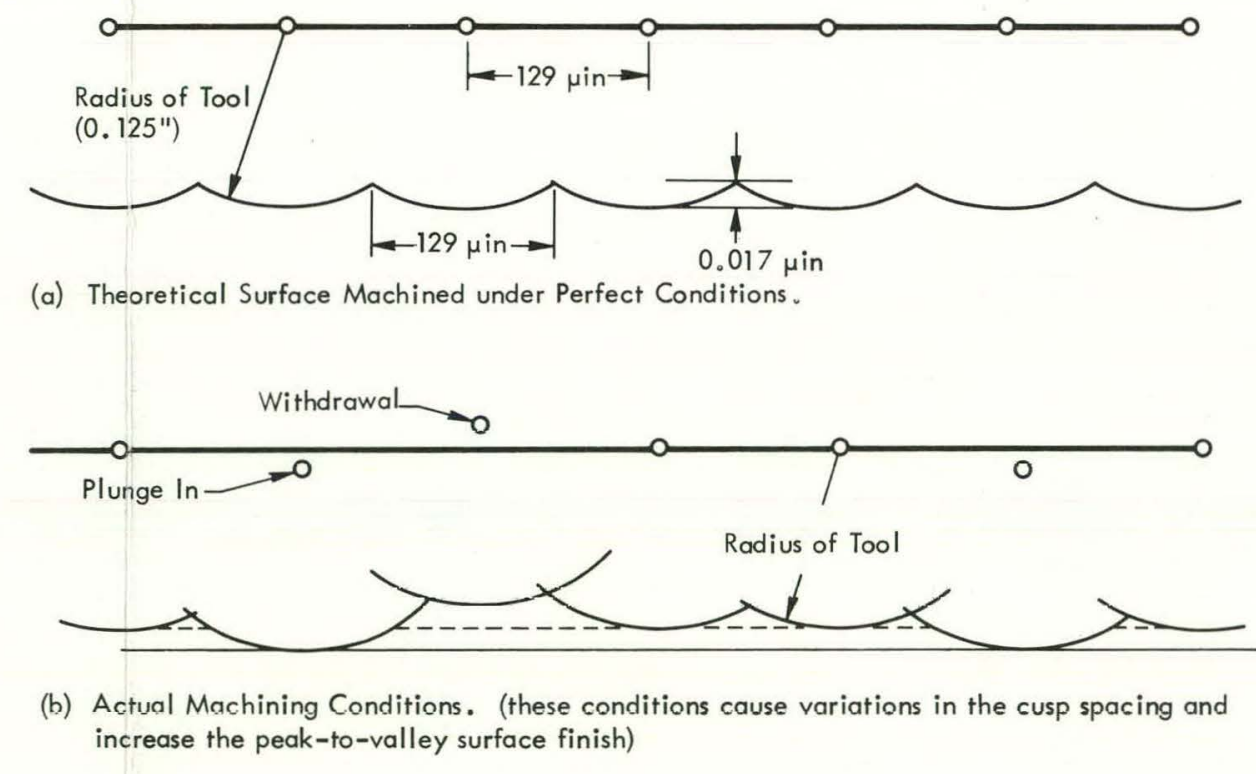

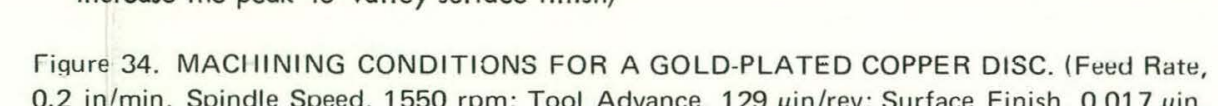

2.2 in/min, Spindle Speed, 1550 rpm; Tool Advance, 129 pin/revi; Surface Finish, 0.017 pin,
feak to Valley
[IIII

(a) Obiective, 10X; NA, 0.18; Resolution, 73 min; Picture

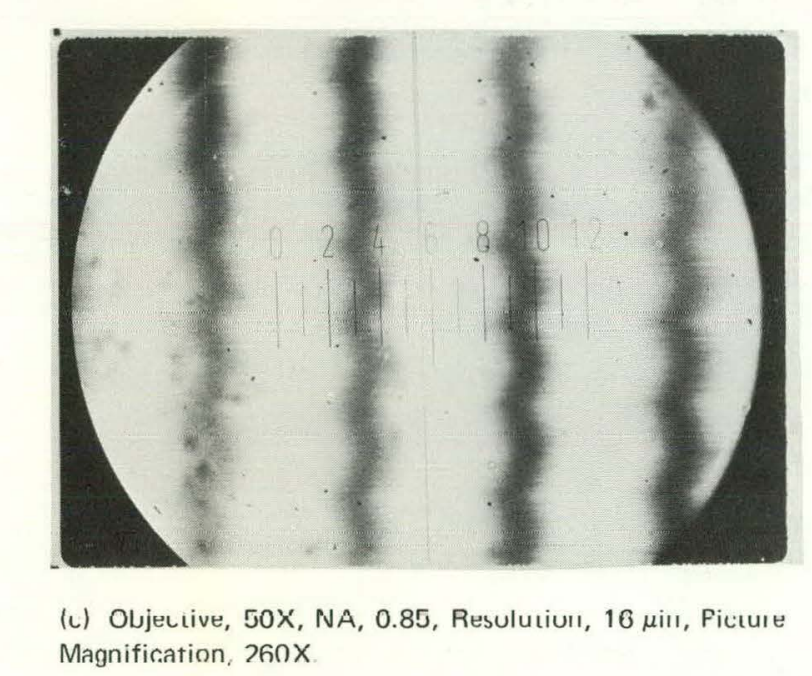

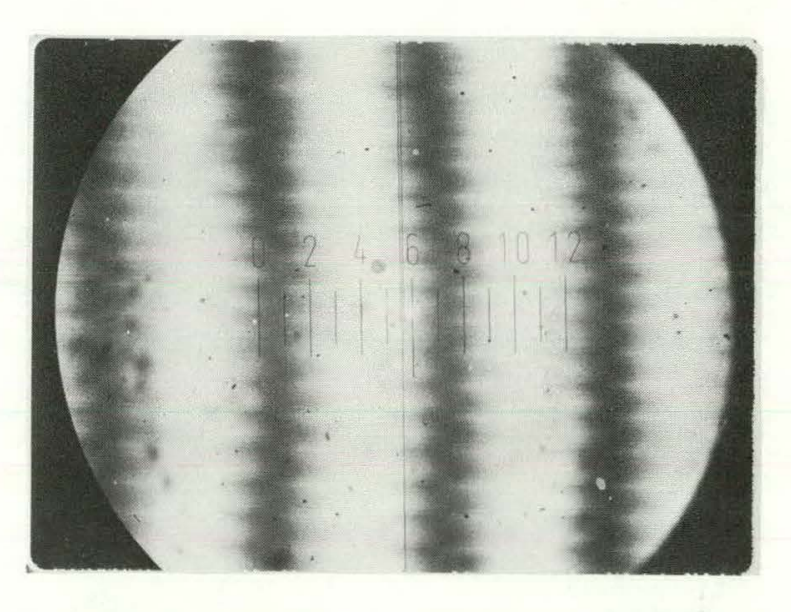

(b) Objective, 20X; NA, 0.35; Resolution, 37 pin; Picture

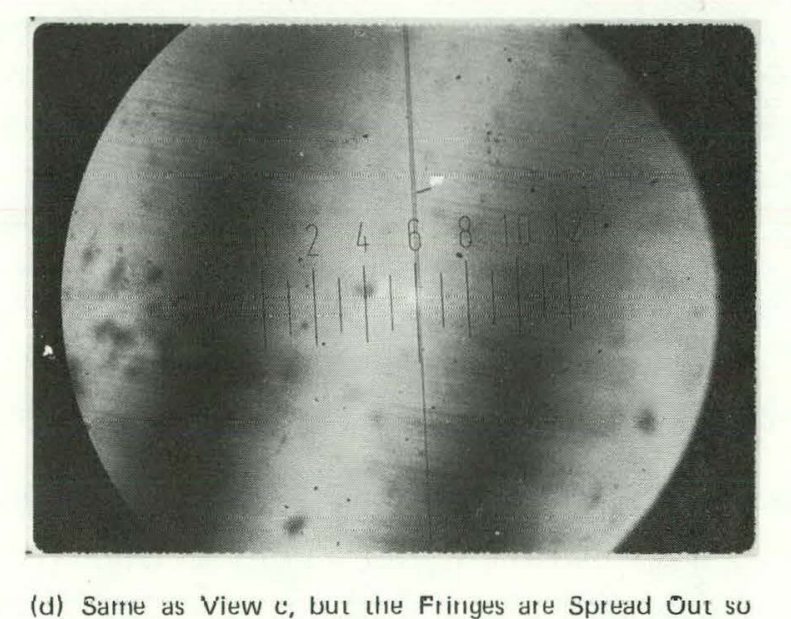

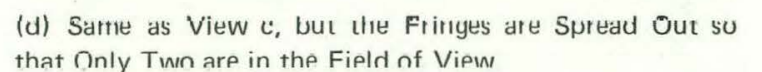

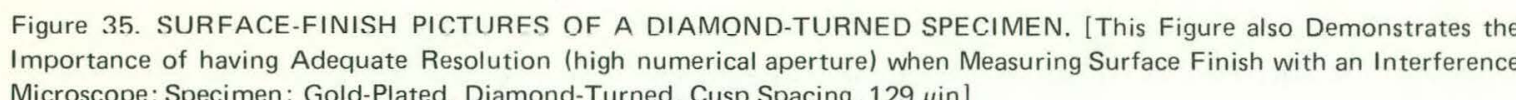




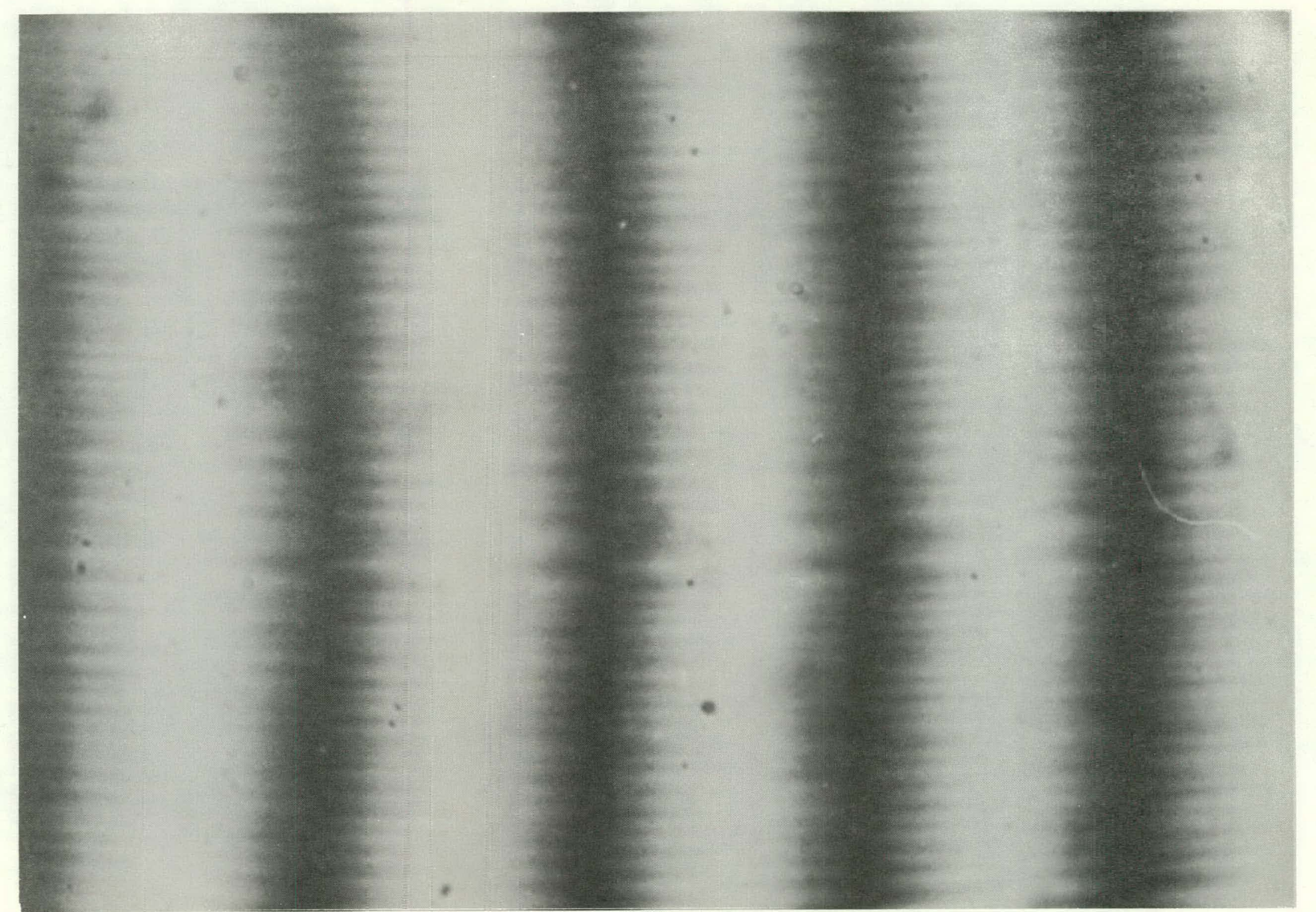

(a) Objective, Leitz 10X; NA, 0.18; Resolution, 73 pin; Cusp Spacing, 129 pin; Picture Magnification, 194X.

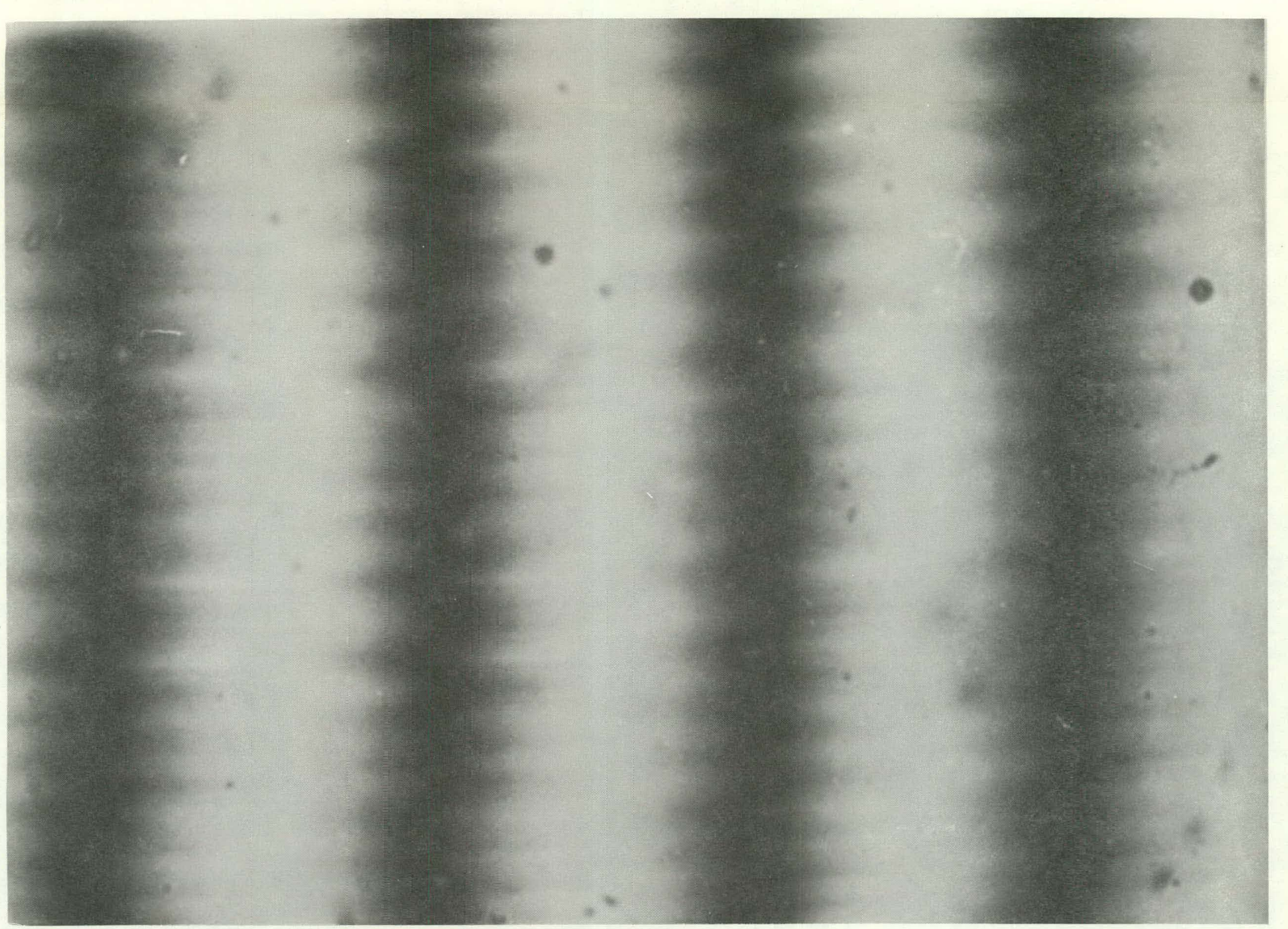

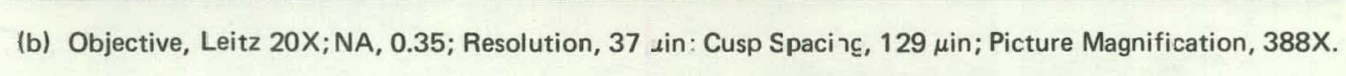

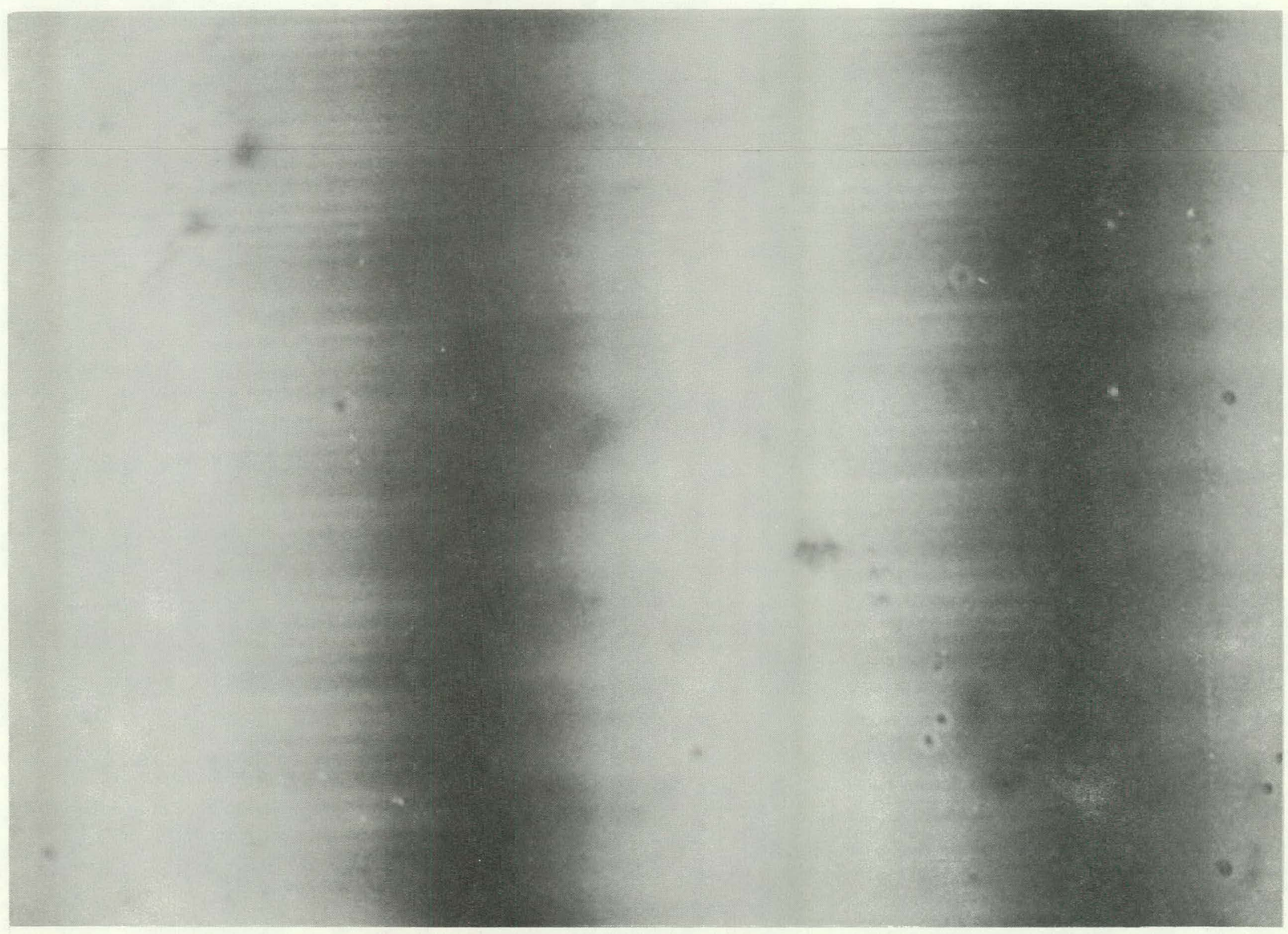

(c) Objective, Leitz 50X; NA, 0.85; Resolution, 16 uin; Cusp Spacing, 129 in; Picture Magnification, 970X.

Figure 36. GOLD-PLATED, DIAMGIND-TURNED, DOUBLE-BEAM INTERFERENCE MICROSCOPE STUDY 


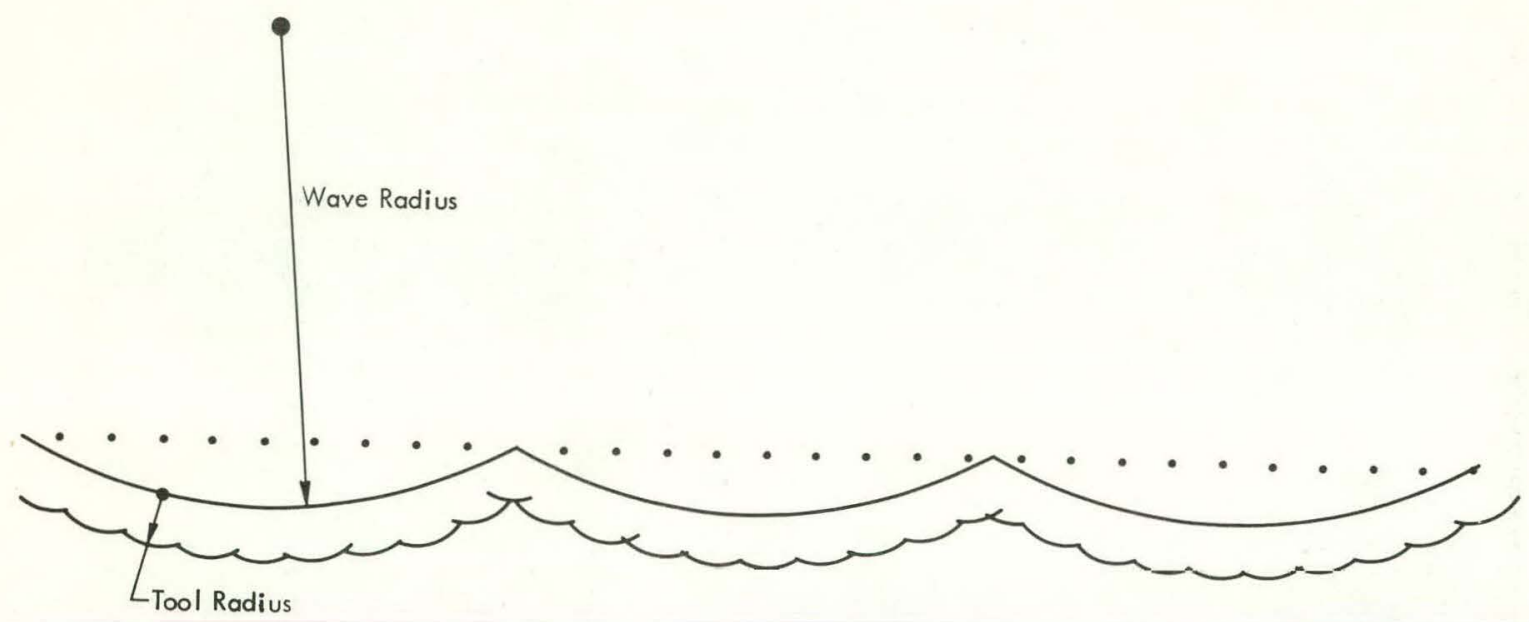

Figure 37 SIIRFAC.F FINISH OF A SAMPI F THAT R.INGISTS OF WAVIFS OF SIIIH I FN(STH THAT THF TOMI WAS ABLE TO MAKE ABOUT TEN CUTS PER WAVE. (Based on the Multiple-Beam Interferogram of Figure 20)

Now, another inspection of the double-beam picture taken with the $10 \mathrm{X}$ objective (Figure 35 . View a) reveals that the uneven fringe that is often called "grass" is nothing but the arches that are revealed with the multiple beam, and the qrooves themselves are not resolved. If enough resolving power is used to resolve the grooves (Figure 35, View d), the arches are basically lost in the width of the fringe.

For final comparison, a FECO fringe of this surface is presented in Figure 38. Since the surface was gold, and not silver plated, only one fringe could be obtained where the reflectivity was high; that is, in the red region of the spectrum. With only one fringe it was not possible to obtain the order number; and, thus, to calculate the surface finish. This FECO fringe clearly shows the tool cusps and the waves in the surface, and distinguishes the hills from the valleys.

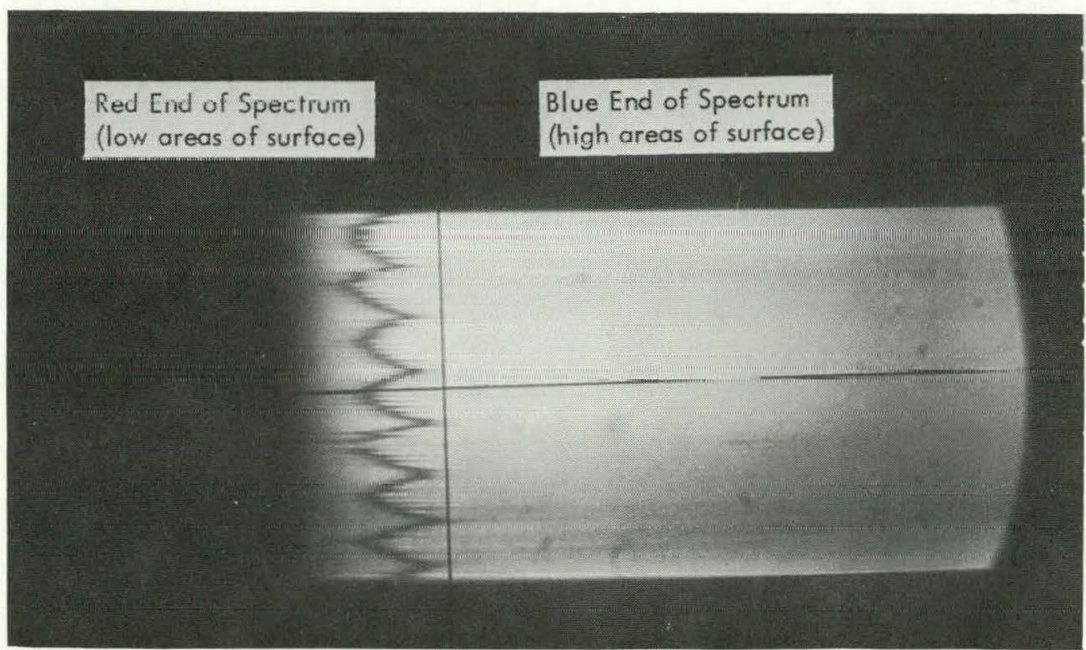

Figure 38. FECO FRINGE OF DIAMOND-TURNED, GOLD-PLATED DISC. [Only One Fringe was Obtained, because this Surface was Gold which has a High Reflectivity for Red Light and Low Reflectivity for other Colors (white light was used); Nikon Multiple-Beam Microscope with Spectrometer Attachment] 
Silver-Coated Copper Disc - The third specimen that was examined using both microscopes was a 38.6-mm (1.52-in) copper disc that was diamond turned with an interrupted cut. (It was one of 18 discs mounted in a large plate and turned simultaneously.) This disc was examined; and, several months later, coated with between 500 and $1000 \AA$ of vacuum-evaporated silver to increase its reflectivity when examined with green light in the multiple-beam microscope. However, it was examined with both red and green. Figure 39,

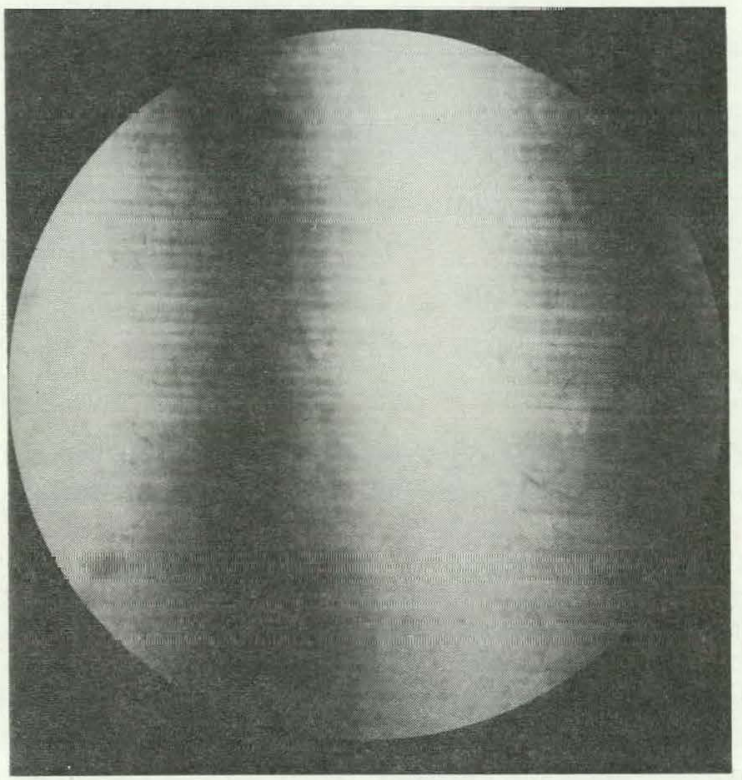

(a) Objective, 10X; Picture Magnification, $41 \mathrm{X}$.

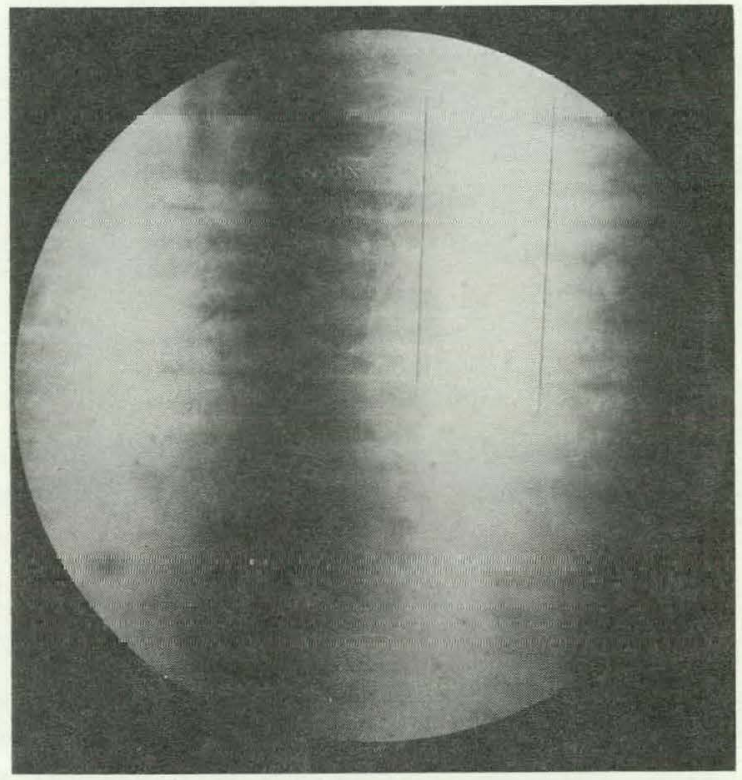

(b) Objective, 25X; Picture Magnification, 105X.

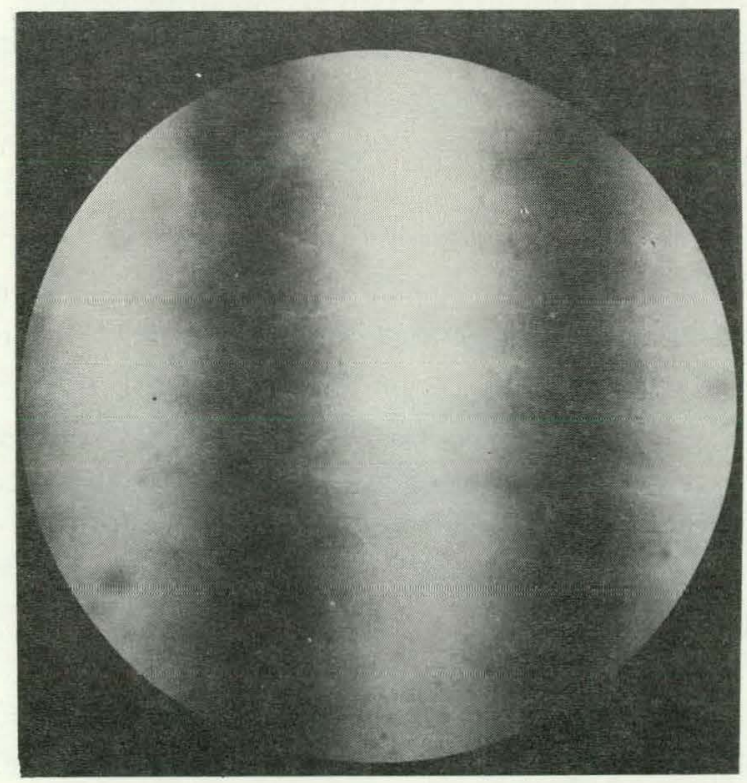

(c) Objective, 60X; Picture Magnification, 267X.

Figure 39. SURFACE-FINISH MEASUREMENT OF THE SILVER-PLATED, DIAMOND-TURNED COPPER DISC WITH ZEISS DOUBLE-BEAM MICROINTERFEROMETER 2. 
Views a - $c$ were taken with the Zeiss double-beam interference microscope. These pictures show that there are quite a few waves in the surface which do not correspond with the cusps, which are determined by the slide speed and spindle speed. These three pictures were made in the same area of the sample using, first, the 60X objective, then the $25 \mathrm{X}$ and $10 \mathrm{X}$ objectives. In this way it was not necessary to adjust the sample position or the objective focus, but it was necessary to align the fringes. Views a and b of Figure 40 were made with the Nikon microscope with two different objectives; View c was made without the reference mirror to show the condition of the surface. It is evident that, when the reference mirror is used, only the fringes are visible. No surface detail can be seen. This restriction is also evident from View b of Figure 36, which shows that when multiple-beam fringes are used in reflection, the first beam is reflected from the reference flat without passing through it and is, therefore, much brighter. It is also interesting to show the effect of interference on surface features with the Zeiss microscope. Figure 41, View a shows the surface with the tringes perpendicular to the grooves, View b shows one broad fringe parallel to the grooves, and View c shows the surface without fringes. The question was to find out if there could be surface features so prominent that they could be mistaken for fringes and thus introduce an error into the data calculated from the fringes. The results show that this problem is not likely to develop. The fringe effect increased the contrast on the surface. What was a gray surface became a surface varying from black to nearly white, making defects clearly visible. However, when the fringe was turned parallel to the grooves and broadened so that it nearly filled the entire field of view, the shade of gray was again surprisingly uniform. However, the crystal boundaries showed up very well.

One of the observations which was made, but not well documented, was that the surface of the disc was rougher after it was silvered than before. This difference is thought to be due to the growth of oxide film on the surface between the time the disc was first examined and then silvered and reexamined-a period of several months. The rate of growth of oxide is ditterent for various crystal surfaces; and, since quite a variety of planes are exposed, the uneven oxide growth will make the surface become rougher with time.

The Nomarski technique was also used on this sample to learn if using higher-power objectives had an effect on the appearance of surface roughness, and to learn more about the surface crystals. Figure 42 , Views a and $b$, taken with the $16 \mathrm{X}$ and $32 \mathrm{X}$ objectives of the Reichert microscope, respectively, had the sample oriented to bring out the crystal structure rather than the grooves in the surface. These pictures show: (1) that the crystal structure is very pronounced; (2) that it is less prominent with the higher-power objective; $(3)$ that it could contribute to the "beady" appearance of the multiple-beam fringes.

\section{Types of Data that can be Obtained}

The most general type of data that can be obtained is film thickness, which was illustrated in Figures 19, 26, 30, and 31. The film rises from the uncoated surface to the coated surface. When the objective is to measure surface finish, the fringes are formed in the same way; but, now, the fringes follow the ridges and valleys of the surface. The slope-distribution function (the rms slope), the height-distribution function (the rms height), and the 


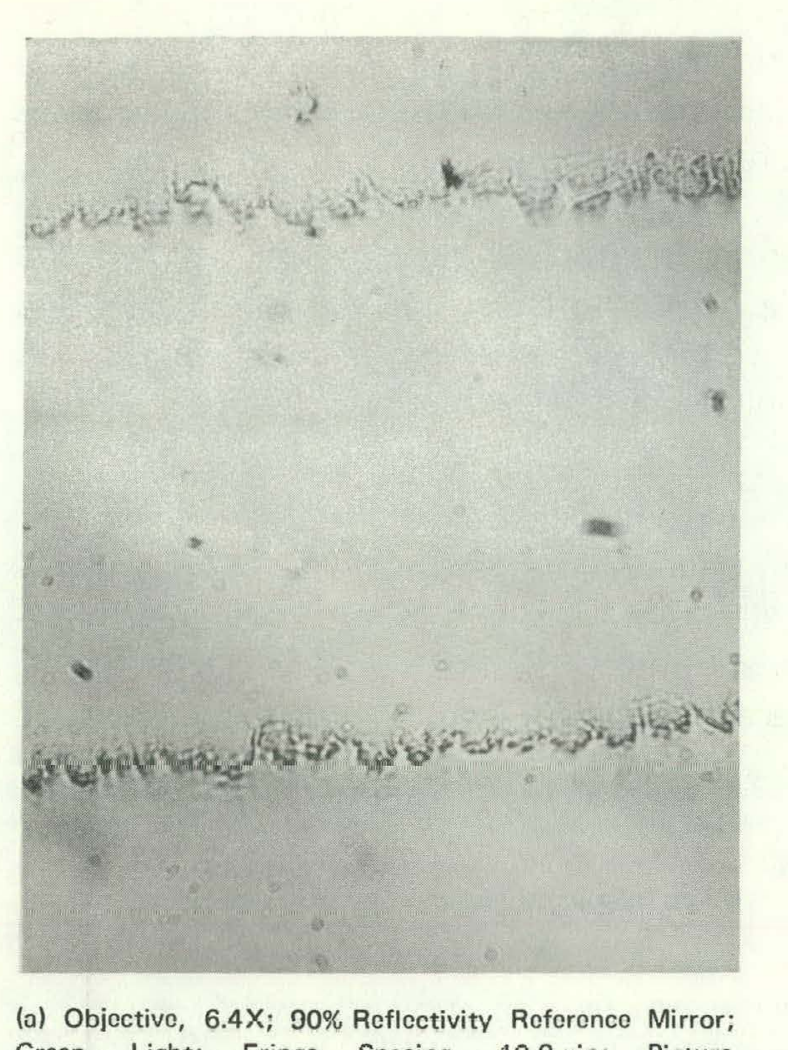

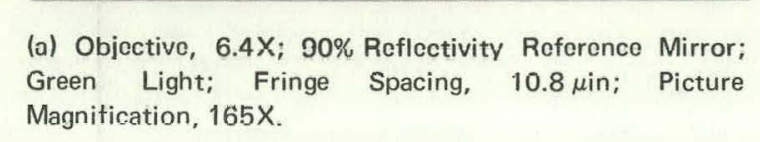

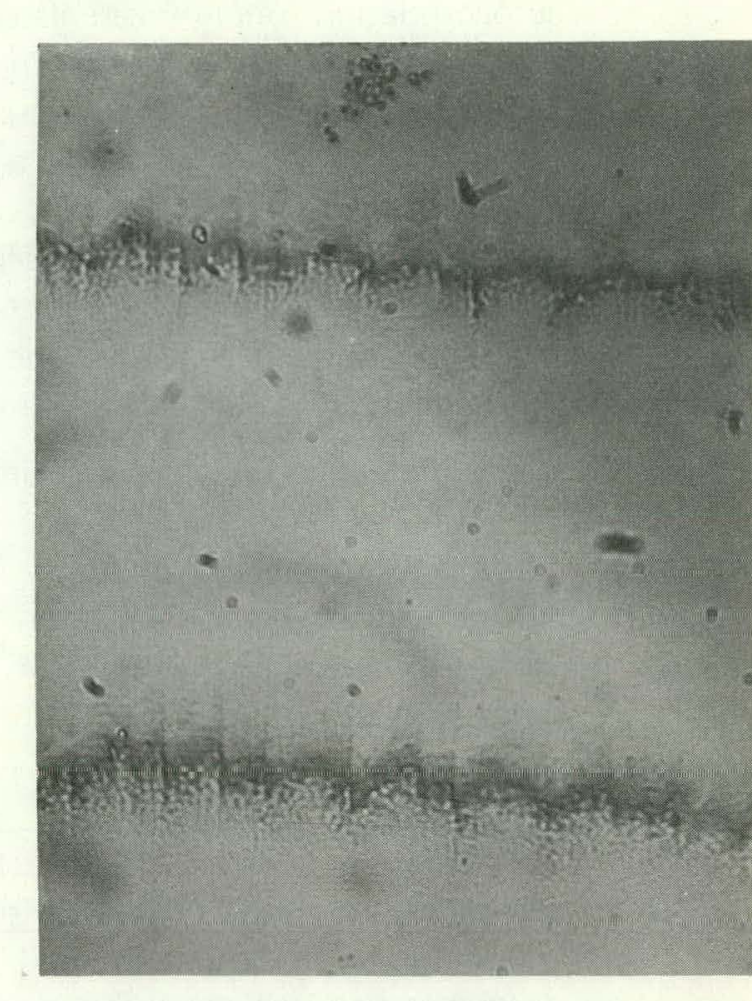

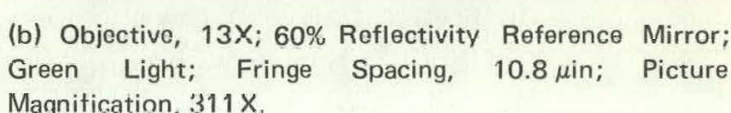

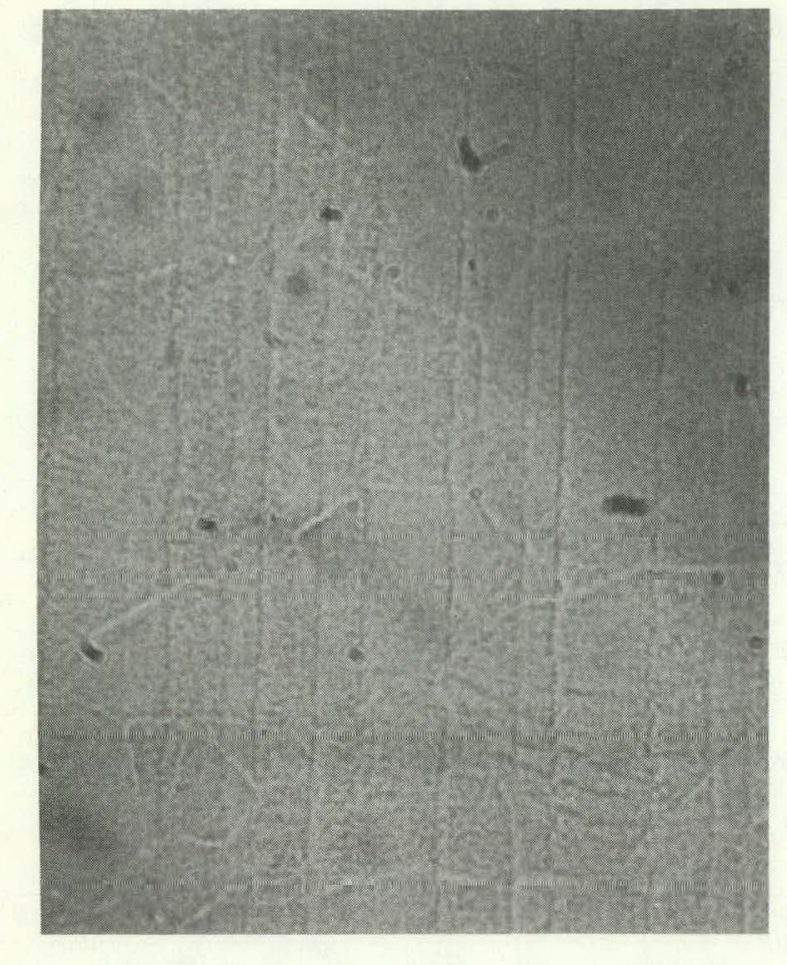

(c) Objective, 13X; No Reference Mirrar: Grean Light:
Picture Magnificication, 3111.

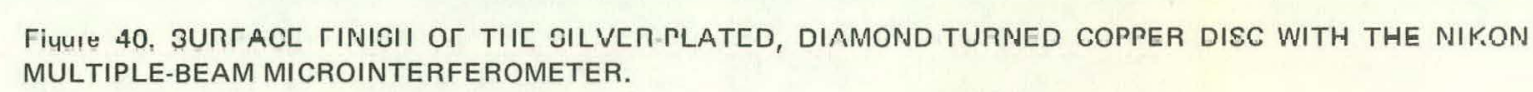
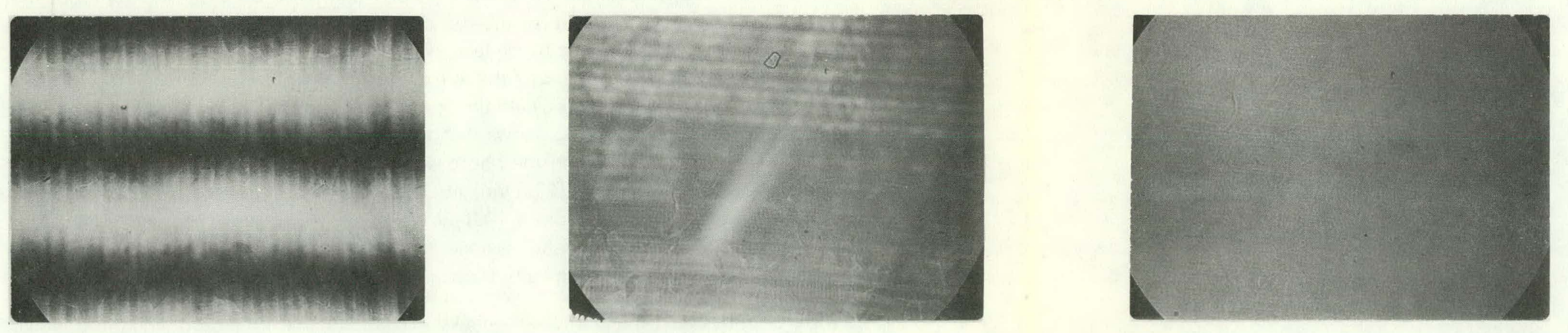

(b) Fringes Parallet to the Grooves

Figure 41. VIEWS OF THE SILVER.PLATED, DIAMOND-TURNED COPPER DISC BY ZEISS DOUBLE-BEAM
MICROINTERFEROMETER 1. (ODjective, 10X; Picture Magification, 66X; these Pictures IIIStrate the Difference in
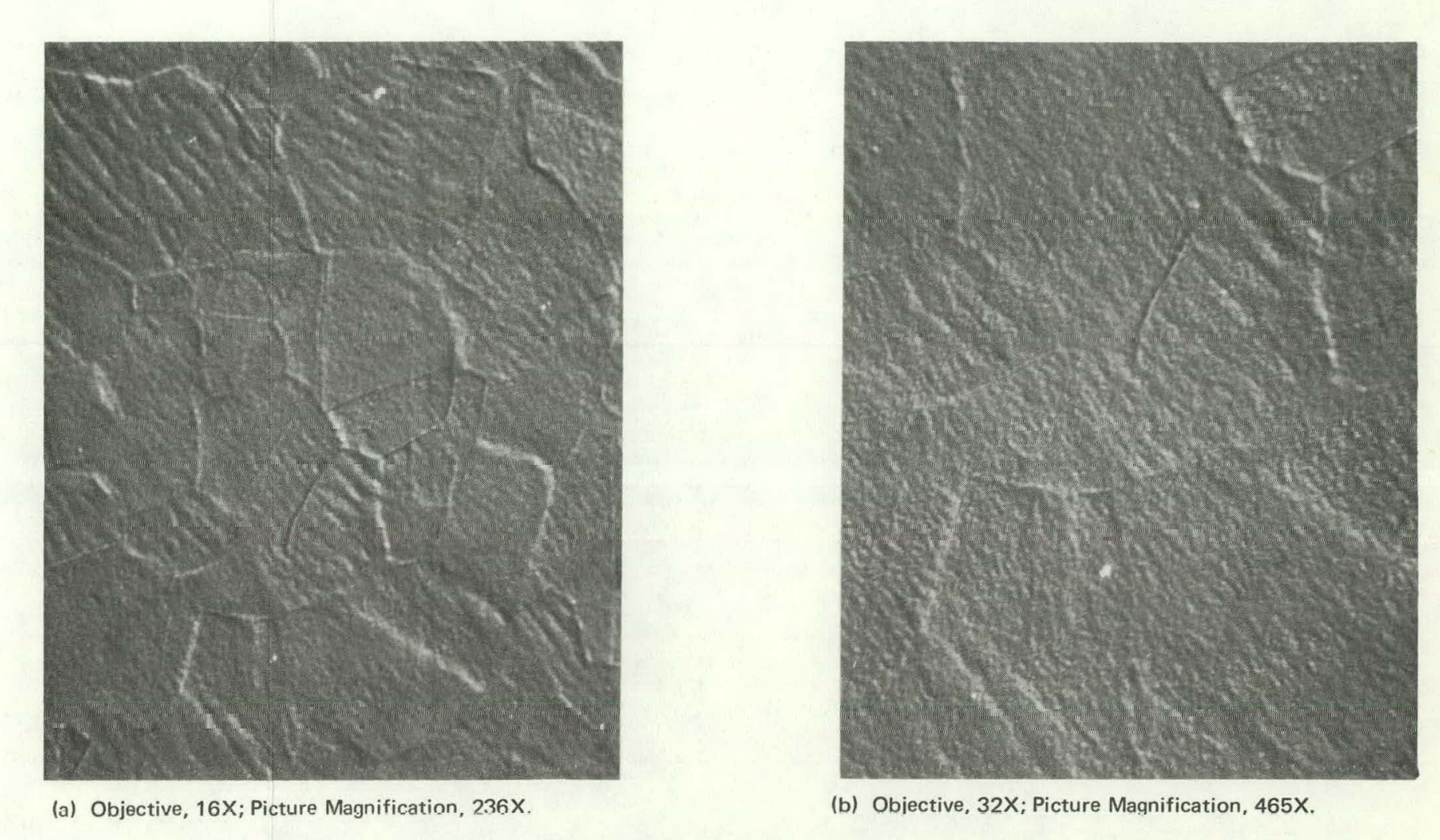

Figure 42. FIGURES, SHOWING THE GRAIN STRUCTURE OF THE COPPER AFTER IT WAS COATED WITH
VACUUM-EVAPORATED SILVER. (Reichert Microscope with Nomarski Polarization Contrast) 
autocorrelation function can also be measured. (18) The slope refers to the angle with which the surface irregularity rises from the basic surface; the correlation length is the separation between similar topographic features. To obtain slope, height, and autocorrelation functions for a surface, it is necessary to have an automatic system for reading fringes, a computer, and software. This equipment is available at the Naval Weapons Center, and some diamond-turned surfaces have been studied at this facility. (18) The system uses $4000-5000$ data points for calculating these statistical properties of surfaces. Excellence in optical figure (contour accuracy), waviness, and surface finish have long been known to be important in achieving sharp focus, high resolution, and minimum distortion in optical systems.

\section{Interpretation of Interference Fringes}

The procedure for measuring the thickness of a film is illustrated in Figure 19, View a. The method of obtaining data for surface finish differs only in thal, instead of having smooth fringes to measure, the edges of the fringes are rough. The magnitude of this roughness depends upon the roughness of the surface, and is the source of the surface-finish information.

The fringe is densest (or blackest) in the middle, and her.nmes lighter at the edges. The theoretical treatments cited before showed that the intensity of light in a fringe; and, consequently, the photographic blackening, is either a $\cos ^{2}$ or a $\sin ^{2}$ function of the phase difference between the specimen and the referencc surface. The rate of intensity change for the double-beam $\cos ^{2}$ function is much slower than for the multiple-beam $\sin ^{2}$ function, and it is more difficult to locate the exact center or codqe of the fringe with certainty.

The difficulty experienced in evaluating roughness from interference fringes is illustrated in Figure 43, Viewa, which is an artificial fringe constructed from a copy of Figure 26, View a. This print was attached to a piece of millimeler yraph paper, then sertinns $(2 \mathrm{~mm}$ wide) were sliced off, one at a time, with a paper cutter. These slices were then misaligned one or two millimeters, as seen in View b of Figure 43 and laped back together. Without the guidance of the uncut fringe it would be difficult to establish a base for measuring deviations. Since the edges of the fringe fade into shades of gray, it is better to try to locate the center of the black area-the way the automatic fringe reader works. ${ }^{(33)}$ The greatesl excursion in a positive direction is called the "peak"; in the negative direction it is called the "valloy". The graph of Figure 43 shouvs llial llı peak is a 2 -mmm offset from the baseline valley, or 0 . The fringe spacing on the photo was $8.4 \mathrm{~mm}$, center to center on the fringes, a distance that represents $274 \mathrm{~nm}(10.8 \mu \mathrm{in})$ in elevation. Thus, the peak-to-valley height on the artificial fringe is $2 \mathrm{~mm} / 8.4 \mathrm{~m} m \times 10.8 \mu \mathrm{in}=2.6 \mu$ in $=65.3 \mathrm{~nm}$. The accepted measure of surface finish is the arithmetic average (AA), (34) which is usually obtained from peak-to-valley readings by dividing hy 5 ; for example. $2.6 \mu \mathrm{in} / 5=0.5 \mu \mathrm{in}, \wedge$.

The difference between the artificial-roughness fringes and the fringes obtained from a real surface is cvident from what has been described earlier in this report:

1. The irregularities are usually spaced much closer than the two-millimeter spacing that was used for the illustration. 


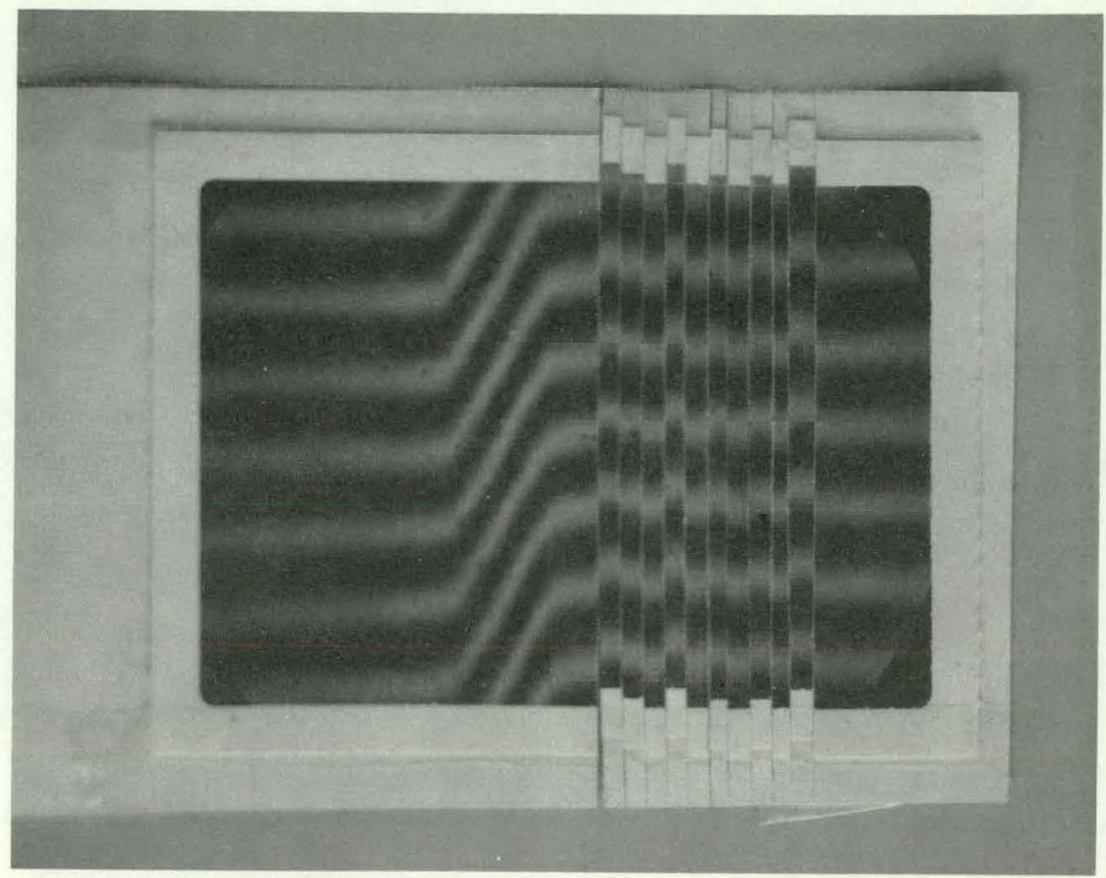

(a) An Artificial Surface-Finish Fringe Made by Taking a Set of Fringes from a Smooth Surface, Slicing Off Strips, Two Millimeters in Width, and Replacing them Out of Register.

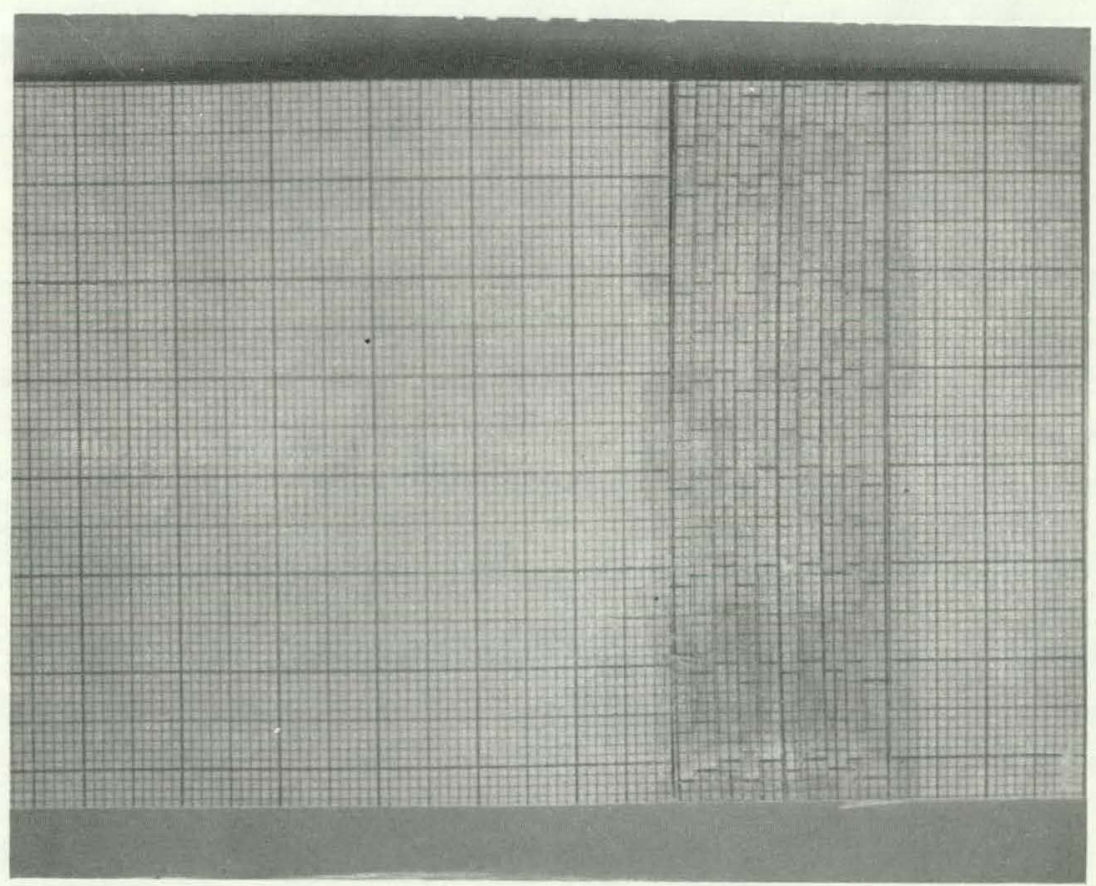

(b) Graph Paper, Showing the Extent to which the Fringes were Misaligned.

Figure 43. ILLUSTRATION OF THE CREATION OF AN ARTIFICIAL SURFACE-FINISH FRINGE AND THE DIFFICULTY IN READING IT WITHOUT THE GUIDANCE OF THE GRID. 
2. The surface may have waves as well as cusps from the tool.

3. The surface may also have a randomly oriented structure due to crystals, oxide growth, lapping marks, scratches, porosity, inclusions, and dirt.

4. The surface may be poorly defined, due to insufficient resolution for some structures like tool cusps; and excessive magnification, real or empty, for waves and crystal orientation. Some particulate matter may prevent the reference mirror from being placed sufficiently close to the surface for the formation of good multiple-beam fringes.

5. The surface quality may be better than the limit of detection of the noncontact, double-beam interferometer.

6. Since the surface is examined microscopically, only a very small area is observed in one view. Generally, this area is found to be typical of the whole surface, but this point should be investigated. If there is cause to suspect variations over the surface, more areas should be examined.

7. The artificial frinqe used, of necessity, flat-bottomed grooves. In the real cases (unless there is tearing of the metal), everything has a radius, and boundaries are poorly defined.

The surface-finish number is a statistical figure and is based on the interpretation of the person reading the fringe and his estimation of the peak-to-valley height. Almost everyone reads surface-finish interferograms by eye. The biqgest uncertainty in reading fringes by eye is determining the position of the peak, because the peak grades into lighter shades of gray. Reading of the peak depends upon the individual's ability to discern shades of gray and also the amount of exposure of the picture. It is also difficult to locate the vallev. Data near the center of the tringe may be obscured, due to a hiqh liqht intensity and photographic broadening. If the fringe spacing is increased to increase the sensitivity, the fringe is also broadened, and the certainty of knowing where the valley is located decreases. This problem arises from the fact that the contrast between shades of gray has decreased. Here, again, the multiple-beam fringes are far superior in delineating the shades of gray.

If the purpose of the surface-finish study is to gain diagnostic information, it is advisable and necessary to study the pictures of the surface rather than rely on a single number. Good communication should be established between the engineer and the laboratory, and the machining parameters should be provided as a guide to the choice of microscopes.

Bennett ${ }^{(33)}$ reported the development of an automatic comparator with photoelectric detection for determining the position of interference fringes. When used to scan fringe lines, the spacing between data points is set approximately equal to the resolution of the optical system so that statistical information is obtained at approximately two-micrometer $(80-\mu \mathrm{in})$ increments along the fringe. The scanner locates the center of the fringe. Assuming that the fringe is a black line on a light background, the scanner locates the center of the 
dark area, or the minimum of intensity. This location is very important in regard to visual reading of peaks. The visual reader is inclined to read too closely to the tip of the peak and, thus, obtain a larger peak-to-valley reading than is obtained by machine processing. This error occurs, probably, because the individual feels that if a gray peak is in the photograph, he can not honestly ignore too much of it. Hence, the visual reading of surface roughness is inherently much less precise than the automated reading of fringes $(33)$ and results in higher numbers for the surface finish. It has also been noted that the reflectivity of a cusp may be less than the surrounding surface. Hence, the narrow cusp is lighter in contrast and longer in extent. If the midpoint is not lost due to poor resolution, or photographic broadening, it would be more accurate to read the fringe center displacement.

Now, suppose it is necessary to obtain surface-finish data from a fringe. The person using visual means can only accumulate data from a limited number of points, probably measuring the deviation of the fringe center from a given line. The location of the centerline is adjusted so that the sum of the deviations on both sides is equal. Then, the largest peak and the deepest valley are chosen to represent the peak-to-valley height, and this number is divided by an arbitrary constant to obtain the AA. Bryan (34) points out that this number depends on the process used for finishing the surface and suggests that this constant be 5 although, in some cases, the number is 20 . For diamond-turned surfaces, 4 seemed to give the better relationship. To obtain a better average of the surface, all of the data should be used instead of only the peak and valley. In this case, the sum of the absolute values of the $(+)$ and $(-)$ deviations is divided by the total number of measurements, and this number should be close to the number obtained by the use of the divisor just mentioned. This point must be kept in mind in examining the data on the following pages. Since working with data from 25 or more points on a fringe is time consuming, most likely the data reported will be given by looking for the highest peak and deepest valley and dividing by four. The machine system obtains data from about 5000 equally spaced points and, thus, can provide a better statistical evaluation of the surface.

As an example of real data, the surface finish of the disc shown in Figure 39, View a (Specimen 2) was obtained by measuring the variations in the fringe position, both at the center and at the edge, to demonstrate the problems inherent in both procedures. (It has already been pointed out that these are not tool cusps, but waves in the surface.) A sharp-pointed pencil and a magnifier were used to locate the center of the fringe; and, in the next case, the edge of the fringe, in uniform steps. The center of the fringe was the center of the darkest area, a spot that seems easy to locate because of the symmetry of the fringe. The distance from each point to a fiduciary line near the estimated center of the points was measured. These data are presented in Table 3. The edge of the fringe was the point where the medium gray fades into white. This point seems to be easy to judge when casually examining a photo, but it is very difficult to ascertain when trying to make a precise measurement. The distance from each point to a fiduciary line was measured. These data are reported in Table 4.

The data represent peaks and valleys and it is necessary to find a centerline ${ }^{(34)}$ such that the sum of the peak, or $(+)$ excursions, is nearly equal to the sum of the valley, or $(-)$ 
excursions. When the centerline was located, the sum of the absolute values of the maximum ( + ) and $(-)$ was the maximum peak-to-valley surface roughness (Table 5). It was $33 \mathrm{~nm}(1.3 \mu \mathrm{in})$ for the fringe center reading and $74 \mathrm{~nm}(2.9 \mu \mathrm{in})$ for the fringe edge reading. Dividing by 4 , the $A A$ values were $8.3 \mathrm{~nm}(0.33 \mu \mathrm{in})$ for the fringe center data and $18.4 \mathrm{~nm}(0.74 \mu \mathrm{in})$ for the fringe edge reading. Another way to obtain the AA is to take the sum of the absolute values of the $(+)$ and $(-)$ readings and divide by $N$. When this step was taken, the results were $9 \mathrm{~nm}(0.36 \mu \mathrm{in})$ for the fringe center and $26 \mathrm{~nm}(1 \mu \mathrm{in})$ for the fringe edge.

There is a substantial difference between these two sets of data-over $100 \%$. Evidently the data taken from the fringe centers are more accurate. The reasons for this conclusion were outlined earlier, but probably the greatest contribution to accuracy is due to considerations of symmetry. For example, an experimental condition not easy to remedy is uniformity of illumination. Although it may be barely noticeable to the eye, uneven illumination broadens the fringe; which, in turn, affects, directly, the fringe-edge readings, but does not affect the fringe-center readings.

The method of obtaining surface-finish information illustrated here is tedious and time consuming. It is much easier to glance at the edge of the fringe and pick out the peak and valley. It should be well noted that this method is subject to error, possibly being $100 \%$ high.

The magnification of the picture chosen for this example was only $41 \mathrm{X}$, and the tool cusps were not visible. Obviously, to obtain complete data it is necessary to use a photograph with a higher NA and magnification, and to proceed with the method just described. It was shown earlier (Figure 20), for another specimen, that the height of the arches was a maxımum of $24 \mathrm{~nm}(U .94 \mu \mathrm{nn})$, peak to valley, and the tool cusps were about $8 \mathrm{~nm}$ $(0.3 \mu \mathrm{in})$. Thus, including the tool-cusp height with the waviness height would not greatly change the surface finish of the specimen. The tool-cusp height is theoretically a function of the tool advance and, thus, can be made very small. The waves, however, depend on the perfection of the bearings, slide, and slide/drive mechanism of the turning machine. Obviously, this condition will vary. In addition, each material-copper, aluminum, nickel, gold, plated materials, plastics, and ceramics-has certaın characteristics which are reflected in the surface finish that can be obtained.

To obtain more detailed data, the surface finish of the gold-plated disc (Specimen 2) was measured from Fiqure 20 (multiple beam) using the line-center technique and many points (Table 6). The maximum peak-to-valley height was $29 \mathrm{~nm}(1.14 \mu \mathrm{in})$; and, dividing by 4 , the AA was $7.2 \mathrm{~nm}(0.29 \mu \mathrm{in})$. Using all 69 points, the AA was $5.8 \mathrm{~nm}(0.23 \mu \mathrm{in})$.

Since this surface was carefully examined using double-beam fringes, the surface finish was also calculated by using one of these photomicrographs (Figure 36, View b). It was chosen because the magnification on the picture $(388 \mathrm{X})$ was close to $311 \mathrm{X}$ on the multiple beam, even though the resolution $(37 \mu \mathrm{in})$ was better than the $61 \mu \mathrm{in}$ obtained with multiple beams. The slow variation in shades of gray on the broad fringe made it difficult to locate 
Table 3

CALCULATION OF SURFACE FINISH BY
MEASRREEN OF THE FINGE-
CENTER POSITION FOR MANY

Specimen: Silver.Plated Copper D

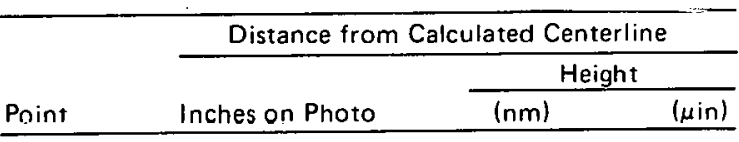

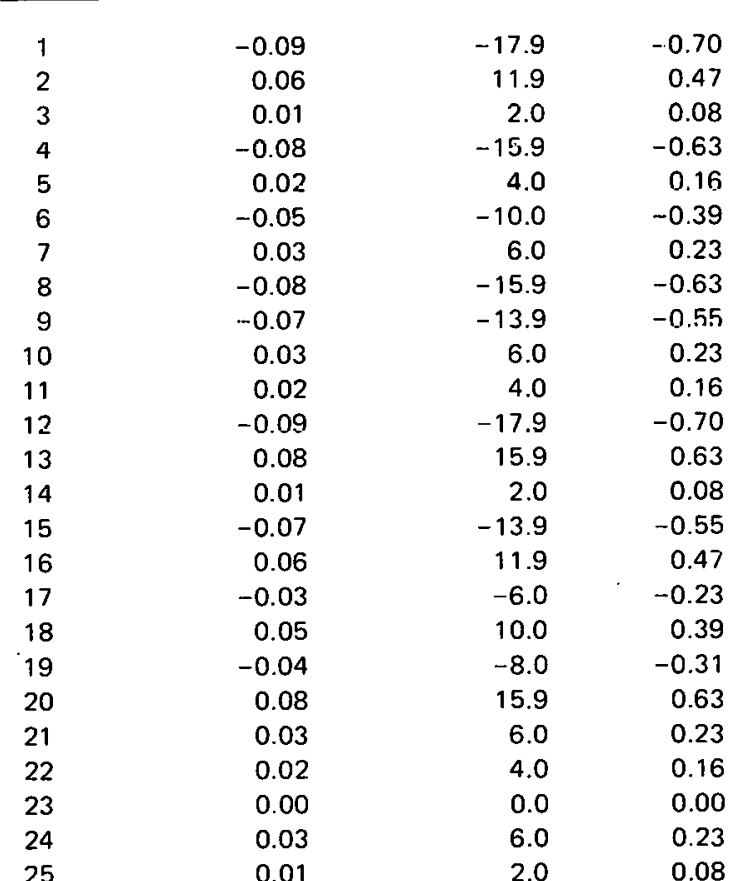

Highest (t)
Hightest (-)

$\begin{array}{cc}15.0 & 0.6 \\ 17.8 & 0.7 \\ 33 & 1.3 \\ 3 & 1.3\end{array}$

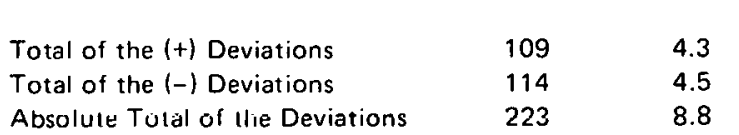

Table 4

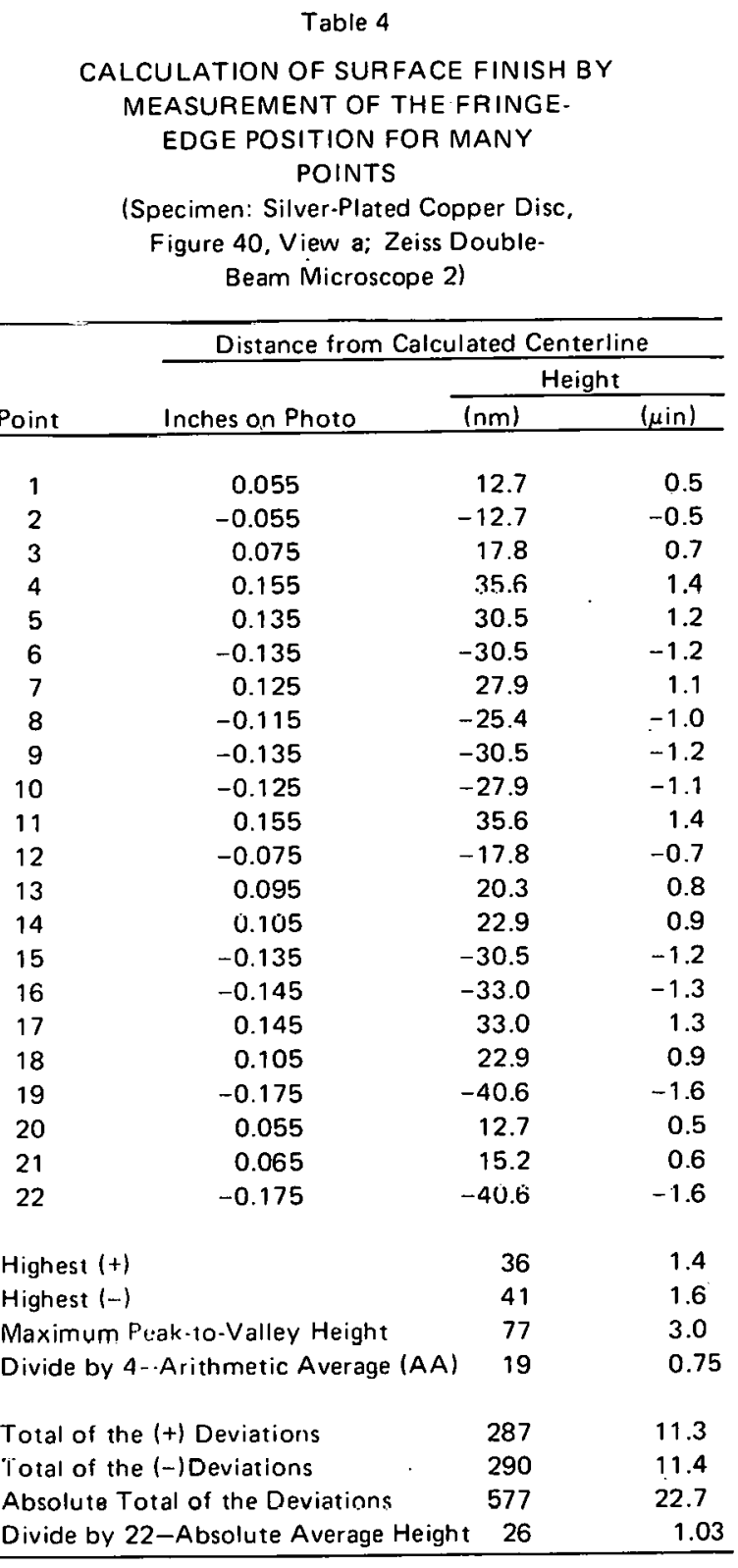

Table 6
CALCULATION OF THE SURFACE FINISH BY MEASUREMENT OF THE

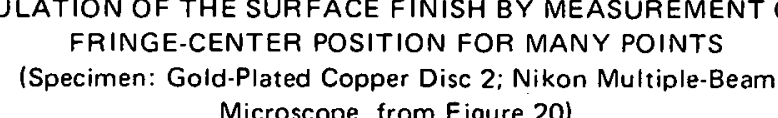

\begin{tabular}{|c|c|c|c|c|c|c|}
\hline \multicolumn{3}{|c|}{ Distance from Calculated Centerline } & \multirow[b]{2}{*}{ Point } & \multicolumn{3}{|c|}{$\begin{array}{c}\text { Distance from Calculated Center line } \\
\text { Height }\end{array}$} \\
\hline Inches on Photo & $\overline{(n m)}$ & $\frac{1 \text { in })}{1}$ & & Inches on Photo & $\frac{\mathrm{t}}{(\mathrm{nm})}$ & $\frac{(\text { in })}{1}$ \\
\hline $\begin{array}{l}0.07 \\
0.02\end{array}$ & $\begin{array}{l}6.9 \\
2.0\end{array}$ & 0.27 & 36 & -0.02 & -2.0 & -0.08 \\
\hline 0.13 & 23.0 & 0.51 & $\begin{array}{l}37 \\
38\end{array}$ & $\begin{aligned} 0.07 \\
-0.06\end{aligned}$ & $\begin{array}{r}6.9 \\
-5.8\end{array}$ & $\begin{array}{c}0.27 \\
-0.23\end{array}$ \\
\hline-0.01 & -1.0 & $\begin{array}{l}-0.04 \\
0.27\end{array}$ & 39 & 0.04 & 4.1 & $\begin{array}{l}-0.16 \\
0.167 \\
-10\end{array}$ \\
\hline -0.04 & $\begin{array}{l}-6.9 \\
-4.1\end{array}$ & 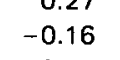 & 41 & $\begin{array}{l}-.02 \\
0.02\end{array}$ & $\begin{array}{l}-6.9 \\
2.0\end{array}$ & $\begin{array}{l}-0.27 \\
0.08\end{array}$ \\
\hline-0.08 & $\begin{aligned} 5.8 \\
-7.9\end{aligned}$ & $\begin{array}{c}0.23 \\
-0.31\end{array}$ & $\begin{array}{l}4_{43}^{2} \\
4\end{array}$ & $\begin{array}{l}-0.08 \\
-0.04\end{array}$ & $\begin{array}{l}-7.9 \\
-4.1\end{array}$ & $\begin{array}{l}-0.31 \\
-0.19\end{array}$ \\
\hline 0.00 & 0.0 & 0.00 & 44 & 0.02 & -2.0 & $\begin{array}{l}-0.16 \\
-0.08\end{array}$ \\
\hline $\begin{array}{l}-0.098 \\
-0.08\end{array}$ & 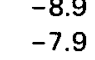 & $\begin{array}{l}-0.35 \\
-0.31\end{array}$ & $\begin{array}{l}45 \\
46\end{array}$ & $\begin{array}{l}0.02 \\
0.04\end{array}$ & $\begin{array}{l}2.0 \\
4.1\end{array}$ & $\begin{array}{l}0.08 \\
0.16\end{array}$ \\
\hline 0.04 & $\begin{array}{c}-4.1 \\
4.1\end{array}$ & 0 & 47 & 0.10 & 9.9 & 0.39 \\
\hline-0.04 & -4.1 & -0.16 & 49 & 0.11 & 10.9 & \\
\hline 0.00 & 9.9 & 0.39 & $\begin{array}{l}50 \\
5 \\
5\end{array}$ & -0.022 & -2.0 & -0.08 \\
\hline 0.16 & 16.0 & 0.63 & 52 & -0.07 & 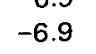 & $\begin{array}{l}-0.27 \\
-2\end{array}$ \\
\hline - 0.06 & & $\begin{array}{l}0.23 \\
-0.16\end{array}$ & $\begin{array}{l}53 \\
5\end{array}$ & $\begin{array}{c}0.03 \\
-0.07\end{array}$ & $\begin{array}{r}3.0 \\
-6.9\end{array}$ & $\begin{array}{c}0.12 \\
-0.27\end{array} \quad \mathrm{Cl} \mathrm{l}$ \\
\hline 0.07 & 6.9 & 0.27 & 55 & -0.08 & -7.9 & -2 \\
\hline $\begin{array}{l}-0.05 \\
0.03\end{array}$ & $\begin{array}{l}-5.1 \\
3\end{array}$ & $\begin{array}{l}-0.20 \\
0.20\end{array}$ & $\begin{array}{l}56 \\
56\end{array}$ & 0.00 & $\begin{array}{l}0.0 \\
0.0\end{array}$ & 0.00 \\
\hline & & & 58 & -0.04 & -4.1 & \\
\hline $\begin{array}{l}-0.12 \\
\end{array}$ & -111.9 & -0.47 & 59 & -0.13 & -13.0 & -0.51 \\
\hline $\begin{array}{l}0.12 \\
0.12\end{array}$ & $\begin{array}{r}-1.9 .9 \\
-9.9\end{array}$ & $\begin{array}{l}-0.439 \\
0\end{array}$ & 60 & $\begin{array}{l}-0.0 .0 \\
0.00\end{array}$ & $\begin{array}{c}-9.9 \\
\end{array}$ & -0.39 \\
\hline 0.03 & & & 62 & -0.06 & -5.8 & -0.23 \\
\hline 0.02 & 2.0 & 0.08 & 63 & 0.02 & $2.0^{\circ}$ & 0.08 \\
\hline 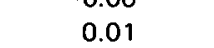 & 1.0 & 0.04 & $\begin{array}{l}64 \\
65\end{array}$ & - 0.06 & -10 & -0.0 \\
\hline 0.13 & 13.0 & 0.51 & 66 & 0.03 & 3.0 & 0.12 \\
\hline $\begin{array}{l}0.02 \\
0.12\end{array}$ & $\begin{array}{l}2.0 \\
2.0\end{array}$ & 0.088 & $\begin{array}{l}67 \\
67\end{array}$ & & 13.0 & 0.51 \\
\hline 0.02 & 2.0 & 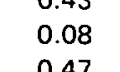 & 69 & -0.01 & $\begin{array}{l}4.1 \\
-1.0\end{array}$ & -0.04 \\
\hline & & $\begin{array}{c}\text { Highest } \\
\text { Highest }\end{array}$ & & & $\begin{array}{l}16 \\
13\end{array}$ & $\begin{array}{l}0.63 \\
0.51\end{array}$ \\
\hline & & $\begin{array}{l}\text { Maximu } \\
\text { Divide b }\end{array}$ & 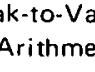 & elight (AA) & 7.3 & $\begin{array}{l}1.14 \\
0.29\end{array}$ \\
\hline & & Total of & +t De & & $\begin{array}{l}212 \\
109\end{array}$ & \\
\hline & & $\begin{array}{l}\text { Absolut } \\
\text { Divide b }\end{array}$ & & ne Height & $\begin{array}{c}406 \\
5.9\end{array}$ & 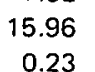 \\
\hline
\end{tabular}

Table 5
COMPARIISON OF THE SURFACE.FINSH DATA OBTAINED FROM THE
CENTER OF A FRINGE AND THE EDGE OF A FRINGE

\begin{tabular}{|c|c|c|c|c|}
\hline Value & $\frac{\text { Cen }}{(n m)}$ & tinge & $\frac{E d}{(n m)}$ & $\begin{array}{l}\text { inge } \\
\text { (uin) } \\
\end{array}$ \\
\hline Peak-to-Valley Heighth & 33 & 1.3 & 76 & 3.0 \\
\hline $\begin{array}{l}\text { Arithmetic Average } \\
\text { (divide peak-tovalley height by 4) }\end{array}$ & 8.4 & 0.33 & 19 & 0.75 \\
\hline $\begin{array}{l}\text { Arithmetic Average } \\
\text { (sum of absolute heights) }\end{array}$ & 8.9 & 0.35 & 25.4 & 1.0 \\
\hline
\end{tabular}


S
S

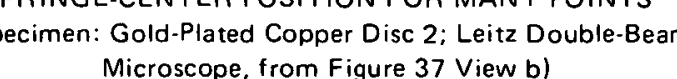

\begin{tabular}{|c|c|c|c|c|c|c|c|}
\hline & Distance fror & Ulated $\mathrm{Ce}$ & & & Distance fro & Iated C & \\
\hline Point & Inches on Photot & $\frac{H}{(\mathrm{~nm})}$ & $\frac{1}{(\mu \text { in })}$ & Point & Inches on Photo & $\overline{(n m)}$ & $\frac{t \text { (min) }}{(t)}$ \\
\hline 1 & 0.04 & $\begin{array}{l}4.8 \\
13\end{array}$ & $\begin{array}{l}0.19 \\
0.5\end{array}$ & & 0.06 & 7.4 & \\
\hline $\begin{array}{l}2 \\
3\end{array}$ & $\begin{array}{r}0.01 \\
-0.01\end{array}$ & $\begin{array}{r}1.3 \\
-1.3\end{array}$ & $\begin{array}{c}0.05 \\
-0.05\end{array}$ & $\begin{array}{l}32 \\
33\end{array}$ & $\begin{array}{l}0.16 \\
0.12\end{array}$ & $\begin{array}{l}7.4 \\
14.7\end{array}$ & $\begin{array}{l}0.29 \\
0.58\end{array}$ \\
\hline $\begin{array}{l}4 \\
5\end{array}$ & $\begin{array}{l}-0.09 \\
-0.10 \\
-0.10\end{array}$ & $\begin{array}{l}-10.9 \\
-12.7\end{array}$ & $\begin{array}{l}-0.43 \\
-0.50\end{array}$ & $\begin{array}{l}34 \\
35\end{array}$ & $\begin{array}{l}-0.02 \\
-0.14\end{array}$ & $\begin{array}{r}-2.5 \\
-2170 \\
-12\end{array}$ & $\begin{array}{l}-0.10 \\
-0.67\end{array}$ \\
\hline 6 & $\begin{array}{l}-.08 \\
-0.08 \\
-0.066\end{array}$ & $\begin{array}{l}-9.6 \\
-7.6\end{array}$ & $\begin{array}{l}-0.38 \\
-0.39\end{array}$ & 36 & 0.00 & 0.0 & $\begin{array}{l}0.00 \\
0.00\end{array}$ \\
\hline 0 & $\begin{array}{l}-0.06 \\
-0.01\end{array}$ & $\begin{array}{l}-7.4 \\
-1.3\end{array}$ & ${ }_{-0.00}^{-2.29}$ & 年 & $\begin{array}{l}0.08 \\
0.10\end{array}$ & $\begin{array}{l}9.6 \\
12.7\end{array}$ & \\
\hline & 0.04 & 4.8 & 0.19 & 39 & 0.1 & 13.5 & 0.53 \\
\hline 11 & $\begin{array}{l}0.08 \\
0.09\end{array}$ & $\begin{array}{c}0.6 \\
10.9\end{array}$ & $\begin{array}{l}0.38 \\
0.43\end{array}$ & $\begin{array}{l}10 \\
41\end{array}$ & $\begin{array}{r}0.03 \\
-0.06\end{array}$ & $\begin{array}{r}3.6 .6 \\
-7.4\end{array}$ & $\begin{array}{r}0.14 \\
-0.29 \\
-\end{array}$ \\
\hline $\begin{array}{l}12 \\
13\end{array}$ & $\begin{array}{l}0.12 \\
0.19 \\
0.19\end{array}$ & $\begin{array}{l}14.7 \\
23.1\end{array}$ & $\begin{array}{l}0.58 \\
0.91\end{array}$ & $\begin{array}{l}42 \\
43 \\
43\end{array}$ & $\begin{array}{l}-0.21 \\
-0.11\end{array}$ & $\begin{array}{l}-25.7 \\
-13.5\end{array}$ & $\begin{array}{l}-1.01 \\
-0.53\end{array}$ \\
\hline & 0.21 & & 1.01 & 44 & $\begin{array}{l}0.02 \\
0.02\end{array}$ & 2.5 & \\
\hline 15 & 0.09 & 10.9 & 0.43 & ${ }^{45}$ & 0.10 & 12.7 & 0.50 \\
\hline & $\begin{array}{l}0.00 \\
0.03\end{array}$ & & & 告 & 0.1 & $\begin{array}{ll}15.5 \\
6.10\end{array}$ & $\begin{array}{l}0.53 \\
0.34\end{array}$ \\
\hline 18 & -0.01 & -1.3 & -0.05 & 48 & 0.0 & 0.0 & 0.00 \\
\hline 19 & $\begin{array}{l}0.02 \\
0.02\end{array}$ & $\begin{array}{l}2.5 \\
2.5\end{array}$ & 0.100 & $\begin{array}{l}49 \\
49 \\
50\end{array}$ & 0 & -2.5 & -0.10 \\
\hline & 0.04 & 4.8 & $\begin{array}{l}.14 \\
0.19\end{array}$ & 51 & -0 & $\begin{array}{l}-15.5 \\
\end{array}$ & $\begin{array}{l}-0.38 \\
-062\end{array}$ \\
\hline 22 & -0.01 & -1.3 & -0.05 & 52 & -0 & -21.8 & -0.86 \\
\hline 24 & $\begin{array}{l}0.02 \\
0.03\end{array}$ & $\begin{array}{l}2.5 \\
3_{6}\end{array}$ & 0.10 & 534 & & $\begin{array}{l}-18.3 \\
-18.3\end{array}$ & $\begin{array}{l}-0.72 \\
-0.72\end{array}$ \\
\hline & 0.03 & 3.6 & 14 & 55 & -0 & $\begin{array}{l}-9.6 \\
\end{array}$ & -0.12 \\
\hline 26 & -0.02 & -2.5 & -0.10 & 56 & -0.6 & 4.8 & -0.19 \\
\hline${ }^{28}$ & $\begin{array}{l}-0.06 \\
-0.06\end{array}$ & -7.4 & $\begin{array}{l}-0.29 \\
-0.29\end{array}$ & 58 & 0.0 & 1.3 & 0.05 \\
\hline $\begin{array}{l}29 \\
{ }_{30}^{29}\end{array}$ & $\begin{array}{l}-0.06 \\
0.03\end{array}$ & $\begin{array}{l}-7.4 \\
3.8\end{array}$ & $\begin{array}{l}-2.29 \\
0.14\end{array}$ & $\begin{array}{l}59 \\
60 \\
60\end{array}$ & 0.0 & $\begin{array}{l}9.6 \\
8.8\end{array}$ & $\begin{array}{l}0.38 \\
0.34\end{array}$ \\
\hline & & & & & & 25.7 & \\
\hline & & & & & $\begin{array}{l}\text { Height } \\
\text { veturture }\end{array}$ & $\begin{array}{l}25.7 \\
51.4 \\
117\end{array}$ & $\begin{array}{l}1.01 \\
2.02 \\
0 \text { rn }\end{array}$ \\
\hline & & & Total o & ti Dev & & 2644 & $\begin{array}{l}10.40 \\
0.72\end{array}$ \\
\hline & & & Dividu & 1-Abso & $\begin{array}{l}\text { sitions } \\
\text { evarae Height }\end{array}$ & & $\begin{array}{l}20.123 \\
0.33\end{array}$ \\
\hline
\end{tabular}

Table 8

CALCULATION OF THE SURFACEFINISH BY MEASUREMENT OF THE

(Specimen: Copper-Plated Aluminum Disc 2 , from Fiose 21, Viven a)

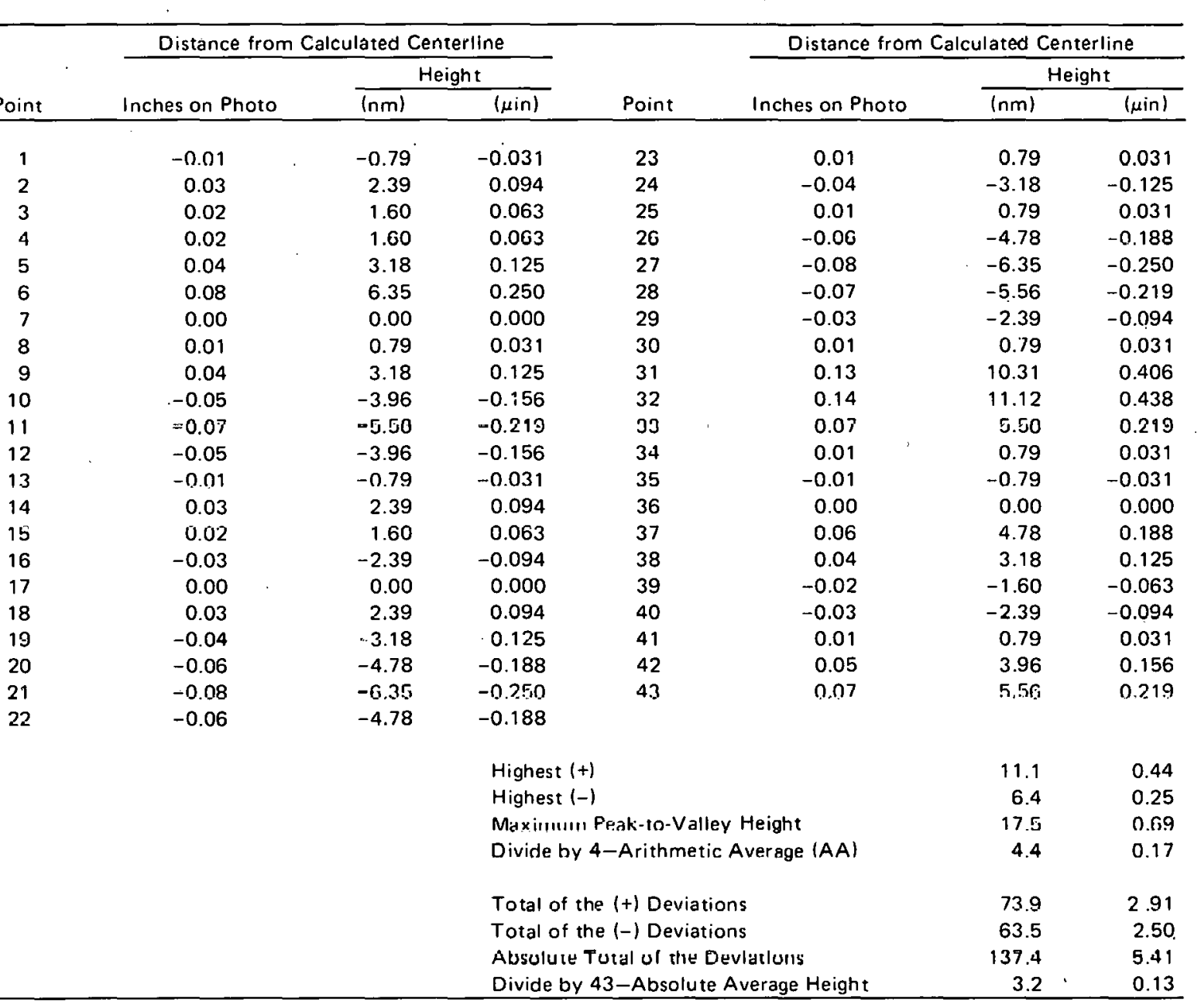

Table 9 CALCULATION OF THF SURFACE FINISH BY MEASUREMENT OF THE Isecimen: Electroless Nickel-Plated Aluminum Disc 3 .

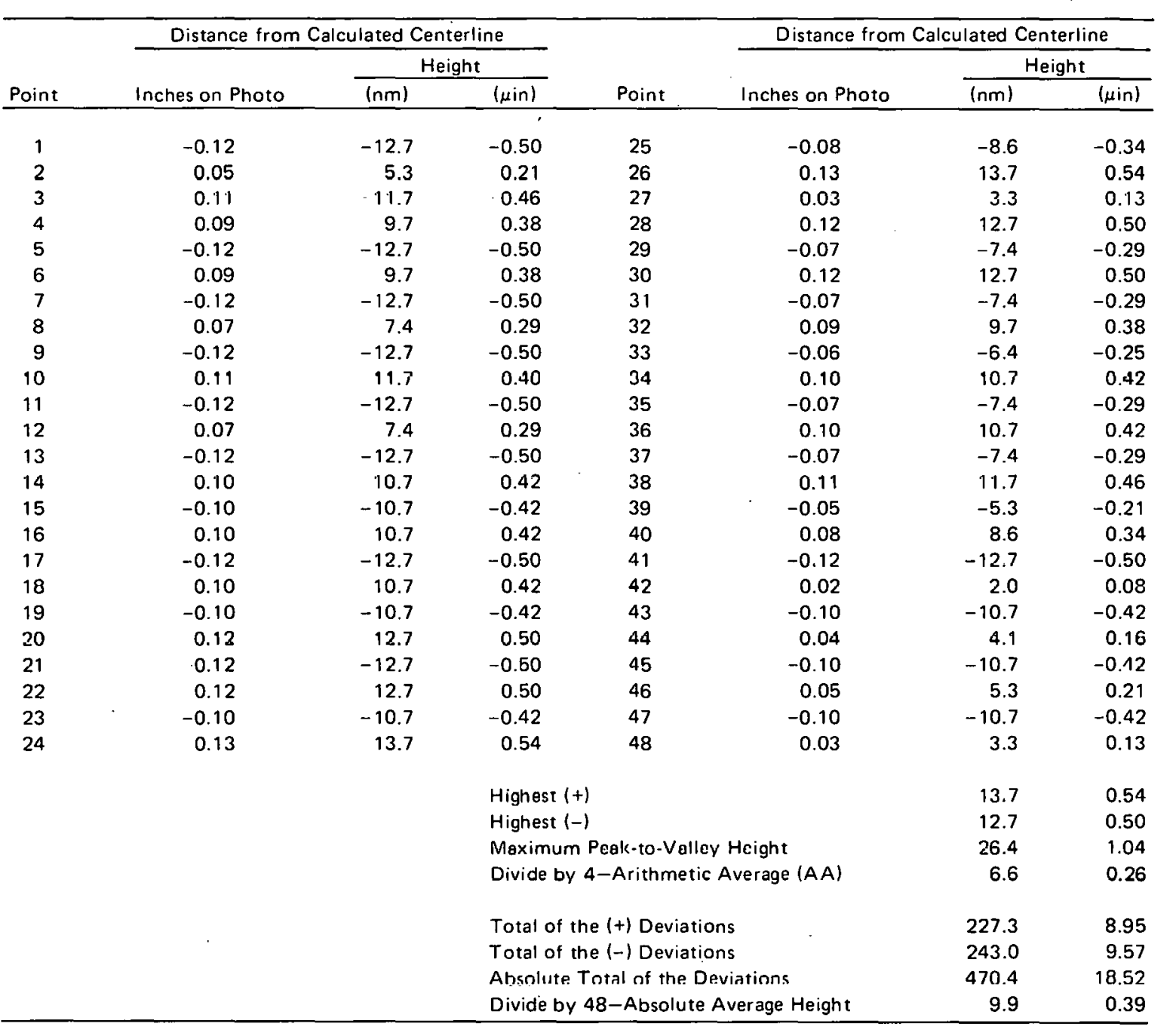


the fringe center for a series of points. The data (Table 7) show, however, that it is possible to measure a distance as small as $10 \mathrm{mils}$ from the fiduciary line. This value represents a sensitivity of $1.3 \mathrm{~nm}(0.05 \mu \mathrm{in})$. It should be emphasized that this can only be obtained on an enlargement, such as Figure 36, View $b$. With regard to the statement that it is difficult to locate the fringe center, it is likely that the position accuracy is \pm 20 mils or, in terms of height, $\pm 2.6 \mathrm{~nm}( \pm 0.10 \mu \mathrm{in})$. This value is still a very sensitive number-about five times more sensitive than Tolansky (15) suggested: $\lambda / 40=14 \mathrm{~nm}(0.54 \mu \mathrm{in})$. This calculation shows that fringe displacement can be measured with a sensitivity about five times greater than the change in fringe blackening with surface height.

The maximum peak-to-valley height calculated from the data was $51.4 \mathrm{~nm}(2.02 \mu \mathrm{in})$, not quite twice the height obtained with multiple-beam fringes. Using the absolute data for all points, the AA was $8.4 \mathrm{~nm}(0.33 \mu \mathrm{in})$, or $43 \%$ higher than for the multiple beam. The reason it is higher is not clear. Possibly it is due to errors in reading the fringe centers; also, the photomicrographs may not include the same area of the specimen. Resolving power of the objectives should not be a problem because the cusp spacing was $129 \mu \mathrm{in}$. To retain perspective, it should be remembered that the difference between 5.8 and $8.4 \mathrm{~nm}(0.23$ and $0.33 \mu \mathrm{in})$ is rather small.

\section{Results on the Present State of the Art}

The specimens used in this report were chosen to illustrate certain points and should not be considered the best that can be prodisced by diamond turning. The nature of the surface depends upon many factors which have already been mentioned and have been discussed elsewhere. $(35,36)$

A typical example of the present state of the art of diamond turning is shown in Figure 21. View a, for a copper-plated disc (Specimen 4) and in Figure 21, View b, for an electroless nickel-plated aluminum disc (Specimen 5). These discs were $125 \mathrm{~mm}$ (5 in) in diameter and $25 \mathrm{~mm}$ (1 in) thick. Surface-finish data for the copper were obtained from the fringe center at 43 adjacent points (Table 8). (Comparable data for the electroless nickel-plated aluminum disc are given in Table 9.) The maximum peak-to-valley height was $17.5 \mathrm{~nm}(0.69 \mu \mathrm{in})$ and (dividing by 4 ) the arithmetic average was $4.3 \mathrm{~nm}(0.17 \mu \mathrm{in}=44 \AA)$. When the sum of the absolute values of the deviations from the midline was used, the arithmetic average was $3.2 \mathrm{~nm}(0.125 \mu \mathrm{in}=32 \AA)$. These figures include the waves in the surface, as well as the tool cusps. Not all the tool cusps were well resolved, but this would not affect the maximum peak-to-valley height since some cusps that are prominent determined the magnitude of this number.

This copper disc was examined using a reference mirror with $90 \%$ reflectivity and red light. The fringe spacing on the photo used for analysis was $100 \mathrm{~mm}$. From these data, the height sensitivity of the multiple-beam system was found to be $0.79 \mathrm{~nm}(0.03 \mu \mathrm{in}=8 \AA)$. The technique for the measurements on nickel (Figure 21, View b) was slightly different because of the lower reflectivity of nickel. The reference mirror with $65 \%$ reflectivity was used, and the fringe contrast was' nearly as good with green light as with red. (Green light was used for

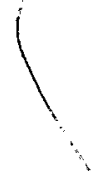


the gain in resolution.) Because of the lowered reflectivity, the fringe was broadened (see Figure 18). The fringe spacing on the photo used for analysis was $75 \mathrm{~mm}$. The cusps are plainly visible in the picture and the spacings are very regular. The data, therefore, alternate between a peak and a valley. The maximum peak-to-valley height was $26.1 \mathrm{~nm}(1.04 \mu \mathrm{in})$ and the arithmetic average was $6.6 \mathrm{~nm}(0.26 \mu \mathrm{in})$. Using the sum of the absolute values, the AA was $9.9 \mathrm{~nm}(0.39 \mu \mathrm{in})$, which is three times greater than for the copper surfacc.

The surface finish of some diamond-turned specimens has been studied by other laboratories. One example(18) shows the autocovariance, height, and slope-distribution functions for a disc with a roughness of $22.5 \AA(2.5 \mathrm{~nm}, 0.1 \mu \mathrm{in}), \mathrm{rms}$. [This paper also presents a graph showing the relationship between a TV-scan roughness and a visually read roughness. On this basis, the disc would have a visual rms roughness of $40 \AA 14.0 \mathrm{~nm}$, $0.16 \mu \mathrm{in})$. This difference is probably due to inadequate resolution of narrow gronves which the visual reader observes, but instrumentation ignores.] Other papers $(37,38)$ report mis roughness of $20-25 \AA$ from light-scattering methods. The diamond-turned specimens were shown to have significantly higher reflectance than typical polished, sputtered, or evaporated copper films.

The methods of turning different materials, as well as the methods of evaluation, are being studied continually. (39-41) Only a few specimens of flat surfaces could be discussed in this report, but it hoped that these illustrations and literature references will prove useful in understanding some of the results and techniques of surface-finish evaluation.

\section{CONCLUSIONS}

The double-beam. multiple-beam, and FECO inteferener systems of moacuriny uurface finisli lave been examined with regard to resolving powcr and application in uhtaining data on diamond-turned surfaces. The following conclusions have been drawn from this study:

1. Where detail of importance is spaced closer than about 60 microinches, the multiple-beam and FECO systems do not, at the present time, have adequate resolving power to measure sur lace finish

2. Whiel illulinle-beam systems have the necessary resolving power, the narrow width of the fringes and greater sensitivity is a distinct advantage in evaluating a surface.

3. Unless it is necessary to establish, unambiguously, the hills and valleys on a diamond-turned surface, or to obtain information on slopes and autocorrelation functions, multiple-beam fringes are adcquate and do not require silvering to obtain the reflectivity necessary for the FECO method.

4. To analyze the performance of the diamond turning lathe of today and measure the surface finish of these mirrors, multiple-beam interference with the highest order of resolution is necessary. 
5. Data on surface finish should be obtained by measuring the deviation of the center of the fringe from a straight line, rather than the edge. The symmetry of the fringe provides greater accuracy, and variations in lamp intensity and film exposure have less of an effect.

6. State-of-the-art plated copper surfaces can be diamond turned with a peak-to-valley surface finish of less than one microinch $[17.5 \mathrm{~nm}(0.69 \mu \mathrm{in})]$ or an arithmetic average of $3.2 \mathrm{~nm}(0.13 \mu \mathrm{in})$. 


\section{REFERENCES}

(1) Born, M. and Wolf, E.; Principles of Optics, pp 316 -322; Pergamon Press, New York (1970).

(2) Ibid, p 322.

(3) Brown, E. B.; Modern Optics, p 5; Reinhold Publishing Corporation, New York (1965).

(4) Ibid, pp 73, 74

(5) Francon, M.; Progress in Microscopy, Row, Peterson, and Company, Evanston, Illinois (1961).

(6) Born and Wolf, Op cit, p 419.

(7) Martin, L. C.; Technical Optics, /1, Second Edition, pp 113 - 124; Sir Isaac Pitman \& Sons, LId (1960)

(8) Johnson, B. K.; Optics and Optical Instruments, pp 78-97; Dover Publications, New York, New York (1960).

(9) Robertson, J. K.; Introduction to Physical Optics, pp $138-144$ and $284-288$; D. Van Nostrand Co, Inc, New York, New York (1941).

(10) Born and Wolf; Op cit, p 259.

(11) Tolansky, S.; Surface Microphotography, p 32; Longmans, London (1960).

(12) Ibid, pp $20-24$.

(13) Francon, M.; Optical Interferometry, p 113; Academic Press, New York, New York (1966).

(14) Born and Wolf; Op cit, p 327.

(15) Tolansky, S.; Multiple Beam Interferometry of Surfaces and Films, p 96; Clarendon Press, Oxford (1948).

(16) Scott, G. D., McLauchlan, T.A., and Sennett, R. B.; J Appl Phys, 21, p 843 (1950).

(17) Bennett, H. E. and Bennett, J. M.; "Precision Measurements in Thin Film Optics", Physics of Thin Films, 4; Academic Press, New York, New York (1967). 
(18) Bennett, J. M.; "Measurement of the rms Roughness, Autocovariance Function, and Other Statistical Properties of Optical Surfaces Using a FECO Scanning Interferometer", Appl Optics, p 2705, November 1976.

(19) Tolansky; Opcit, p 51.

(20) Kohler, W. F.; J Opt Soc Am, 43, p 738 (1953).

(21) Koester, C. J.; J Opt Soc Am, 48, p 255 (1958).

(22) Bennett, J. M.; J Opt Soc Am, 54, p 621 (1964).

(23) Gifkins, R. C.; Optical Microscopy of Metals, pp 90 - 97; American Elsevier Publishing Co, New York, New York (1970).

(24) Francon; Op cit, pp 118, 135.

(25) Hoffman, R. and Gross, L.; "Refleeted Light Differential Interference Microscopy: Properties, Uses, and Image Interpretation", Journal of Microscopy, 91, pp 149 - 172 (1970).

(39)

(26) Gates, J. W.; "Fringe Spacing in Interference Microscopes", J Sci Instr, 33, p 507 (1956).

(27) Bruce, C. F. and Thornton, B. S., "Obliquity Effects in Interference Microscopes", J Sci Instr, 34, p 203 (1957).

(28) Ingelstam, E. and Johansson, L. P.: "Correction Due to Aperture in Transmission Interference Micruscopes", J Sci Instr, 35, p 15 (1958).

(29) Ingelstam, E., Johansson, L. P., and Bruce, C. F.; "Obliquity Corrections in Transmission Interference Microscopes", J Sci Instr, 36, p 246 (1959).

(30) Mykura, H. and Rhead, G. E.; "Errors in Surface Topography Measurements with High Aperture Inteference Microscopes", J Sci Instr, 40, p 313 (1963).

(31) McCutchen, C. W.; "Inteference Microtopography with Incoherent Light", Rev Sci Iristr, 37, p 1490 (1966).

(32) Pliskin, W. A. and Esch, R. P.; "Effect of Numerical Aperture of Microscope Objectives on Film-Thickness Determinations", J Appl Phys, 38, p 3274 (1968).

(33) Bennett, J. M. and Koehler, W. F.; "Comparator with Photoelectric Detection for Setting on Broad Interference Fringes with Precision", J Opt Soc Am, 49, p 466 (1959). 
(34) Bryan, J. B., et al; Surface Finish Metrology, ASME paper 62-WA-266 (1962).

(35) Arnold, J. B., Steger, P. J., and Saito, T. T.; "Tool Feed Influence on the Machinability of $\mathrm{CO}_{2}$ Laser Optics", Appl Opt, 14, p 1777 (1975).

(36) Arnold, J. B., Steger, P. J., and Burleson, R. R.; Slide Position Errors Degrade Machined Optical Component Quality, Y-DA-6346; Union Carbide CorporationNuclear Division, Oak Ridge Y-12 Plant, Oak Ridge, Tennessee; December 12, 1975. Also Published in National Bureau of Standards Special Publication 435: LaserInduced Damage in Optical Materials, pp 57 - 65 (1975).

(37) Bennett, H. E., Soileau, M. J., and Archibald, P. C.; "Diamond-Turned Mirrors" in High Energy Laser Mirrors and Windows, p 53; Michelson Laboratory, Naval Weapons Center, China Lake, California; May 1975.

(39) Bennett, H. E., Soileau, M. J., and Archibald, P. C.; Diamond-Turned Mirrors. Published in National Bureau of Standards Special Publication 435, pp 49 - 56 (1975).

(4Ü) Bırkebak, R. C.; "Uptical and Mechanical RMS Surface Roughness Comparison", Appl Optics, 10, p 1970 (1971).

(40) Whitehouse, D. J., et al; "Assessment of Sur.face Typology Analysis Techniques in Turning", Annals of the CIRP, 2312, p 265 (1974).

(41) Vitenberg, Uy. R.; "Evaluation of Surface Finish by Covariance Functions", Russian Engineering Journal, $X L I X,(1), p 58$. 


\section{APPENDIX A}

\section{ENGLISH-TO-SI CONVERSION FACTORS}

The following conversion factors were used:

$$
\begin{aligned}
& 1 \text { inch (in) }=25.4 \text { millimeters }(\mathrm{mm}) \\
& 1 \text { microinch }(\mu \mathrm{in})=25.4 \text { micromillimeters }(\mu \mathrm{mm})(\mathrm{c}) \\
& 25.4 \text { micromillimeters }=25.4 \times 10^{-6} \times 10^{-3} \text { meter }(\mathrm{m}) \\
& =25.4 \times 10^{-9} \text { meter } \\
& 1 \text { microinch }(\mu \mathrm{in})=25.4 \text { nanometers }(\mathrm{nm})
\end{aligned}
$$

Surlace finish is sometimes expressed in angstroms:

$$
\begin{aligned}
& 1 \mathrm{~nm}=10 \AA \\
& 1 \mu \mathrm{in}=254 \AA
\end{aligned}
$$

(c) The micromillimeter is a mixed unit which is not permitted in the SI system; the correct unit is the nanometer. 


\section{APPENDIX B}

\section{DERIVATION OF THE THEORETICAL SURFACE FINISH}

In the sketch:

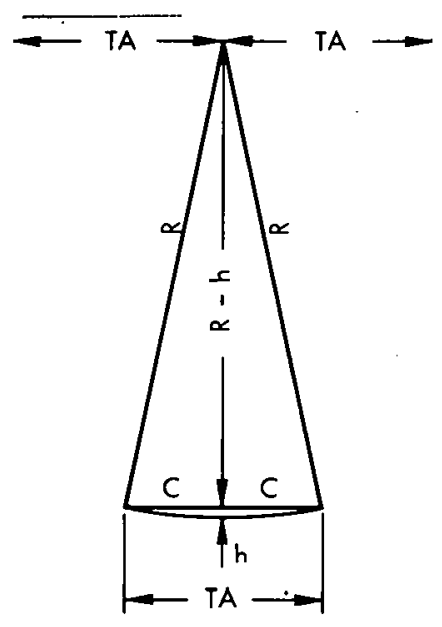

$h$ is the height of the cusp (also called sagitta) and it is the peak-to-valley surface finish, and

$\frac{\text { Slide Speed }}{\text { Spindle Speed }}$

$\mathrm{C}$ is $\mathrm{TA} / 2$, which is one side of the right triangle,

$\mathrm{K}-\mathrm{h}$ is the second side of the triangle.

For any right triangle:

$$
R^{2}=(R-h)^{2}+C^{2}=R^{2}-2 R h+h^{2}+C^{2} .
$$

For the work in diamond turning, $\mathrm{h}^{2}$ is very small and may be neqlected.

Then:

$$
\begin{aligned}
& 2 R h=C^{2}, \text { and } \\
& h=\frac{C^{2}}{2 R}=\frac{(1 \mathrm{~A})^{2}}{8 R} .
\end{aligned}
$$

If the radius of the diamond is $1 / 8$ inch, then $h=(T A)^{2}$, the peak-to-valley surface finish. 


\section{ACKNOWLEDGEMENTS}

The author wishes to thank the following persons who contributed, in a special way, to this report: P. J. Steger, the author's immediate supervisor, for many stimulating discussions on the methods of measuring surface finish and the meaning of the results; T. T. Saito, for much encouragement and many suggestions about the interpretation of the data; J. M. Bennett for many helpful discussions about the multiple-beam and FECO systems; R. H. Dean who did much of the laboratory work; J. B. Arnold, H. L. Gerth, W. H. Rasnick, J. L. Huff, and N. D. Woodall who supplied the diamond-turned specimens. The results on most specimens were not included in this report, but they served to stimulate thinking about interpretation of the fringe patterns and about the type of diagnostic information the engineers need to obtain for the development and evaluation of their machine systems. 


\section{Distribution}

Air Force Weapons Laboratory Kirtland Air Force Base

Bcttis, J.

Charlton, G. B.

Guenther, A. II.

House, $R$.

Wick, R. V.

\section{Arnold Research Organization}

Young, R. P./Warmbrod, W. M.

Department of the Army -

Frankford Arsenal

Church, E. L.

Energy Research and Development Administration - Oak Ridge

Hickman, H. D.

Leed, R. E.

Zachry, D. S., Jr

\section{Lawrence Livermore Laboratory}

Brown, N.

Bryan, J, B.

Glass, A.

Nelson, W. E.

Saito, I: T.

Wollcorstein, E. P.

\section{Los Alamos Scientific Laboratory}

Hoyt, H. C.

Reichelt, W. H.

Singer, $S$.

Sollid, J. E.

\section{Oak Ridge Gaseous Diffusion Plant}

Stief, S. S.

Wilcox, W. J., Jr

Oak Ridge National Laboratory

Weir, J. R., Jr

\section{Oak Ridge Y-12 Plant}

Alvey, H. E.

Armstrong, R. C.

Arnold, J. B.

Bender, F. D.
Bernander, N. K.

Burditt, R. B.

Burkhart, L. E./Mason, D. L.

Dean, R. H.

DeRoos, L. $\Gamma$. Dodson, W. H.

Dritt, W. S.

Duggan, H. G.

Ellingson, R. D.

Foulk, D. L.

Fraser, R. J.

Gerth, H. L.

Gritzner,.V. B.

Hensley, C. E.

Huddleston, R. L.

Huff, J, L:

Hurst, J. S.

Jackson, V. C.

Jones, F. W. (5)

Kalli, K. G.

Keith, A.

Kite, H. T. (10)

Martin, W. R./Googin, J. M.

Mills, J. M.

Oliphant, G. W.

Perry, A. E.

Phillips, L. K.

Prcuss, H. M.

Prewett, H. P...Ir

Raspilck, viv. H

Schede, R.W.

Schreyer, J. M.

Sladky, R. F. (10)

Smith, H. F., Jr

Smith, R. D.

Steger, P. J. (10)

Stoner, H. II.

Thompson, C. H. (6)

Tilson, F. V.

Weathersby, W. E.

Whitson, W. K.

Whitten, L. G. (5)

Woodall, N. D.

$Y-12$ Central Files (master copy)

$Y-12$ Central Files (route copy)

$Y-12$ Central Files $(Y-12 R C)$

$Y-12$ Central Files (5)

Paducah Gaseous Diffusion Plant

Bewley. H. D. 
Redstone Arsenal

Hutcheson, G. J.

Union Carbide Corporation -

New York

Winters, Charles

Union Carbide Corporation -

Parma Research Center

Chambers, W. E.

University of Arizona - Optical

Sciences Center

Shagam, R. N.

Wyant, J. C.

University of Tennessee -

College of Engineering

Stansbury, E. E.

US Naval Weapons Center -

China Lake

Bennett, J. M.

In addition, this report is distributed in accordance with the category UC-37, Instruments, as given in the USERDA Standard Distribution Lists for Unclassified Scientific and Technical Reports, TID-4500. 